\title{
Improving the phase stability and oxidation resistance of $\beta-\mathrm{NiAl}$
}

by

\section{Travis Michael Brammer}

\begin{abstract}
A thesis submitted to the graduate faculty
in partial fulfillment of the requirements for the degree of MASTER OF SCIENCE
\end{abstract}

Major: Materials Science and Engineering

\author{
Program of Study Committee: \\ Mufit Akinc, Co-major Professor \\ Matthew J. Kramer, Co-major Professor \\ Iver Anderson
}

lowa State University

Ames, lowa

2011

Copyright (@ Travis Michael Brammer, 2011. All rights reserved. 
Graduate College
lowa State University

This is to certify that the master's thesis of

Travis Michael Brammer

has met the thesis requirements of lowa State University 


\section{TABLE OF CONTENTS}

CHAPTER 1: GENERAL INTRODUCTION

Thesis Organization

Motivation

Literature Review

References

CHAPTER 2: A MULTI-STAGE HEIRARCHICAL APPROACH 17

TO ALLOY DESIGN

Abstract

Introduction

Experimental Procedure

Results and Discussion

Conclusions

Acknowledgement

32

References

32

CHAPTER 3: EFFECT OF PLATINUM GROUP METAL

SUBSTITUTIONS AND HAFNIUM ADDITION ON OXIDATION

RESISTANCE OF $\beta$-NiAI

Abstract

Introduction

Experimental Procedure 36

Results and Discussion 38

Conclusions

55

Acknowledgement

55

References

CHAPTER 4: ROLE OF GRAIN SIZE ON THE OXIDATION 58

RESISTANCE OF $\beta$-NiAI

Abstract

Introduction

59

Experimental Procedure

60

Results and Discussion

62

Conclusions

75

Acknowledgement

76

References

76

CHAPTER 5: EFFECT OF PLATINUM GROUP METALS ON THE

MELTING TEMPERATURE OF $\beta$-NiAI

Abstract 
Results and Discussion $\quad 81$

Conclusions $\quad 86$

$\begin{array}{lr}\text { Acknowledgement } & 87\end{array}$

$\begin{array}{ll}\text { References } & 87\end{array}$

CHAPTER 6: GENERAL CONCLUSIONS 88

$\begin{array}{ll}\text { ACKNOWLEDGEMENTS } & 90\end{array}$ 


\section{CHAPTER 1: \\ GENERAL INTRODUCTION}

\section{Thesis Organization}

This thesis is written in an alternate format. The thesis is composed of a general introduction, four original manuscripts, and a general conclusion. References cited within each chapter are located immediately after that section. In addition, figures and tables are numbered independently within each chapter.

The general introduction focuses on the driving force behind this research, and gives an overview of previous work done on nickel-based superalloys. Chapter

2 describes the preliminary experiments and how those experiments guided the rest of the thesis work. Chapter 3 deals specifically with the oxidation performance of platinum group metal (PGM) and hafnium modifications to $\beta-\mathrm{NiAl}$ intermetallic. Chapter 4 investigates the role of grain size on the oxidation resistance of $\mathrm{NiAl}$ based alloys. Chapter 5 focuses on the role of melting temperature on the oxidation resistance of NiAl based alloys. Chapter 6 summarizes the important results of this study.

\section{Motivation}

High temperature alloys are essential to many industries that require a stable material to perform in harsh oxidative environments. Many of these alloys are suited for specific applications such as jet engine turbine blades where most other materials would either melt or oxidize and crumble (1). These alloys must have a high melting temperature, excellent oxidation resistance, good creep resistance, and decent fracture toughness to be successfully used in such environments. The discovery of $\mathrm{Ni}$ based superalloys in the 1940s revolutionized the high temperature alloy industry and there has been continued development of these alloys since their advent (2). These materials are capable of operating in 
oxidative environments in the presence of combustion gases, water vapor and at temperatures around $1050^{\circ} \mathrm{C}$. Demands for increased fuel efficiency, however, has highlighted the need for materials that can be used under similar atmospheres and at temperatures in excess of $1200^{\circ} \mathrm{C}$. The current $\mathrm{Ni}$ based superalloys are restricted to lower temperatures due to the presence of a number of low melting phases that result in softening of the alloys above $1000^{\circ} \mathrm{C}$.

Therefore, recent research has been aimed at exploring and developing newer alloy systems that can meet the escalating requirements. This thesis comprises a part of such an effort. The motivation of this work is to develop a novel high temperature alloy system that shows improved performance at higher temperatures than the currently employed alloys. The desired alloy should be in accordance with the requirements established in the National Energy Technology Laboratory (NETL) FutureGen program having an operating temperature around $1300^{\circ} \mathrm{C}$.

\section{Literature Review}

\section{High Temperature Alloys}

Initially stainless steels were used for high temperature applications such as jet engines in WWI planes (4), but these alloys were limited by their melting temperature. Later, scores of alloys have been discovered and developed for use in high temperature environments. Cobalt, nickel, and iron based superalloys were developed in the 1940s with a large alloy constituent being either chromium or aluminum to act as the reservoir for a passivating layer. These alloys have been improved for high temperature oxidative environments through various processing innovations. But when the highest temperatures $\left(1200-1350^{\circ} \mathrm{C}\right)$ must be achieved and strength is the consideration, then nickel-based superalloys are the materials of choice. Nickel based superalloys can be used to a higher 
fraction of their melting points than just about any other commercially available materials (1).

Refractory metal silicides have been produced that form a protective silica layer when exposed to temperatures up to $1700^{\circ} \mathrm{C}$ (3). Cur rently $\mathrm{MoSi}_{2}$ is used as a heating element in furnaces. Yet these alloys are quite dense and show poor fracture toughness at ambient temperatures.

As shown in Figure 1, increases in operating temperature for superalloys have increased over the past seven decades and this improvement relies heavily on the microstructure of the alloy. Wrought alloys were improved through conventional casting. The creep resistance was then improved through directional solidification followed by single crystals of the alloys. Decreasing the number of grains in the alloy significantly reduces the creep tendencies at high temperature.

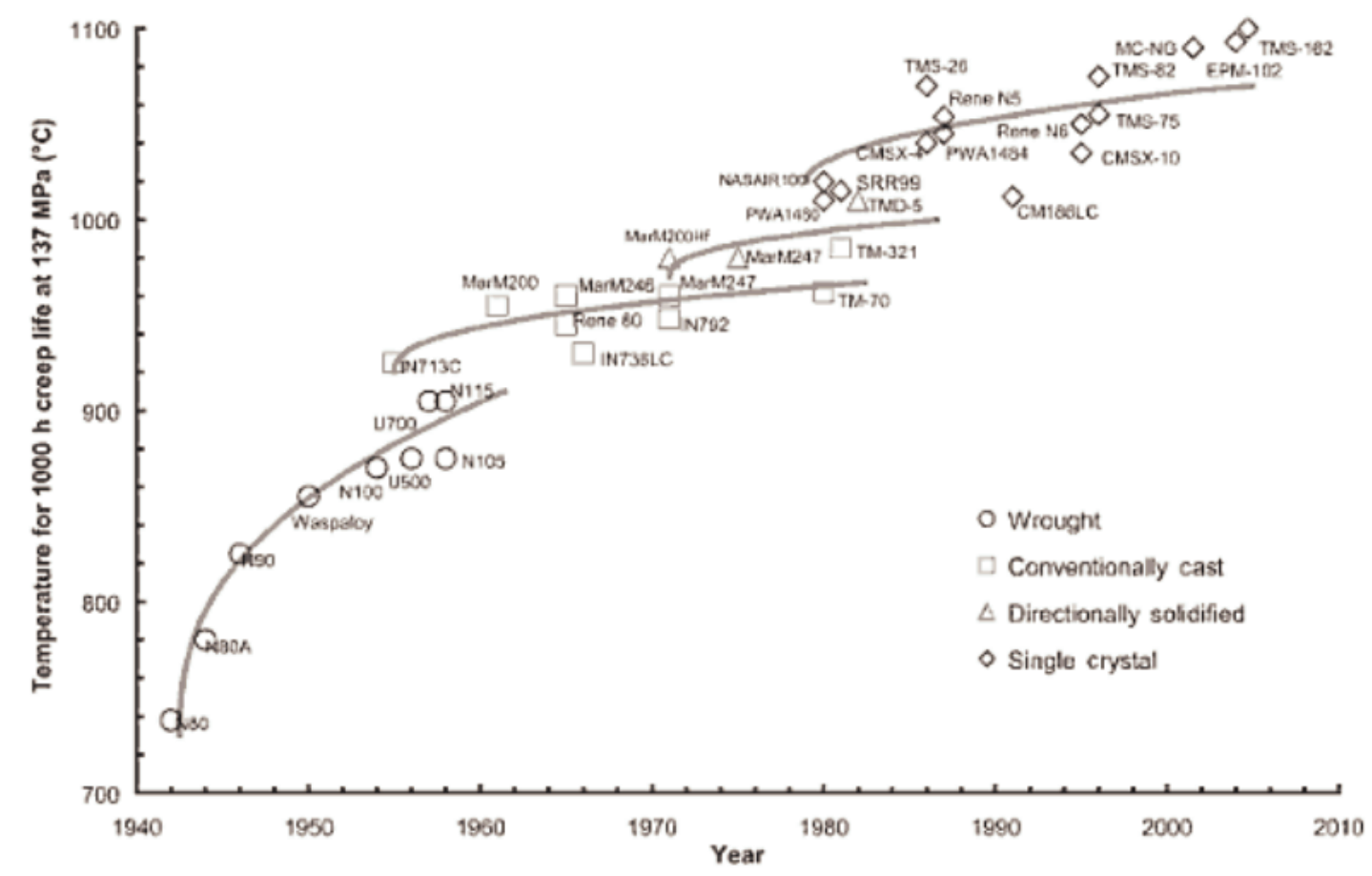

Figure 1: Evolution of the high temperature capability of the superalloys (2)

\section{Cooling Systems and Coatings}


Gas turbine engines typically utilize Ni based superalloys which are composed of a number of low melting phases with melting points ranging from $1250-1450^{\circ} \mathrm{C}$. They are applied in combustion gas environments where temperatures can exceed $1480^{\circ} \mathrm{C}$ for brief times, making them susceptible to softening and environmental damage due to oxidation $(1,2,5-11)$. Cooling systems and coatings are employed to decrease the temperature the superalloy sees during operation. Figure 2 below shows a schematic of the layers within the top surface of a current superalloy system. The development timeline for these two systems is displayed in Figure 3 and shows that cooling systems were first utilized in the 1960s while the thermal barrier coatings (TBCs) emerging in the 1990s.

\section{Hot Combustion Gases}

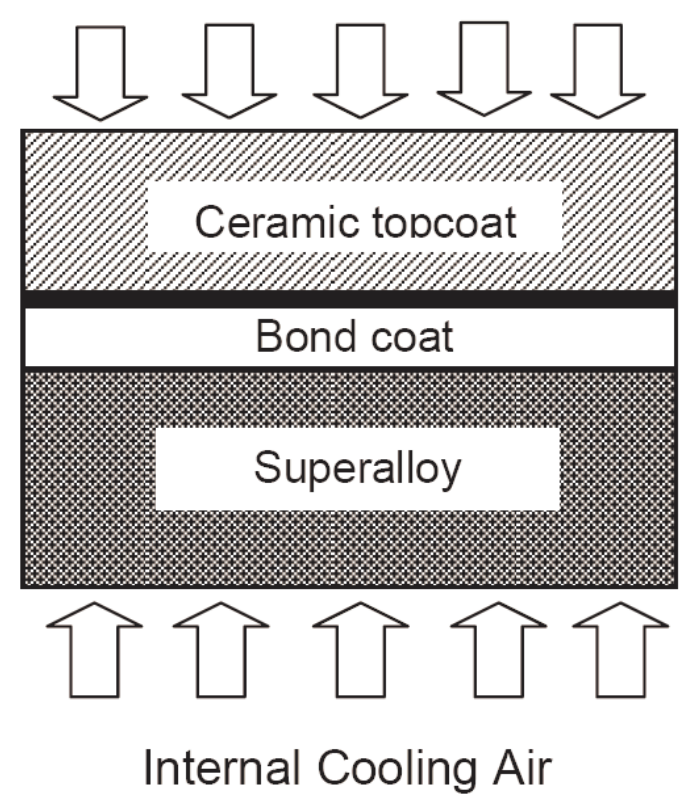

Figure 2: Schematic representation of a multi-layer thermal barrier coating system (12) 


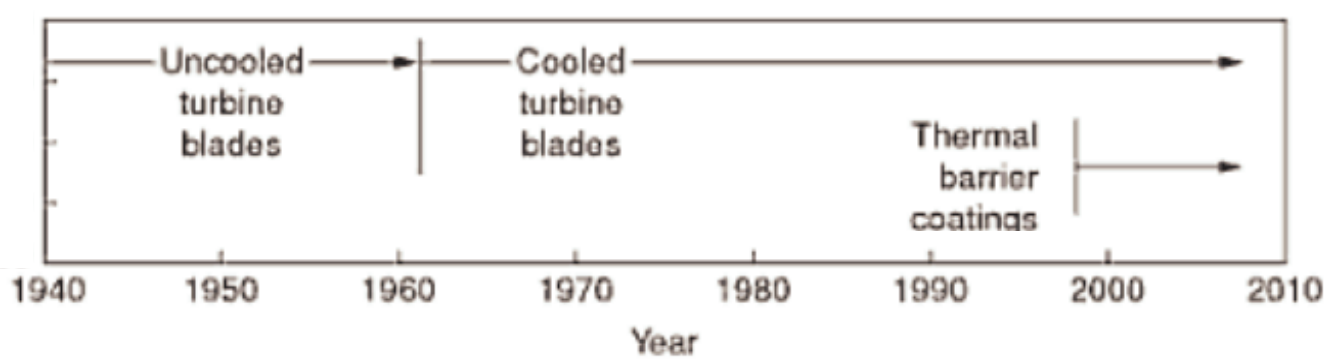

Figure 3: Evolution of cooling systems and coatings for turbine engines (2)

Current combustor and turbine engine components must be actively cooled with air from the compressor. An obvious approach to maximize efficiency is to reduce the use of cooling air. One way to accomplish this is to design more effective heat transfer geometries. This can be achieved by drilling holes through the component to bleed in air, which cools the combustion gas path surface (2, 13).

However, more significant benefits can be obtained by the application of thin thermally insulating layers known as thermal barrier coatings or TBCs (12). TBCs protect turbine engine components by acting as thermal insulators between the base metal and the hot gases to which they are exposed. Thermal barrier coatings based on zirconium oxide with a couple of orders of magnitude lower TCE than the base metal have been used for nearly three decades to extend the operational lifetime of aircraft turbines and their components operating in hostile thermal and corrosive environments $(14,15)$.

Generally, TBCs are attached to the superalloy via a bond coat layer as shown in Figure 2. The bond coat is an interlayer between the metal substrate and the ceramic coating. The bond coat produces its own thermally grown oxide (TGO). $\mathrm{NiAl}$ and its derivatives have been used for more than 30 years as bond coats in TBCs due to their excellent oxidation and corrosion resistance and their ability to 
maintain their structural integrity during service. The specific properties of $\mathrm{NiAl}$ that relate to high temperature applications are described next.

\section{Properties of NiAl}

The first recorded reference to the compound $\mathrm{NiAl}$ appeared in a phase diagram study published in 1908, where the unusually high melting temperature of this phase was noted (16). Subsequent research has identified NiAl as an ordered intermetallic material which possess low density, good oxidation resistance, and metal-like thermal conductivity. These properties have made NiAl an attractive material for a wide range of engineering applications, including electronic metallization in advanced semiconductor heterostructures, high temperature environmental coatings, surface catalysts, and high-current vacuum circuit breakers. However, lately there has been a strong interest to understand and develop alloys based on NiAl for high temperature applications in advanced propulsion systems and turbine generators. The following sections will give a brief overview of the general properties of NiAl.

\section{Phase Equilibria and Crystal Structure:}

The binary Ni-Al phase diagram is shown in Figure 4 and it reveals that there are five intermetallic phases in this system: $\mathrm{NiAl}_{3}, \mathrm{Ni}_{2} \mathrm{Al}_{3}, \mathrm{NiAl}, \mathrm{Ni}_{5} \mathrm{Al}_{3}$, and $\mathrm{Ni}_{3} \mathrm{Al}$. NiAl exhibits a wide range of compositional deviations from stoichiometry that is accommodated by the substitution of nickel atoms onto aluminum sites in nickelrich compositions and by the formation of vacancies on the nickel sites in aluminum-rich compositions. 


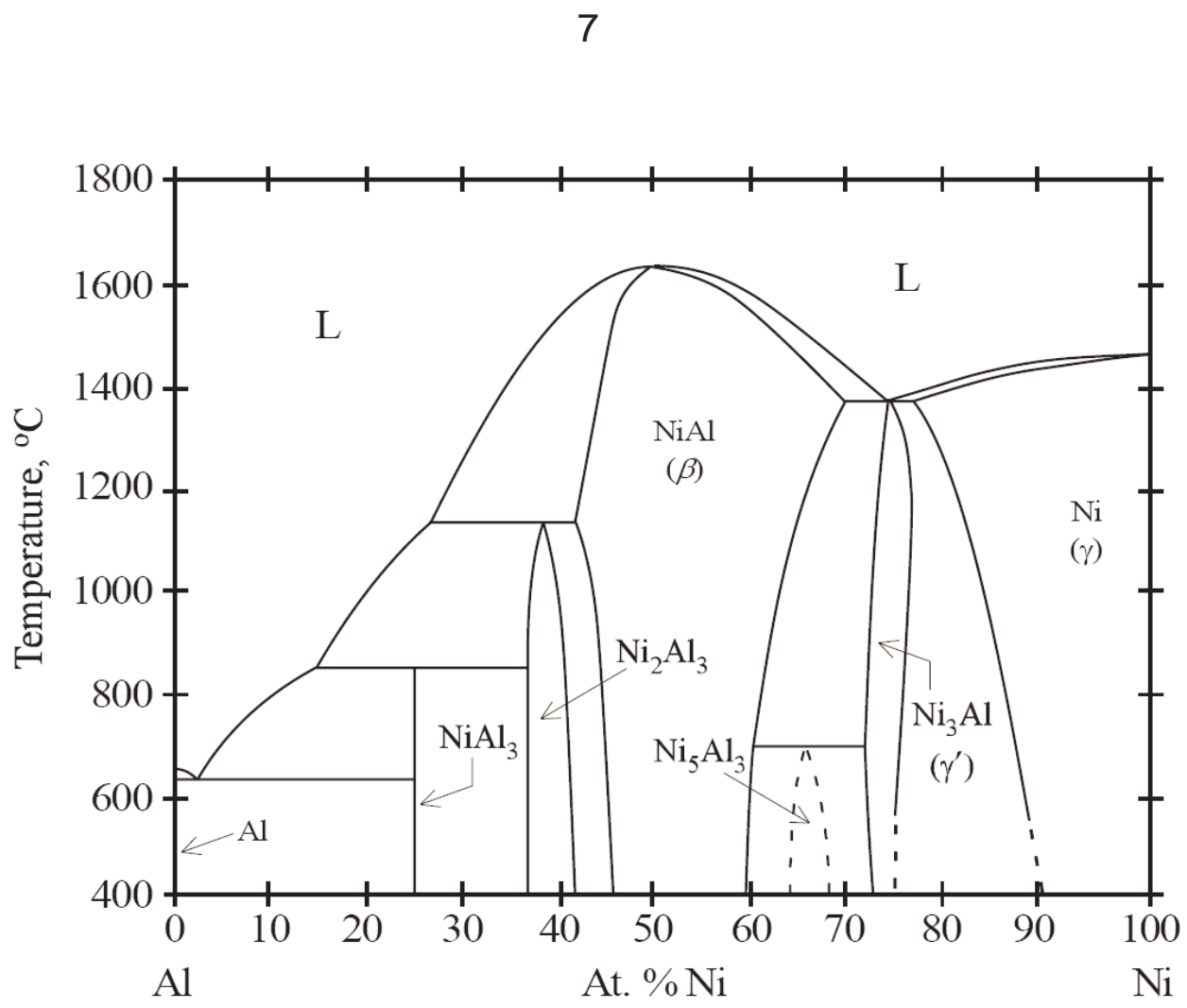

Figure 4: Phase diagram of Ni-Al (17)

$\mathrm{NiAl}$ has a $\mathrm{B} 2 \mathrm{CsCl}$ type crystal structure which means that the $\mathrm{Ni}$ and $\mathrm{Al}$ atoms form interpenetrating simple cubic sublattices which has an overall crystal structure of body centered cubic. As shown in Figure 5, one type of atom locates at $0,0,0$ and the other at $1 / 2,1 / 2,1 / 2$. The lattice parameter of the stoichiometric composition at room temperature is $0.2887 \mathrm{~nm}(18)$.

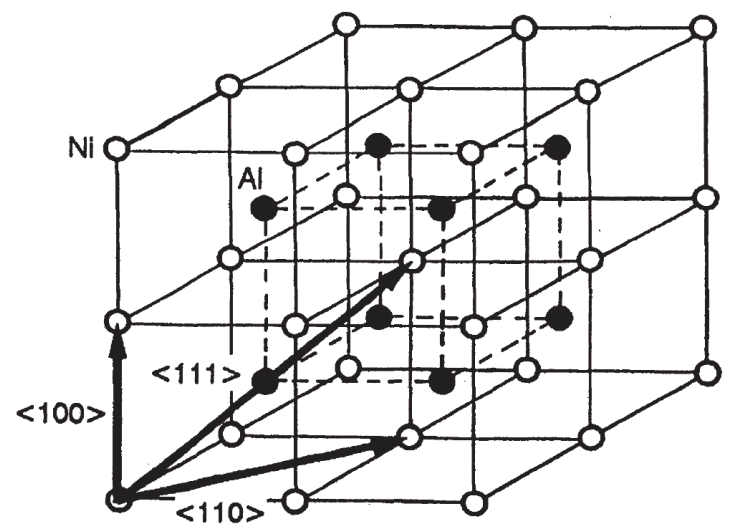

Figure 5: Illustration of the B2 crystal structure for NiAl (19) 


\section{Melting Temperature}

Stoichiometric $\beta-\mathrm{NiAl}$ has a melting temperature of $1638^{\circ} \mathrm{C}$ as shown in Figure 4. Such a high melting temperature indicates strong interatomic bonding and is necessary for high temperature applications. Current $\mathrm{Ni}$ based superalloys have phases that start melting at $1250^{\circ} \mathrm{C}$ and soften abov e $1000^{\circ} \mathrm{C}$ which creates an upper limit of use for any ultra-high temperature applications. Also a higher melting temperature would result in a lower homologous temperature at the surface of the alloy which means the alloy could run at hotter temperatures.

\section{Young's Modulus}

NiAl exhibits a high Young's modulus over a wide range of temperatures as shown in Figure 6. This indicates that the intermetallic retains its stiffness even at high temperatures which ensures minimal flexing and distortion of parts under load. This high stiffness can be attributed to the partially nonmetallic bonding of the intermetallic as well as the high melting temperature.

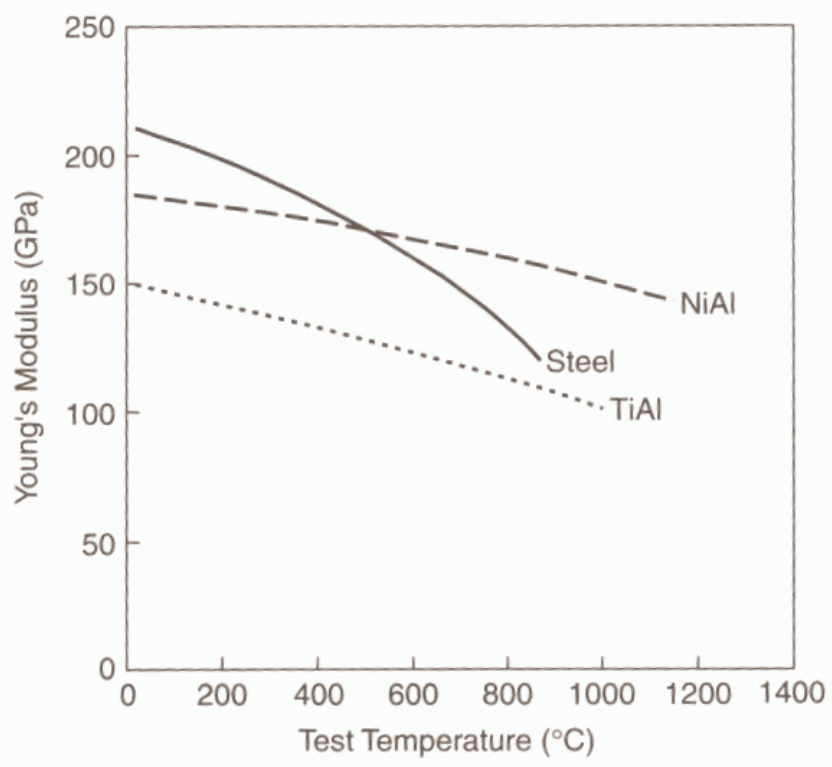

Figure 6: Elastic modulus of NiAl compared with steel and TiAl (3)

Creep Behavior 
Highly creep-resistant materials are desirable to maintain the aerodynamic shape of the airfoil and a tight clearance between the blade tip and the seal, which controls the cycle efficiency of the turbine engine. Typical creep requirements for a $\mathrm{Ni}$ based superalloys include stresses up to $200 \mathrm{MPa}$ at temperatures as high as $1000^{\circ} \mathrm{C}$ for over $300 \mathrm{~h}$. NiAl on the other hand does not have useful creep strength above $50 \%$ of its absolute melting temperature $\left(\sim 680^{\circ} \mathrm{C}\right)$ due to the $\mathrm{BCC}$ derivative crystal structure. However, addition of $1 \% \mathrm{Hf}$ to the NiAl greatly improves the creep resistance making it on par with current single crystal $\mathrm{Ni}$ based superalloy creep behaviors (20).

\section{Density}

Current nickel-based superalloys have densities of up to $9 \mathrm{~g} / \mathrm{cm}^{3}(6)$. In 1985 it was estimated that superalloys accounted for $50 \%$ of the total weight of an aircraft (1). . Density can also be important in gas turbines where increased density can result in increased stress on mating components. Improvement in alloy capability at the expense of density increase is not desirable. Modern cast nickel-based superalloys tend to have densities in the high end of the density range. Stoichiometric NiAl has an intrinsic density of $5.9 \mathrm{~g} / \mathrm{cm}^{3}$ which is about two thirds that of current Ni based superalloys $(16,19)$.

\section{Thermal Conductivity}

The thermal conductivity of NiAl was measured to be $76 \mathrm{Wm}^{-1} \mathrm{~K}^{-1}(20)$. This is 48 times greater than the $\mathrm{Ni}$ based superalloys. The relatively high conductivity would help to quickly dissipate the heat that the part sees which would result in lower metal temperature or would require less cooling air.

\section{Strength and Fracture Toughness}

A turbine airfoil is subjected to many stresses such as centrifugal stress, thermal stresses from temperature gradients, and vibrational excitation. A typical $\mathrm{Ni}$ 
based superalloys require tensile yield strength of approximately 700-1000 MPa at room temperature and up to $500 \mathrm{MPa}$ at $800^{\circ} \mathrm{C}$ (16). Polycrystalline NiAl has a room temperature yield strength of around $200 \mathrm{MPa}$ and only $100 \mathrm{MPa}$ at $800^{\circ} \mathrm{C}$ as shown in Figure 7.

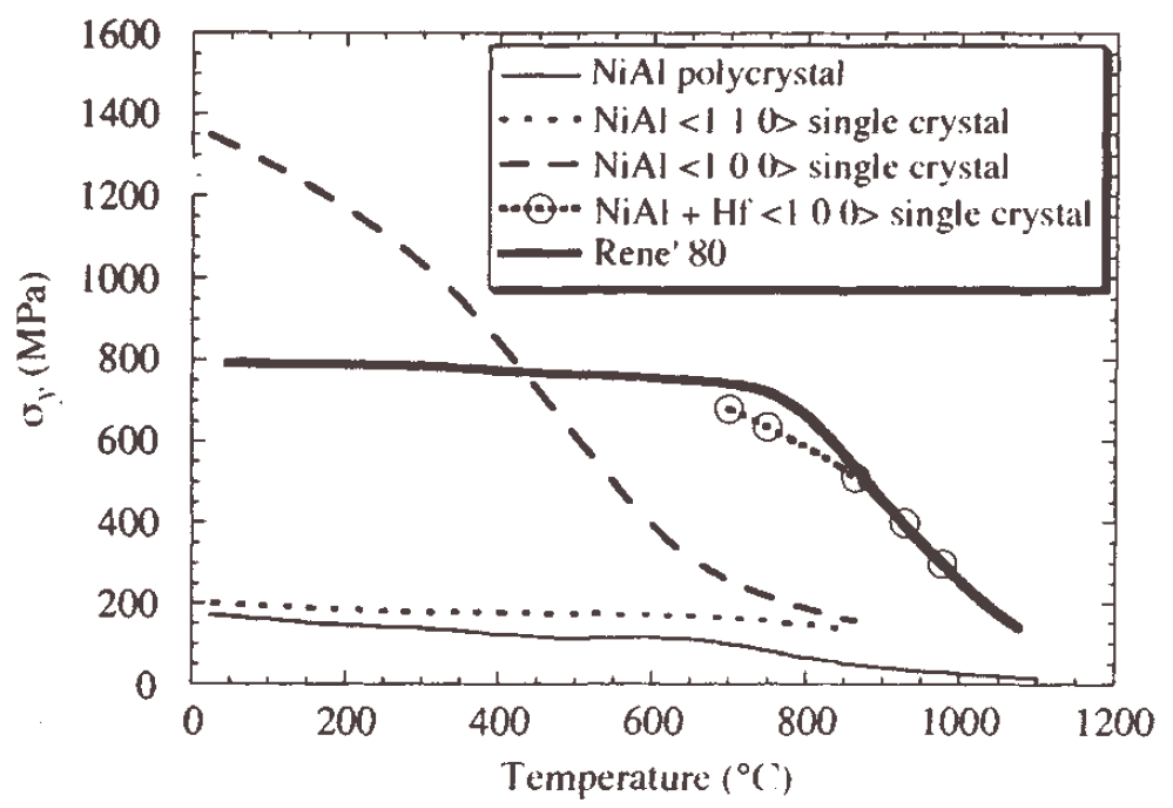

Figure 7: Temperature dependence of tensile yield strength of NiAl alloys (20)

For polycrystalline NiAl the fracture toughness has been measured to be about 5 $\mathrm{MPa} \cdot \mathrm{m}^{1 / 2}$ at ambient and $22 \mathrm{MPa} \cdot \mathrm{m}^{1 / 2}$ at $430^{\circ} \mathrm{C}(21)$ with the most dramatic increase in fracture toughness occurring at the ductile to brittle transition temperature (DBTT). The fracture toughness values are essentially independent of grain size, stoichiometry, and processing technique as shown in Figure 8. Fracture of $\mathrm{NiAl}$ at room temperature occurs by transgranular cleavage without any stable crack growth (22). This unstable crack growth at ambient temperatures is one of the main reasons that this alloy has not risen to replace the current $\mathrm{Ni}$ based superalloys which have a much higher typical room temperature fracture toughness around $50 \mathrm{MPa} \cdot \mathrm{m}^{1 / 2}(20)$. 


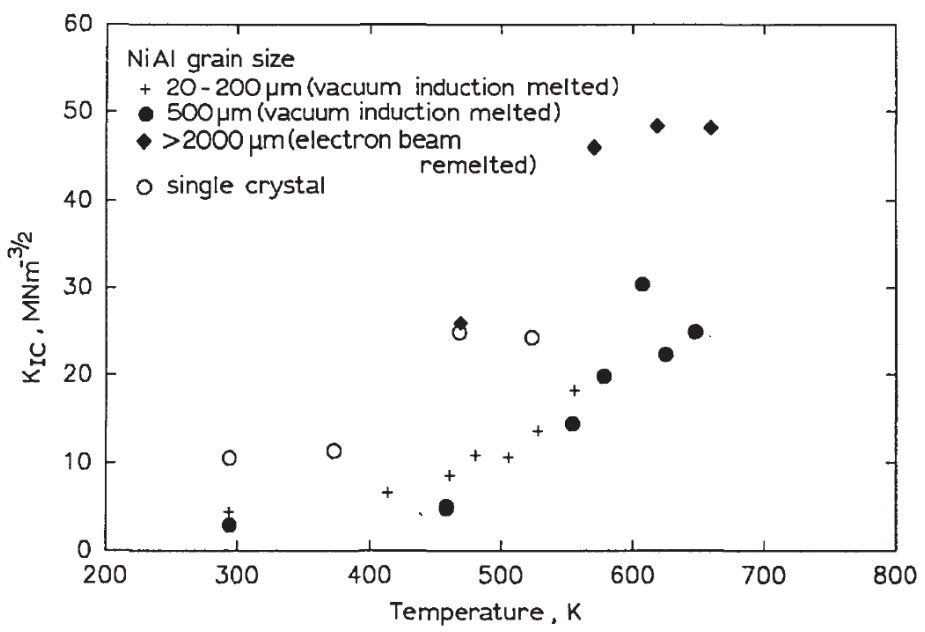

Figure 8: Fracture toughness of $\mathrm{NiAl}$ as a function of temperature (19)

The DBTT for stoichiometric NiAl is $3^{\circ 00} \mathrm{C}$ which the $\mathrm{n}$ increases the thermally activated slip systems allowing for improved ductility and fracture toughness. Although the transition temperature is relatively low, NiAl alloys still have unfavorable brittle characteristics at ambient temperatures. Figure 9 shows the tensile elongation as a function of temperature with the first signs of ductility occurring at the DBTT.

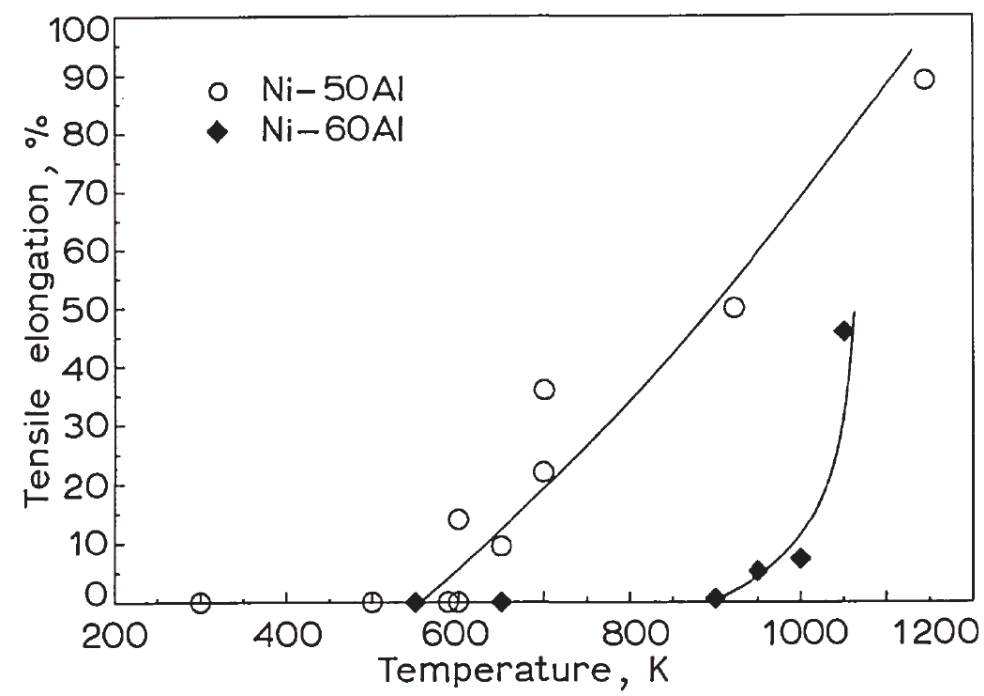

Figure 9: Ductile to brittle transition for $\mathrm{NiAl}(23)$ 
Coefficient of Thermal Expansion

The coeffiecient of thermal expansion (CTE) is important for structural applications since thermal stresses depend directly on the magnitude of the CTE. The CTE for NiAl is very close to $\mathrm{Ni}$ based superalloys (24). The stable protective oxide that forms on NiAl based alloys is $\mathrm{Al}_{2} \mathrm{O}_{3}$. Differences in the CTE of the substrate and the oxide can cause thermal stresses to build up at the interface which eventually cause the oxide to spall off of the surface. A substrate and oxide with similar CTE is preferred for applications where many thermal cycles are necessary.

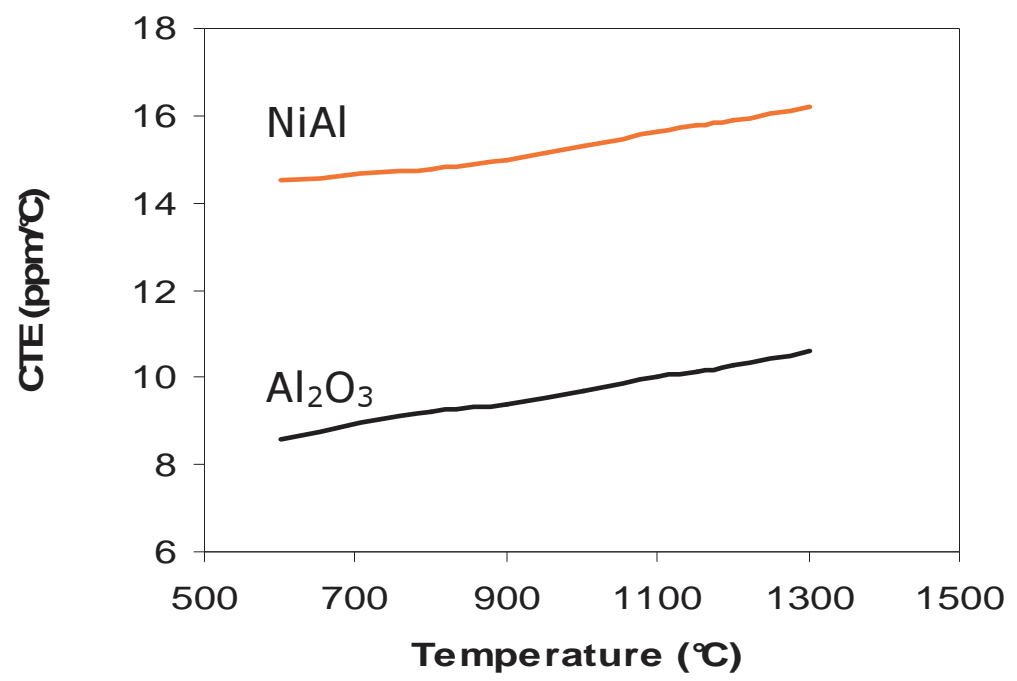

Figure 9: Coefficient of thermal expansion of $\mathrm{NiAl}$ and $\mathrm{Al}_{2} \mathrm{O}_{3}$ (25)

\section{Oxidation}

The Pilling-Bedworth ratio of oxides relates the volume of the oxide formed to the volume of the metal consumed. If the ratio is less than unity, the oxide will be in tension and will not be adherent and will spall off. If the ratio is more than unity, the oxide layer will be in compression and will uniformly cover the metal surface and be protective. If the ratio is much greater than unity, there is risk of too much compressive stresses being built up and the oxide might crack and will not be protective. The Pilling-Bedworth ratio for the alumina scale that the NiAl forms is 
1.38 (26). This means that the scale formed by $\mathrm{NiAl}$ is uniform and protective to the underlying metal which acts as a diffusion barrier for continued oxidation.

The alumina undergoes several phase transitions as it is heated before reaching its thermodynamically stable $\alpha-\mathrm{Al}_{2} \mathrm{O}_{3}$ forms. The phase transition temperatures along with the stable temperature ranges for various forms are shown in Figure 10. The $\alpha-\mathrm{Al}_{2} \mathrm{O}_{3}$ is the most stable and serves as a protective scale.

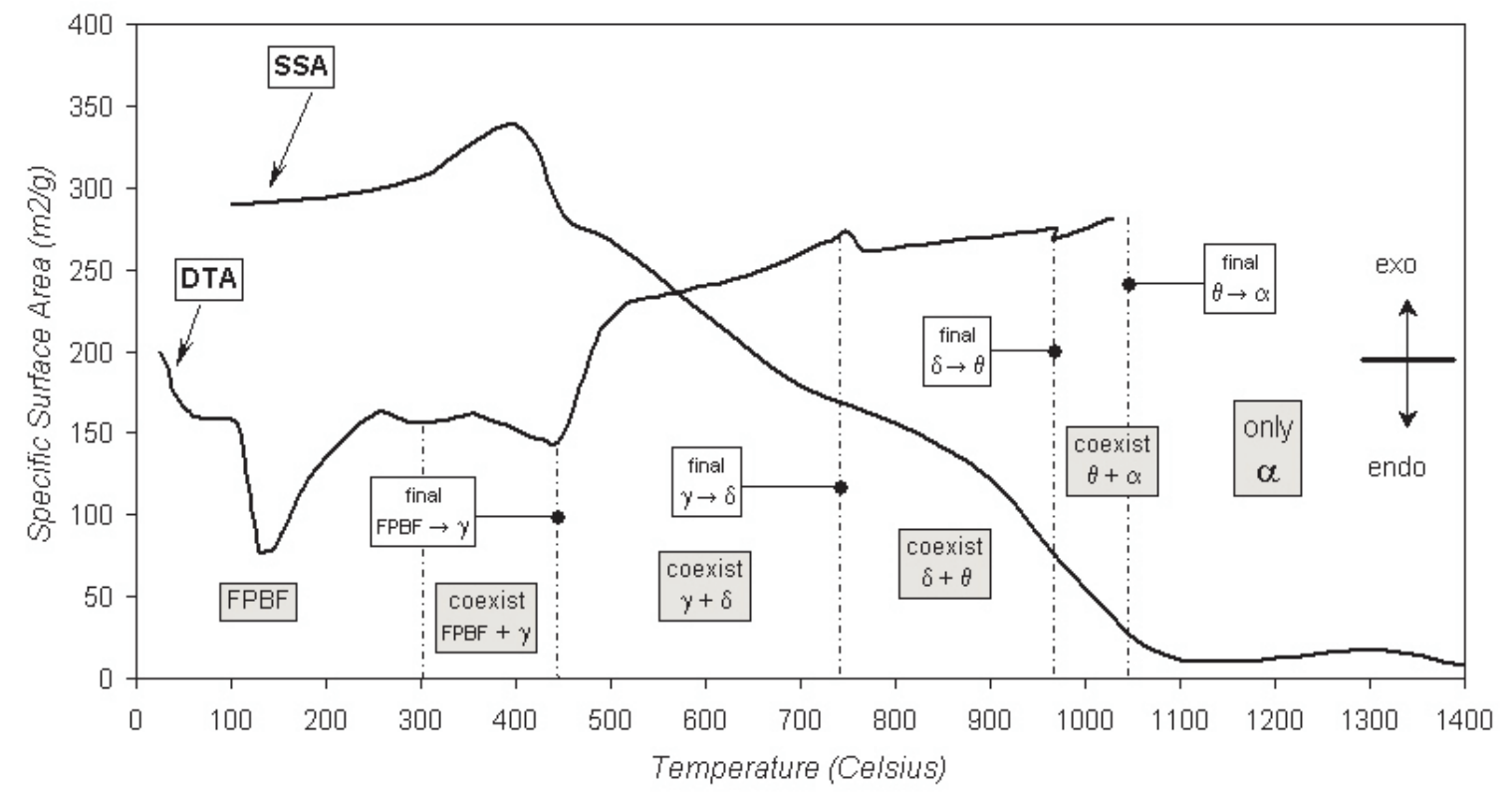

Figure 10: Temperature ranges and transition temperatures of the aluminas (27) 


\section{References}

1) H. Okamoto, Al-Ni (aluminum-nickel), Journal of Phase Equilibria and Diffusion, Vol. 25, No. 4, pp. 394, 2004

2) R.D. Noebe, R.R. Bowman, and M.V. Nathal, Physical and mechanical properties of the B2 compound NiAl, International Materials Reviews, Vol. 38 No. 4, pp. 193-232, 1993

3) S.M. Meier, D.K. Gupta, K.D. Sheffler, Ceramic Thermal Barrier Coatings for Commercial Gas Turbine Engines. JOM, Vol. 43, No. 3, pp. 50-53, 1991

4) R.L. Jones, Thermal Barrier Coatings, in Metallurgical and Ceramic Protective Coatings, Chapman \& Hall: London, pp. 194-235, 1996

5) R.C. Reed, Superalloys, Cambridge: Cambridge University Press, 2006

6) M.J. Donatchie Jr., S.J. Donatchie, Superalloys: A Technical Guide (2nd Ed.), Materials Park, OH: ASM International, pp. 439, 2002

7) C.T. Sims, W.C. Hagel, The Superalloys, John Wiley and Sons: New York, 1972

8) C.T. Sims, N.S. Stoloff, W.C. Hagel, Superalloys II, John Wiley and Sons: New York, pp. 615, 1987

9) N. Birks, G.H. Meier, F.S. Pettit, High-Temperature Oxidation of Metals (2nd Ed.), Cambridge, UK: Cambridge University Press, 2006

10) P. Kofstad, High Temperature Corrosion, New York: Elsevier Applied Science, 1988

11) S. Bose, High Temperature Coatings, Burlington, MA: ButterworthHeinemann, 2007

12) A.C. Vieria Coelho, G.A. Rocha, P.S. Santos, H.S. Santos, P.K. Kiyohara, Specific surface area and structures of aluminas from fibrillar pseudoboehmite, Revista Materia, Vol. 13, No. 2, 2008

13) D.B. Miracle, The physical and mechanical properties of NiAl, Acta Metallurgica et Materialia, Vo. 41, pp. 649, 1993 
14) M. Bestor, Investigation of the effect of hafnium on the properties of $\beta-\mathrm{NiAl}$ bond coats deposited on Ni-based superalloys, PhD dissertation, University of Alabama, 2010

15) A. Russell, K. Lee, Structure-Property Relations in Nonferrous Metals, John Wiley \& Sons, Hoboken, NJ, 2005

16) J.A. Haynes, B.A. Pint, W.D. Porter, I.G. Wright, Comparison of thermal expansion and oxidation behaviors of various high-temperature coating materials and superalloys, Materials at high temperatures, Vol. 21, No. 2, pp. 87-94, 2004

17) $\mathrm{H}$. Cobb, History of stainless steel, ASM International, Materials Park, $\mathrm{OH}$, 2010

18) F.O. Soechting, A design perspective on thermal barrier coatings. Proceedings of the thermal barrier coating workshop, Cleveland, $\mathrm{OH}$ : NASA Lewis Research Center, 1995

19) S.M. Meier, D.K. Gupta, The evolution of thermal barrier coatings in gas turbine engine applications, Journal of Engineering for Gas Turbines and Power, Vol. 116, No. 1, pp. 250-257, 1994

20) H.W. Grunling, W. Mannsmann, Plasma sprayed thermal barrier coatings for industrial gas turbines: morphology, processing and properties, Journal De Physique IV, Vol. 3, No. 11, pp. 903-912, 1993

21) S. Reuss, H. Vehoff, Temperature dependence of the fracture toughness of single phase and two phase intermetallics, Scripta Metallurgica et Materialia, Vol. 24, pp. 1021-1026, 1990

22) R.R. Bowman, R.D. Noebe, R. Darolia, in 2nd Annual HITEMP Review, NASA CP-10039, pp. 41-47, 1989

23) J.J. Lewandowski, G.M. Michal, I.E. Locci, J.D. Rigney, in Alloy phase stability and design, Materials Research Society CP, pp. 341-347, 1991

24) D.B. Miracle, R. Darolia, NiAl and its alloys, Structural Applications of Intermetallic Compounds, John Wiley \& Sons, 2000 
25) S. Takizawa, S. Miura, T. Mohri, Structural stability of NiAl with the L10 structure and local lattice distortion in the Ni3Al alloy around excess Al atoms, Intermetallics, Vol. 13, No. 11, pp. 1137-1140, 2005

26) R.L. Wachtell, in Investigation of various properties of NiAl, Technical Report 52-291, Wright Air Development Center, 1952

27) V. Raghavan, Material Science and Engineering: A first course ( $4^{\text {th }}$ Ed.), Jay Print Pack Private Ltd., New Delhi, India, 1998 


\title{
CHAPTER 2:
}

\section{A MULTI-STAGE HEIRARCHICAL APPROACH TO ALLOY DESIGN}

\author{
P.K. Ray, T. Brammer, Y.Y. Ye, M. Akinc and M.J. Kramer \\ Ames Laboratory and Department of Materials Science and Engineering \\ lowa State University, Ames, IA 50011
}

(Published in JOM, Vol.62, pp. 25-29, 2010)

\begin{abstract}
A multi-stage hierarchical sieving approach based on a combination of semiempirical and ab initio calculations along with selected experimental studies were used to down-select potential alloy systems for ultra-high temperature applications. This approach indicates that the Mo-Ni-Al system has potential for applications at the target temperatures of $1200-1300^{\circ} \mathrm{C}$. The Mo was selected for its high melting temperature, room temperature toughness and creep resistance while the $\mathrm{NiAl}$ is a reservoir for the $\mathrm{Al}_{2} \mathrm{O}_{3}$ passivating scale. Microstructures based on casting and powder processing of the Mo-Ni-Al alloys was studied. Oxidation behavior of the Mo-Ni-Al alloys at 1100 and $1200^{\circ} \mathrm{C}$ in dry air was determined and those alloys with $\leq 20$ at\% Mo were shown to be superior to the $\mathrm{T} 2\left(\mathrm{Mo}_{5} \mathrm{SiB}_{2}\right)$. Furthermore, the calculations predicted that small amounts of platinum group metals (PGM) Pd, Ir and Rh additions would increase the melting temperature without forming detrimental intermetallic phases, in which resulted in improved oxidation stability of the NiAl phase.
\end{abstract}




\section{Introduction}

Superalloys are the workhorse materials for land based gas turbine blades, which are required to operate under extremely harsh combustion environment while retaining their mechanical integrity. Operating temperatures for Ni-based superalloys have been greatly increased by application of the thermal barrier coating along with a suitable $\mathrm{Ni}-\mathrm{Al}$ based bond coat. Commercial turbine blades are routinely operated at temperatures up to $1150^{\circ} \mathrm{C}$ (1). Even higher efficiencies such as envisioned in the DOE NETL's FutureGen gas turbine program will require alloys that can function at temperatures above melting point of today's commercial alloys. Hence, design of ultra high temperature alloys will require a major breakthrough. Refractory metal silicides in the metal-T2-A15 phase field region can operate at high temperatures and retain their strength (2-5). However, oxidation resistance of these alloys is significantly reduced. Alloys in the T1-T2A15 or disilicides of refractory metals offer improved oxidation resistance (6). However, the presence of only brittle intermetallics in the phase assemblage renders them unusable in practice.

A significant increase in operating temperatures is not likely to be achieved by tweaking current Ni-based alloy compositions. A trial-and-error based approach towards the discovery of new materials is tedious; yet we lack the numerical tools to efficiently and accurately predict new phases and their properties. Potential phase space is enormous. For instance, a 4-component Ni based system, with all the elements selected from the transition metal elements, yields 3,654 possible combinations, and adding only one more constituent expands the number of combinations to 23,751 . Considering that many commercial high temperature alloys can have in excess of 8 constituents, a systematic investigation of even a fraction of the potential phase space through computational thermodynamics or $a b$ initio methods are unrealistic. Hence using rapid sieving techniques in an alloy design project is essential. Faster but lower accuracy approaches to quickly 
screen out the least favorable combinations followed by more rigorous methods to narrow the potential phase space offers an efficient alloy design approach.

Fortunately, we do have a few clues to pursue for developing fast screening methods. For instance, the melting temperature of a material can be taken as one of the guidelines for a prospective high temperature alloy. The melting temperature of a compound, in turn, correlates well with the interatomic bond strength and its formation enthalpy (7-9). It has been demonstrated that the formation enthalpy of multicomponent system can be estimated with a reasonable degree of accuracy and extremely low computational cost using an extended Miedema approach (10). However, melting temperature is not the only requirement; only certain elements are known to promote the formation of protective oxide scales, most notably, $\mathrm{Al}, \mathrm{Cr}$ and $\mathrm{Si}$. Therefore, additional screening criteria include developing alloys comprising of a phase that will promote the formation of a slow growing protective oxide scale. Due to the low stability of chromia at the target operating temperatures, $1350^{\circ} \mathrm{C}$, and susceptibility of a silica based scales to moisture in coal combustion byproducts, we are left with an alumina forming alloy (11). Alloys based on a mix of refractory metals (RM) and $\mathrm{Ni}-\mathrm{Al}$ are believed to be the best candidates. The refractory metal forms the backbone of the alloy, providing toughness at low temperatures and creep resistance at high temperatures. The $\beta$-NiAl (B2 structure, SG 221), in turn, acts as a reservoir for the passivating alumina scale. However, alloying additions to the $\mathrm{NiAl}$ are required in order to boost its melting temperature $(\mathrm{Tm}=$ $1640^{\circ}$ ).

The primary focus of this study was to evaluate a series of alloy combinations narrowed down by the guidelines mentioned above, using semi-empirical, as well as $a b$ initio calculations for their potential as a high temperature (T 1300' $\mathrm{C}$ ), oxidation and fracture resistant material. Select alloy compositions predicted by 
the computational tools were then synthesized, characterized and tested for their high temperature oxidative stability as the first goalpost in the alloy development process.

\section{Experimental Procedure}

Theoretical calculations

The initial cut through the prospective phase space was performed using semiempirical calculations based on an extended Miedema approach (10). Briefly, this approach is based on using an energy minimization scheme by optimizing the compositions of the constituent binary systems under appropriate mass balance constraints. Our modified Miedema model was used for estimating the difference in formation enthalpies between $\mathrm{Ni}-\mathrm{Al}$ and $\mathrm{TM}-\mathrm{Al}$ ( $\mathrm{TM}=$ transition metal). Twenty six elements from the transition metal block were tested over the entire composition range of their ternaries with $\mathrm{Ni}$ and $\mathrm{Al}$. Three considerations were given for the selection of the TM : <1> high formation enthalpy, <2> absence of intermetallics with $\mathrm{Ni}$ or $\mathrm{Al}$ over a significant composition range and $<3>$ a cubic crystal form to insure some ductility at lower temperatures. Using these criteria, Mo was clearly the best candidate. Molybdenum retains its bcc structure up to its melting temperature and has a limited solubility with $\mathrm{Al}$ or $\mathrm{Ni}$. While not possessing good oxidation stability in of itself, its low diffusivity and low solubility with $\mathrm{NiAl}$ suggests that a graded microstructure can be designed to minimize susceptibility for oxidation.

The next step in alloy design was to search for ternary addition to the NiAl to boost its melting temperature. As mentioned above, the ternary addition to the $\mathrm{NiAl}$ should not only raise the melting temperature but should be retained in solid solution with the NiAl. Again we used our modified Miedema model to downselect the most promising candidates based on their formation enthalpies. Of the late-transition elements, only $\mathrm{Hf}, \mathrm{Y}, \mathrm{Zr}, \mathrm{Nb}, \mathrm{Pd}, \mathrm{Rh}$ and $\mathrm{Ir}$ showed the highest 
formation enthalpies with $\mathrm{NiAl}$ and a smaller affinity for Mo. It is critical that the ternary addition to NiAl do not exhibit high heat of mixing with Mo. At this point, more accurate calculations were required.

$A b$ initio methods are preferred at this stage. Unlike embedded atom methods, interatomic potentials do not have to be developed or in the case of computational thermodynamics, developing databases are not necessary. The disadvantage of $a b$ initio methods is in instances where the crystal structure and its atomic decoration are not known so that a large number of prospective structures must be calculated. It should be stressed that unless specifically determined, ab initio provides only the most enthalpically stable structure $(0 \mathrm{~K})$. Entropically stable structures or highly complex low symmetry systems are very difficult to identify with this approach. In this particular system we suspected that the small platinum group metal (PGM) additions will not result in degeneracy of the $\beta$-NiAl, which was readily confirmed experimentally. Therefore the number of calculations required was small.

The ab initio calculations were carried out using the Vienna ab initio Simulation Package (VASP) (12-14) to get the thermodynamically stable structure of B2 phase in the $\mathrm{Ni}_{1-x} \mathrm{AlTM}_{\mathrm{x}}$ and $\mathrm{NiAl}_{1-\mathrm{x}} \mathrm{TM}_{\mathrm{x}}$ systems using a 54-atom supercell, where TM represents the transition metal element selected by the Miedema's model. The density functional calculations are performed using a plane-wave pseudopotential representation, with ultra-soft pseudo-potentials (13) for all species and with a plane-wave energy cutoff of $300 \mathrm{eV}$. The k-point sampling was chosen to converge all of the total energies to an accuracy of $2 \mathrm{meV} / \mathrm{atom}$. The k-point grid used for structural relaxation was $6 \times 6 \times 6$, chosen according to the MonkhorstPack scheme (15), and symmetry reduced to the irreducible Brillouin zone. 


\section{Experimental methods}

Based on our calculations, the Mo-Ni-Al system was selected as a viable candidate for the base alloy. A number of compositions in this system were tested for their resistance to high temperature oxidation. The testing temperatures were restricted to $1200^{\circ} \mathrm{C}$ due to massi ve scale spallation at higher temperatures. This pointed to a need for improving the NiAl phase with selected transition metal additions as indicated by the calculations above.

\section{Mo-Ni-Al alloys}

Mo-Ni-Al alloys are known to exhibit a two phase (bcc Mo $+\beta-\mathrm{NiAl}$ ) microstructure over a limited range of compositions (16). All the experiments in the present study were carried out in this phase field. Higher phase fraction of Molybdenum would be detrimental to the oxidation resistance; hence the phase fraction of Mo was kept below 35 at\% in all cases. The alloys were synthesized using powder metallurgical techniques as well as casting. The powder metallurgy involved mixing the pure metal powders $(\sim 10 \mu \mathrm{m})$ in a mixer/shaker (SPEX 8000 , SPEX CertiPrep Inc, Metuchen, NJ) for 10 minutes followed by compaction of the powders by dry pressing at a pressure of 3500 psi (24 MPa). The cylindrical pellets thus produced had a diameter of $10 \mathrm{~mm}$ and a height of 20 $\mathrm{mm}$. The pellets were then sintered at $1750^{\circ} \mathrm{C}$ for 45 minutes. The pellets synthesized by this route had nominal compositions of $M o=15,20,25$ and 35 at\%, with the balance in each case being equiatomic NiAl. Oxidation coupons having a diameter of $10 \mathrm{~mm}$ and a thickness of $1 \mathrm{~mm}$ were cut from the cylindrical samples and subjected to interrupted oxidation tests at $1100^{\circ} \mathrm{C}$ which is the maximum temperature that current superalloys are exposed to in practice. Oxidation tests with multiple compositions allowed us to study the effect of Mo phase fraction and determine an appropriate composition range where the oxidation resistance was reasonably optimized. 
The composition of the drop cast alloy $\left(\mathrm{Mo}_{20} \mathrm{Ni}_{40} \mathrm{Al}_{40}\right)$ was decided based on the oxidation behavior of the sintered alloys. Drop cast samples were prepared from pelletized elemental powder mixture of Mo (Alfa Aesar, 99.5\% purity), Ni (MPC, 99.6\% purity) and Al (Alfa Aesar, 99.8\% purity) which were arc-melted. The alloys were re-melted thrice to achieve a greater degree of homogenization followed by drop-casting in order to obtain a cylindrical rod. The drop-cast alloy was subject to interrupted oxidation tests over a range of temperatures from $1000^{\circ} \mathrm{C}$ to $1200^{\circ} \mathrm{C}$.

In this test, the samples were exposed to the target temperatures for a total of 20 hours with occasional interruptions for mass measurements at ambient temperature. The testing temperatures were deliberately kept at $1200^{\circ} \mathrm{C}$ or lower since our work on oxidation of pure nickel aluminides at temperatures above $1200^{\circ} \mathrm{C}$ (discussed below) has shown massive scale sp allation. Microstructures of the as-prepared alloys as well as the oxidized coupons were studied using a JEOL 5910LV scanning electron microscope (JEOL, Tokyo, Japan) at an accelerating voltage of $20 \mathrm{kV}$.

\section{Nickel Aluminides with TM additions}

The Ni-Al-TM alloys were produced from pieces cut from pure bulk metal sheets obtained from the Materials Preparation Center at Ames Laboratory, having a purity of $99.7 \%$ or more. Pure $\mathrm{Ni}$ and $\mathrm{Al}$ were first arc-melted together in an argon atmosphere to form $\beta-\mathrm{NiAl}$. The ab initio calculations suggested that the transition metals have a preference for the $\mathrm{Ni}$ site in the B2 structure. Alloys with compositions $\mathrm{Ni}_{50-\mathrm{x}} \mathrm{Al}_{50} \mathrm{TM}_{\mathrm{x}},(\mathrm{x}=3,6$ and 9) were then arc-melted in an argon atmosphere. The samples were re-melted thrice to achieve better homogenization before drop-casting. The rods were annealed at $1300{ }^{\circ} \mathrm{C}$ in an argon atmosphere for 6 hours to ensure homogeneity. SEM was used to characterize the microstructure while phase analysis was done using $x$-ray 
diffraction (XRD) on a Philips PANalytical x-ray diffractometer (Panalytical, Almelo, Netherlands) with a Bragg-Brentano geometry and $\mathrm{Cu}$ Ka1 radiation ( $\lambda=$ $1.54056 \AA$ ). . The $x$-ray data was Rietveld refined using the GSAS software in order to estimate the lattice parameters of the phases as well as determine site preference for different elements (17). Of the transition metals studied, it was observed that alloys with Platinum group metal (PGM) modifications formed single phase alloys while the other alloys showed a eutectic microstructure. Hence, further studies were carried out only on the PGM modified alloys. Oxidation coupons were prepared as described above, but more aggressive testing conditions, $1300^{\circ} \mathrm{C}$ for two hours and ambien t for $30 \mathrm{~min}$, were employed to determine if the PGM improved the oxidation stability of NiAl reservoir phase.

\section{Results and Discussion}

Oxidation behavior of the Mo-Ni-Al alloys

Samples processed by liquid phase sintering showed the influence of alloy composition on the oxidation behavior. Alloys under 20 at\% Mo, with equiatomic $\mathrm{NiAl}$ showed fairly good oxidation resistance, while the alloys with a higher volume fraction of Mo (e.g. $\mathrm{Mo}_{35} \mathrm{Ni}_{32.5} \mathrm{Al}_{32.5}$ ) failed to form a passivating oxide layer (Figure 1). The strong composition dependence of oxidation is due to Mo's deleterious effect on the oxidation resistance. Minimizing the inter-connected Mo network is required. Continuity of Mo phase depends on its volume fraction and the size of the Mo grains. Higher the volume fraction of the Mo phase, and larger the grain size, larger is the probability of connectivity and resulting in poorer oxidation resistance. 
25

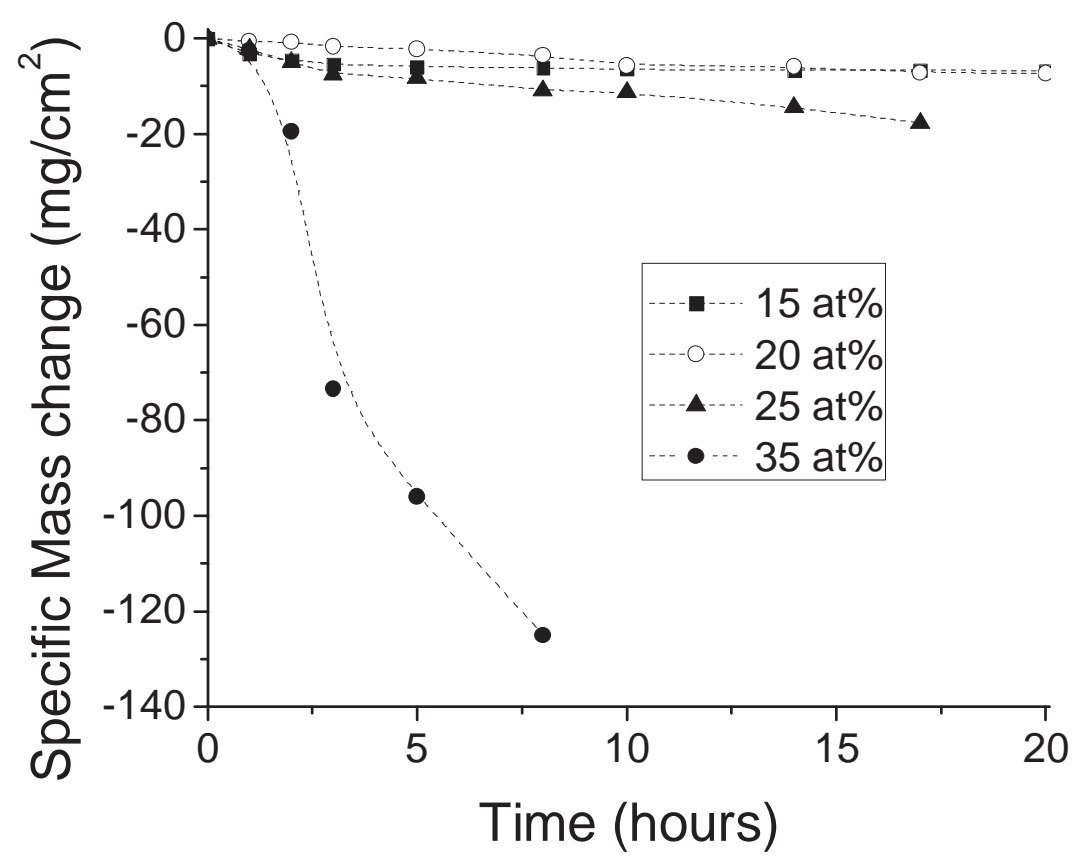

Figure 1: Interrupted flowing air oxidation of liquid phase sintered alloys of different Mo content at $1100^{\circ} \mathrm{C}$.

Figure 2a shows a low magnification microstructure of the oxidized $\mathrm{Mo}_{20} \mathrm{Ni}_{40} \mathrm{Al}_{40}$ cast alloy at $1200^{\circ} \mathrm{C}$. It can be seen that the alloy has developed a continuous alumina scale of about $5 \mu \mathrm{m}$ thickness, albeit not uniform, across the length of the sample. A closer look at the oxide scale at higher magnification (Figure $2 b$ ) shows that the scale thickness fluctuations is due to presence of long Mo dendrites growing into the alloy. 

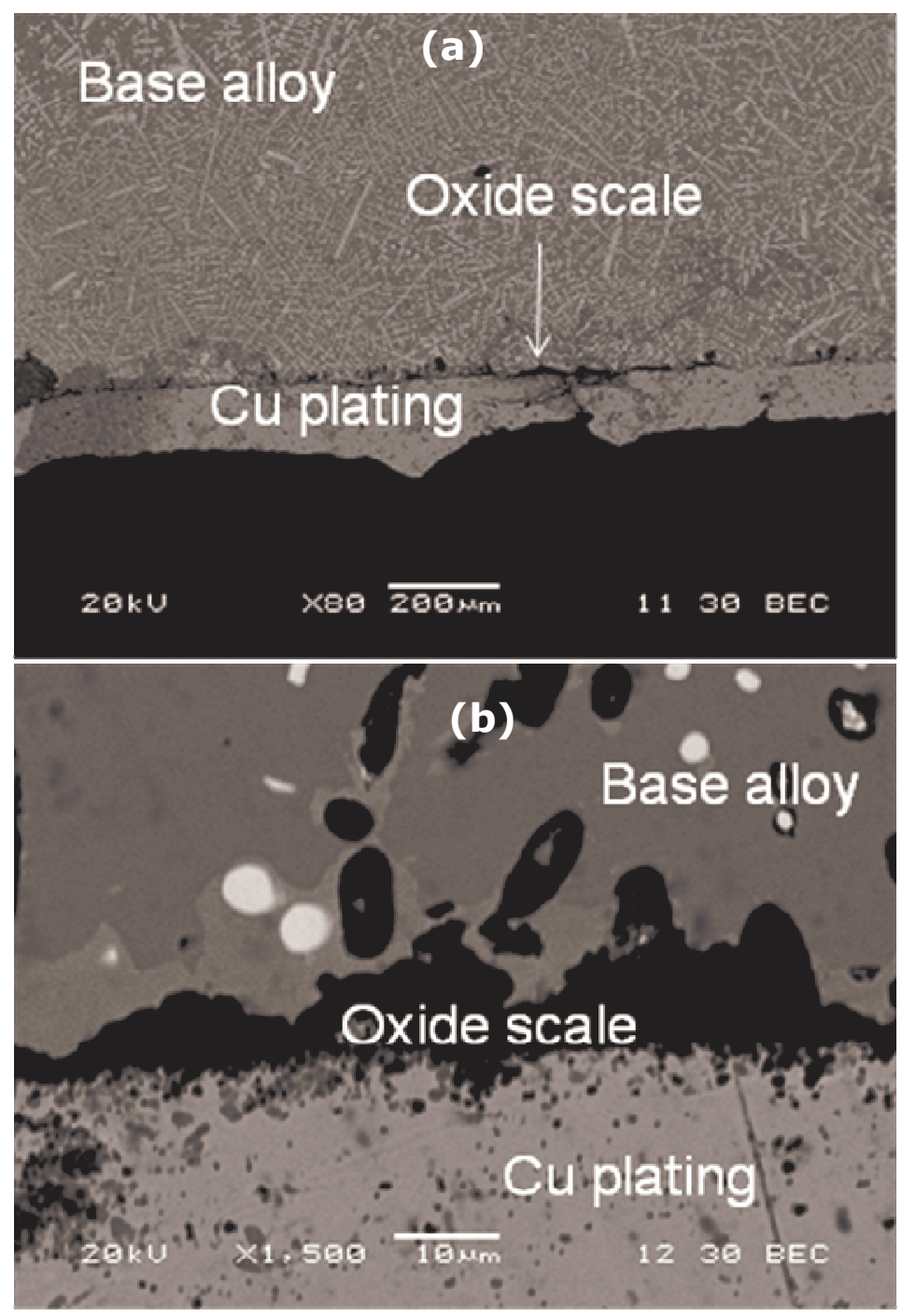

Figure 2: (a) Low magnification image of the oxidized alloy. The alumina scale appears to have formed continuously on the surface. (b) Higher magnification image of the oxidized alloy showing the non-uniformity of scale thickness primarily as a result of presence of Mo phase at the surface. Mo gets oxidized and the resultant $\mathrm{MoO}_{3}$ volatalizes allowing oxygen to penetrate relatively larger distances into the alloy.

It has been widely observed in case of nickel based alloys that the initial oxidation product of $\mathrm{NiAl}$ is the formation of $\mathrm{NiO}$ (18). Subsequently, $\mathrm{NiO}$ is reduced by $\mathrm{Al}$ resulting in the formation of $\mathrm{Ni}$ and $\mathrm{Al}_{2} \mathrm{O}_{3}$. Typically such a 
reduction results in linear rather than parabolic kinetics. Aluminum can also react with atmospheric oxygen to form $\mathrm{Al}_{2} \mathrm{O}_{3}$ which should exhibit parabolic oxidation kinetics. Additionally, $\mathrm{NiO}$ and $\mathrm{Al}_{2} \mathrm{O}_{3}$ can react to form a $\mathrm{NiAl}_{2} \mathrm{O}_{4}$ spinel (19). All the reactions involving $\mathrm{Ni}$ and $\mathrm{Al}$ result in a slow mass gain, whereas the oxidation of $\mathrm{Mo}$ and the subsequent volatilization of $\mathrm{MoO}_{3}$ results in a rapid mass loss (4). Consequently, the overall oxidation rate is a sum of mass gain due to oxidation of $\mathrm{Ni}$ and $\mathrm{Al}$ and loss due to volatilization of $\mathrm{MoO}_{3}$. Figure 3 shows the oxidation kinetics during the interrupted oxidation process for the $\mathrm{Mo}_{20} \mathrm{Ni}_{40} \mathrm{Al}_{40}$ alloy at $1200^{\circ} \mathrm{C}$. As a baseline comparison the stead y state mass loss value for the $\mathrm{T} 2-\mathrm{Mo}_{5} \mathrm{SiB}_{2}$ compound is shown on the same figure for comparison. The preliminary data indicates that the oxidation behavior of Mo-Ni-Al alloy is comparable to the refractory metal silicides at fairly elevated temperatures.

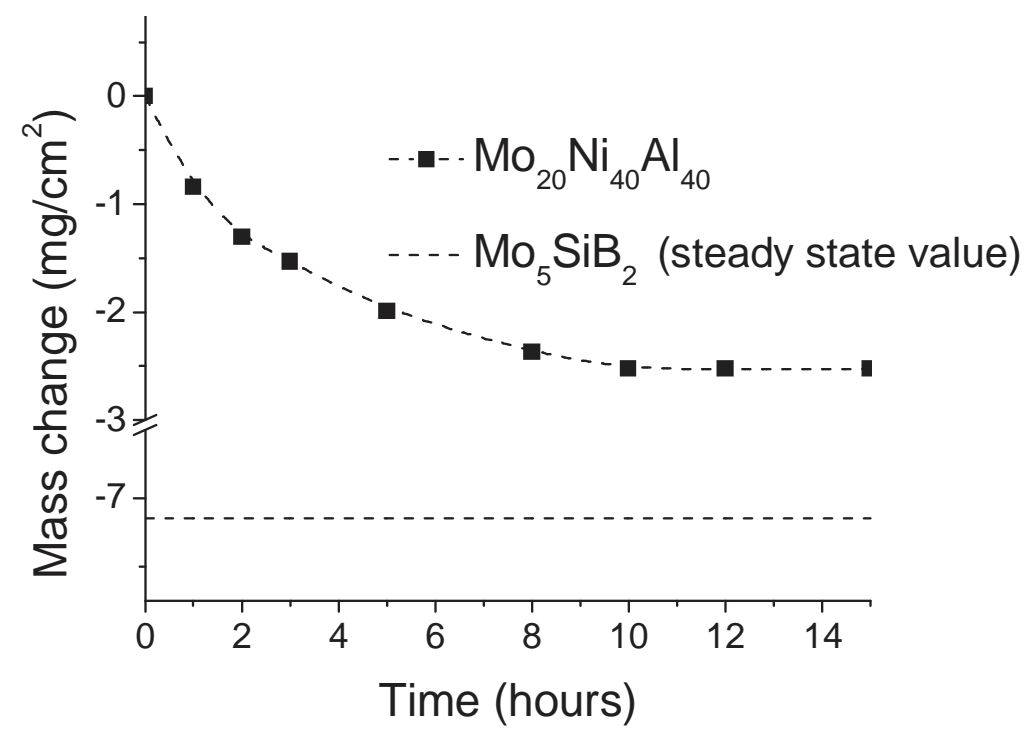

Figure 3: Interrupted flowing air oxidation of an arc-melted and drop cast alloy $\left(\mathrm{Mo}_{20} \mathrm{Ni}_{40} \mathrm{Al}_{40}\right)$ at $1200^{\circ} \mathrm{C}$

Oxidation studies were limited to a temperature of $1200^{\circ} \mathrm{C}$ because the alumina scale formed on nickel aluminides is prone to spallation above $1200^{\circ} \mathrm{C}$. This can be seen clearly in Figure 4, which shows the cyclic oxidation response of the 
pure nickel aluminide at $1300^{\circ} \mathrm{C}$. The next section will discuss the role of alloying additions to increase the melting temperature and the oxidation behavior of these allows.

\section{Oxidation behavior of the nickel aluminide}

X-ray diffraction studies on the nickel aluminides with $\mathrm{Zr}, \mathrm{Y}, \mathrm{Hf}$ and $\mathrm{Nb}$ additions indicated a two phase mixture. The PGM additions were shown to form a single phase with the same crystal system as the $\beta$-NiAl. A monotonic and approximately linear increase in the lattice parameter was observed with increasing PGM additions. Subsequent Rietveld refinement confirmed that PGM substitutions preferred the $\mathrm{Ni}$ site, which is in accordance with the ab initio calculations (Figure 4).

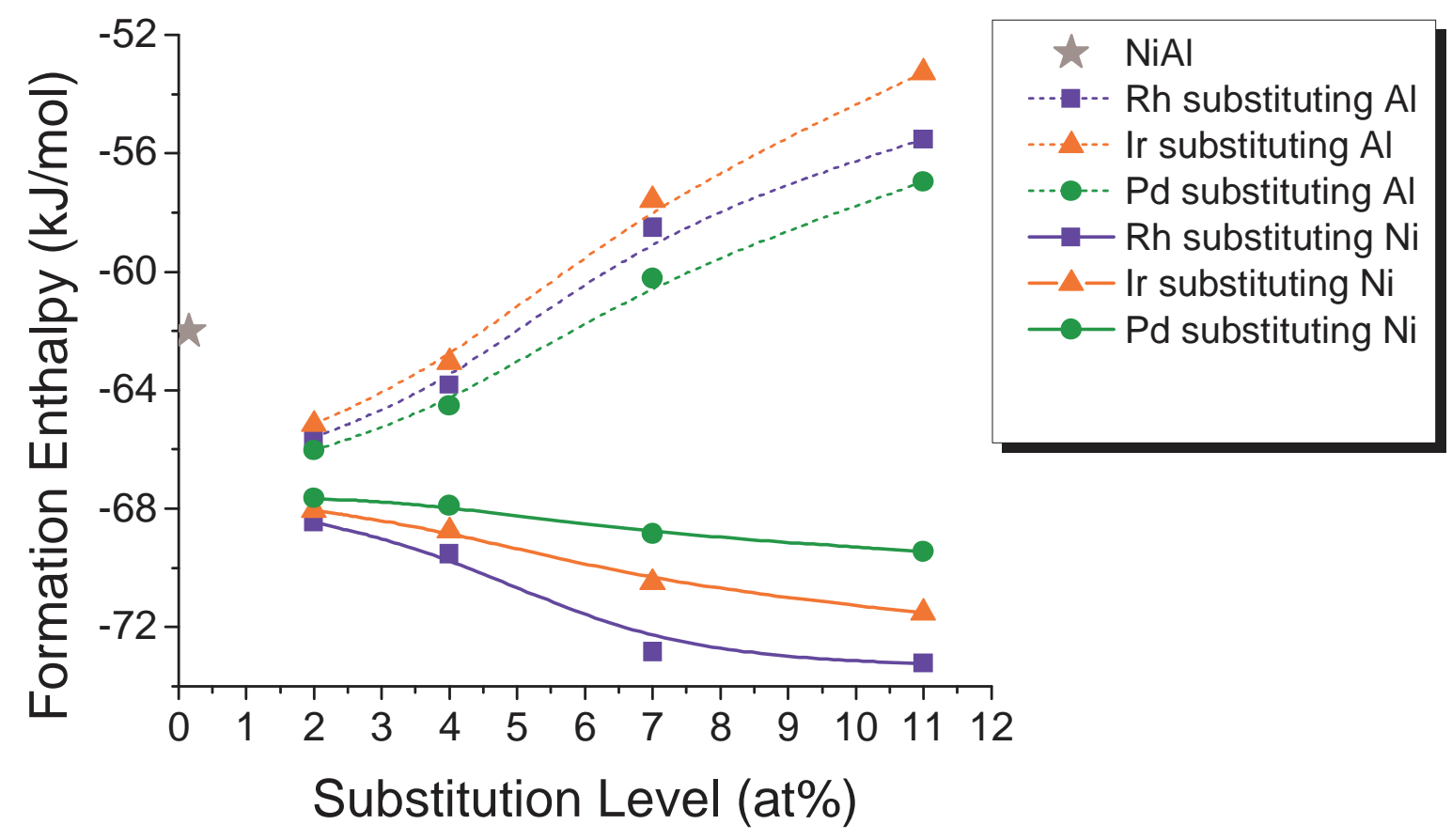

Figure 4: Variation of formation enthalpy of $\beta$-NiAl with PGM additions. 
Figure 4 shows the variation of formation enthalpy of PGM substituted $\beta$-NiAl. It can be seen that substitution of PGM elements for $\mathrm{Ni}$ is energetically favorable. Also, controlled additions result in a monotonic change in formation enthalpy. This suggests that these PGM additions might be beneficial for obtaining an increase in the melting temperature of the nickel aluminide. The other transition metals that showed large negative formation enthalpies with the nickel-aluminide included $\mathrm{Hf}, \mathrm{Y}, \mathrm{Zr}$, and $\mathrm{Nb}$. All of these additions were experimentally found to produce deep eutectics. A high formation enthalpy can indicate high stability of both the solid and the liquid phase. The phase selection is decided by the relative stability of these two phases. Miedema's model is a structure-less model; hence it can't be used to predict which of these two phases will be more stable. Formation of a eutectic suggests that the liquid phase is relatively more stable compared to a single phase intermetallic with the same composition in case of these alloying additions. Hence, further oxidation studies were carried out with only the PGM additions, since they were readily soluble in the $\beta$-NiAI.

Figure 5 shows the oxidation kinetics for the three PGM substitutions (all 6 at\%) to the $\beta$-NiAl compared against undoped $\beta$-NiAl as a benchmark. It can clearly be seen that the Pd substitution performed worse than the $\beta$-NiAl during oxidation testing at $1300^{\circ} \mathrm{C}$. The oxide spallation of the $\mathrm{Pd} s$ ample was noticeable early on during the test. The spallation flakes were large and discernable with the naked eye, just like the $\beta$-NiAl spallation. The Rh sample performed better than the base alloy $\mathrm{NiAl}$, but worse than the alloy doped with Ir. The sample with $\mathrm{Rh}$ showed an adherent oxide scale initially, but after five hours oxide spallation was observed. From the oxidation resistance point of view, Ir substitution to $\beta-\mathrm{NiAl}$ appears to be superior. No sign of spallation was evident at times shorter than 20 $\mathrm{h}$ for alloys with 9 at\% substitution. In all cases it should be noted that the best performing alloy at the end of 20 hours was always the alloy with highest fraction of the ternary substitution for all of the elements tested. 


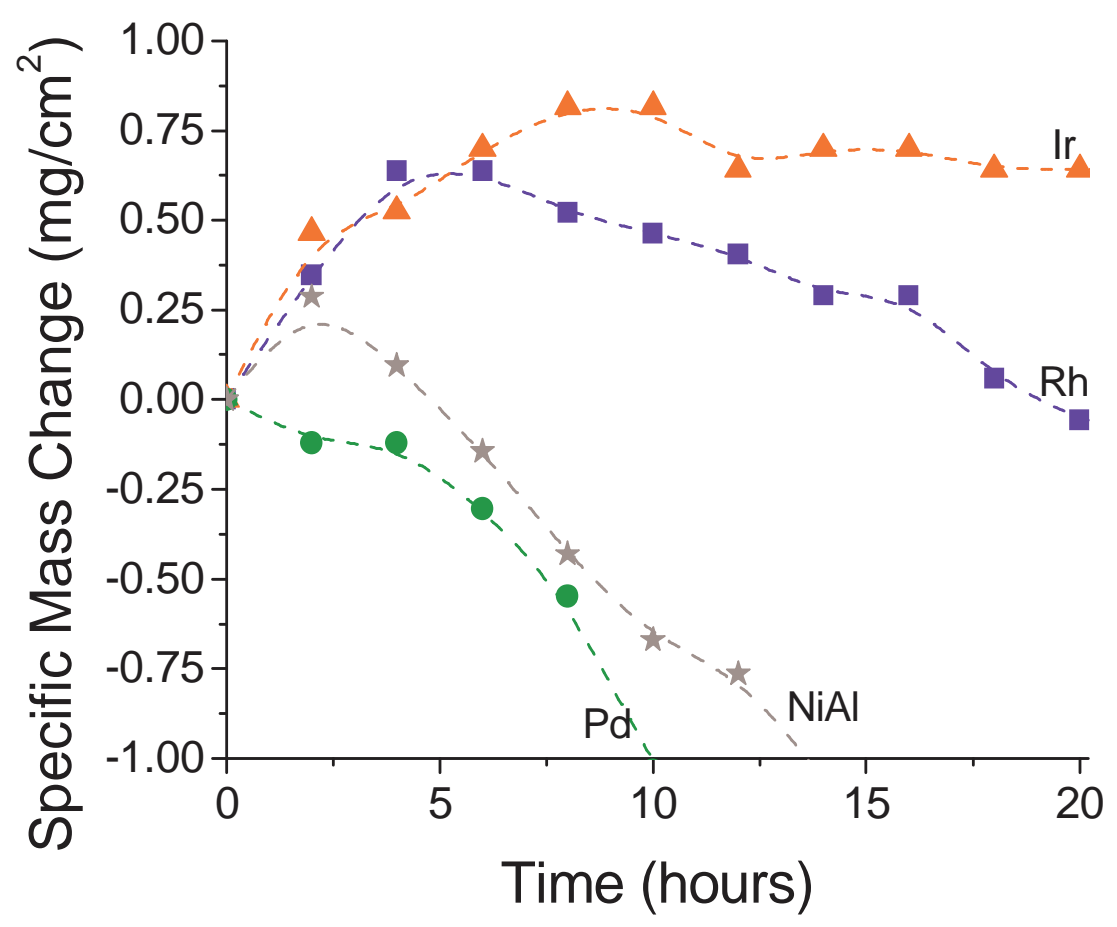

Figure 5: Cyclic oxidation of $\beta-\mathrm{NiAl}$ with and without PGM substitutions.

Figure 6a-d shows the oxidation microstructures of the baseline NiAl along with each ternary substitution set at 6 at\%. These samples were oxidized for 24 hours at $1300^{\circ} \mathrm{C}$ and then examined to better assess the ev olution of the oxide scale formation. Figure 4 clearly displays that neither the benchmark $\beta$-NiAl alloy nor the $\beta$-NiAl doped with $\mathrm{Pd}$ additions show an adherent oxide layer. Since both alloys had relatively significant mass loss, the surface would be devoid of a continuous oxide scale. The Rh doped $\beta$-NiAl showed an overall mass gain as well as signs of spallation. Looking at the oxide microstructure, it can be seen that the oxide layer is fairly continuous with a thickness of approximately $10 \mu \mathrm{m}$. The Ir addition showed an almost continuous oxide scale with a thickness of 8 microns. The only discontinuities were observed at the corners of the specimen where stresses in the oxide layer would be highest. 

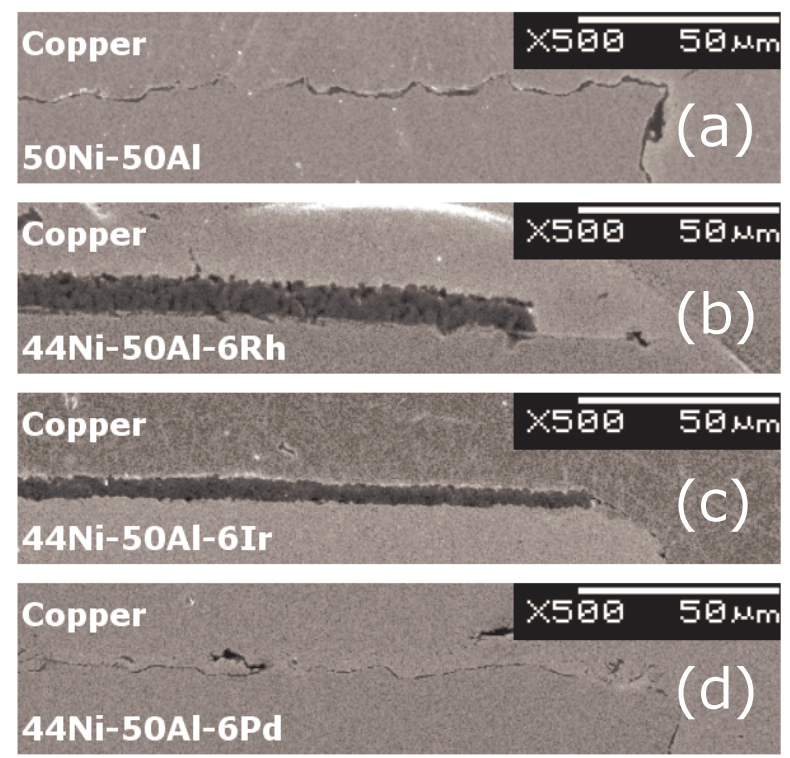

Figure 6: Microstructures of oxidized alloys after oxidation at $1300^{\circ} \mathrm{C}$ for 24 hours. (a) $\beta$-NiAl; and $\beta$-NiAl with 6 at\% (b) Rh, i.e. $\mathrm{Ni}_{44} \mathrm{Al}_{50} \mathrm{Rh}_{6}$; (c) Ir, i.e. $\mathrm{Ni}_{44} \mathrm{Al}_{50} \mathrm{Ir}_{6}$; (d) Pd i.e. $\mathrm{Ni}_{44} \mathrm{Al}_{50} \mathrm{Pd}_{6}$

\section{Conclusions}

We have shown that a hierarchical approach to alloy design starting with a less accurate but fast tool, followed by a more accurate but time consuming computational tools can be an efficient and effective means of down-selecting high temperature alloys. Our modified Miedema model is particularly effective in identifying regions of high (negative) formation enthalpies, indicative of high melting temperatures. Using the criteria of refractory base metal as the backbone of the alloy and identifying the NiAl as the most promising reservoir compound for alumina scale former, we demonstrated that Mo-Ni-Al-(PGM) shows good promise as a high temperature alloy. To further stabilize the reservoir compound, the most enthalpically stable ternary additions were determined. The most promising of the Ni-Al-(PGM) alloys based on ab initio 
calculations were synthesized and their oxidation behavior was studied. It was found that a few alloys in this system had enough potential to warrant further investigation of these materials for ultra-high temperature applications. The Mo phase fraction and its grain size play a critical role in the oxidation behavior of these alloys. Future work would be focused on developing PGM substituted Mo$\mathrm{Ni}-\mathrm{Al}$ alloys in the two phase bcc-Mo (ss) + $\beta$-NiAl phase fields.

\section{Acknowledgement}

This work was supported by the DOE-FE (AMR program) through Ames Laboratory contract no. DE-AC02-07CH11358 through lowa State University.

\section{References}

1) R. C. Reed, The superalloys: Fundamentals and applications, Cambridge University Press, Cambridge, 2006.

2) M. Meyer, M. Kramer, M. Akinc, Advanced Materials 8 (1996) 85-88.

3) M. K. Meyer, M. J. Kramer, M. Akinca, Intermetallics 4 (1996) 273-281.

4) M. K. Meyer, M. Akinc, Journal of the American Ceramic Society 79 (1996) 938-944.

5) J. R. Nicholls, MRS Bulletin 28 (2003) 659-670.

6) A. J. Thom, E. Summers, M. Akinc, Intermetallics 10 (2002) 555-570.

7) J. H. Rose, J. Ferrante, J. R. Smith, Physical Review Letters 47 (1981) 675.

8) Li, P. Wu, Chemistry of Materials 14 (2002) 4833-4836.

9) C. Li, J. Lim Hoe, P. Wu, Journal of Physics and Chemistry of Solids 64 (2003) 201-212.

10) P. K. Ray, M. Akinc, M. J. Kramer, Journal of Alloys and Compounds 489 357-361.

11) J. E. Croll, G. R. Wallwork, Oxidation of Metals 4 (1972) 121-140.

12) G. Kresse, J. Furthmüller, Physical Review B 54 (1996) 11169.

13) G. Kresse, J. Furthmüller, Computational Materials Science 6 (1996) 15-50. 
14) G. Kresse, J. Hafner, Physical Review B 47 (1993) 558.

15) H. J. Monkhorst, J. D. Pack, Physical Review B 13 (1976) 5188.

16) X. Lu, Y. Cui, Z. Jin, Metallurgical and Materials Transactions A 30 (1999) 1785-1795.

17) B. H. Toby, Journal of Applied Crystallography 34 (2001) 210-213.

18) G. R. Wallwork, Reports on Progress in Physics 39 (1976) 401-485.

19) X. Zhao, I. P. Shapiro, P. Xiao, Surface and Coatings Technology 202 (2008) 2905-2916. 


\title{
CHAPTER 3:
}

\section{EFFECT OF PLATINUM GROUP METAL SUBSTITUTIONS AND HAFNIUM ADDITIONS ON THE OXIDATION RESISTANCE OF $\beta-\mathrm{NiAl}$}

\author{
T. Brammer, M. Akinc and M.J. Kramer \\ Ames Laboratory and Department of Materials Science and Engineering \\ lowa State University, Ames, IA-50011
}

(To be submitted to Corrosion Science Journal)

\begin{abstract}
High temperature oxidation studies were performed on $\beta$-NiAl along with modified $\mathrm{NiAl}$ alloys using Platinum Group Metal (PGM) substitutions in the range of 3-9 at\%. Both isothermal and cyclic tests were carried out in the temperature range of $1150-1300^{\circ} \mathrm{C}$ using dry flowing air. The PGM that showed the biggest improvement in oxidation resistance to NiAl was iridium which was shown to slightly decrease the oxidation growth rate as well as create an oxide layer that was more adherent to the surface. Alloys that had up to 0.1 at $\%$ hafnium addition were also tested in the same manner for comparison. Hafnium additions showed a greater effect of slowing the oxidation growth rate and still afforded good adherence of the oxide scale to the surface. The most oxidatively resistant sample tested was the $6-9$ at\% iridium containing NiAl alloys with addition of 0.05 at\% hafnium.
\end{abstract}




\section{Introduction}

Many of the current land based gas turbine blades utilize a nickel-based superalloy, which have two major phases, $\mathrm{Y}-\mathrm{Ni}$ and the $\mathrm{L}_{2} \mathrm{Ni}_{3} \mathrm{Al}$. Although these alloys have good oxidation resistance and excellent fracture toughness, they have reached their limit with respect to operating temperature. The melting temperature of $\mathrm{Ni}_{3} \mathrm{Al}$ is $1^{1363^{\circ}} \mathrm{C}$, while that for $\mathrm{Ni}$ is $1450^{\circ} \mathrm{C}$. These $t$ urbine blades must employ the use of cooling systems along with a thermal barrier coating (TBC) to shield the base alloy from the extreme gas temperatures (1). Even then, these alloys have an upper use temperature of $1100^{\circ} \mathrm{C}$ (1). A higher combustion temperature results in improved Carnot engine efficiency (2); hence alloys that can be used at higher operating temperatures while retaining their oxidation resistance and mechanical strength are highly desirable.

The base alloy selected was the intermetallic $\beta-N i A l$ which has a high melting temperature and inherently good oxidation resistance (5). Its high melting temperature of $16400^{\circ} \mathrm{C}$ allows it to operate at higher combustion temperatures yielding greater turbine engine efficiencies. An extended Miedema model is employed as a rapid sieving tool to determine which third element substitution predicts an increase the enthalpy of formation of the base alloy which also manifests itself with an increase in melting temperature (4). The extended Miedema model calculations predicted that PGM substitutions will lead to reduction in formation enthalpy relative to the base alloy. $A b$ initio calculations were then carried out for the systems identified as potential candidate alloys by the extended Miedema approach. Alloys were also screened for their ability to form a protective oxide scale when subjected to high temperature environments. Although the operating temperatures are a point of interest, the main subject of focus of this report is the oxidation resistance of ternary alloys based on $\beta-\mathrm{NiAl}$. 
In this paper, we report the isothermal and cyclic oxidation behavior of $\beta-\mathrm{NiAl}$ with PGM substitutions and with $\mathrm{Hf}$ additions. The PGM alloying additions were expected to increase the melting temperature of $\mathrm{NiAl}(3)$ as well as improve the oxidation resistance (6-9). Alloys were subjected to both isothermal and cyclic oxidation tests. Wherever applicable, the rate constants were estimated from the isothermal oxidation plots. The scale adherence and relative protection afforded to the underlying base alloy were assessed from the cyclic oxidation runs. Both types of tests are critical to characterize the growth kinetics of the oxide and stability of the protective oxide scale. Additionally, microscopic examination of the oxide scales was carried out to assess the scale thickness and microstructure.

\section{Experimental Procedure}

\section{Materials}

The alloys were synthesized from pieces cut from pure bulk metal sheets obtained from the Materials Preparation Center (USDOE, Ames Laboratory, Ames, lowa) having a purity of $99.7 \%$ or better. Pure $\mathrm{Ni}$ and $\mathrm{Al}$ were first arcmelted together on a chilled copper hearth in an argon atmosphere using a nonconsumable tungsten electrode. This initial melting ensured formation of $\beta$-NiAl. The alloying additions were then melted along with the $\beta$-NiAl synthesized according to the aforementioned steps. The nominal compositions were prepared according to $\mathrm{Ni}_{50-x} \mathrm{Al}_{50} \mathrm{PGM}_{\mathrm{x}}(\mathrm{x}=0,3,6$, and 9 at \%). The alloys containing $\mathrm{Hf}$ were produced by using pieces of $\mathrm{Hf}$ modified $\mathrm{Ni}$ sheet metal instead of pure $\mathrm{Ni}$. After synthesis of desired composition by arc-melting, the samples were turned over and re-melted a minimum of three times in the argon atmosphere to achieve better bulk homogenization. After re-melting the samples were drop-cast into a 10-mm-diameter cylinder using the arc-melting furnace. These rods were then annealed in an inert atmosphere at $1300^{\circ} \mathrm{C}$ for 6 hours to achieve a better compositional homogeneity. 
The annealed rod was sectioned into $1 \mathrm{~mm}$ thick discs using a circular precision saw. The samples to be tested in the cyclic furnace were then mechanically polished using wet 600 grit SiC paper. A 1-mm-diameter hole was drilled into samples for the isothermal testing and suspended vertical furnace tube by a sapphire wire. All samples were washed with methanol before testing.

\section{Oxidation testing and characterization}

Isothermal oxidation at 1150 and $1200^{\circ} \mathrm{C}$ was carried out using a high temperature oxidation testing rig fitted with a Mellen SC13R 1.25 inch vertical tube furnace (Concord, New Hampshire) and a Cahn 2000 recording electrobalance (Madison, Wisconsin) having an accuracy of $0.1 \mathrm{mg}$. The sample was suspended from the balance on a sapphire wire hook. Dry air was passed through the system at a rate of $60 \mathrm{~mL} / \mathrm{min}$. An lonmaster fan was used to remove the static electricity in the system to ensure a higher signal to noise ratio in the measurements. The furnace was turned on and set to the desired dwelling temperature using a heating rate of $15^{\circ} \mathrm{C} / \mathrm{m}$ in and then held at the temperature for 100 hours. Since the Mellen furnace could not maintain operating temperatures as high as $1300^{\circ} \mathrm{C}$, a differe nt furnace was used for experiments at $1300^{\circ} \mathrm{C}$. Isothermal oxidation at $1300^{\circ} \mathrm{C}$ was carried out in a Thermo Scientific Lindberg Blue M 1500 (Asheville, North Carolina) horizontal open tube furnace by passing dry air at a rate of $200 \mathrm{~mL} / \mathrm{min}$. The masses of the coupons were recorded before and after the oxidation test for each alloy. After each 100 hour test, the samples were removed from the furnace fore microstructural characterization. Each test was conducted twice for each of the alloys shown with the average being reported.

Cyclic oxidation at $1150^{\circ} \mathrm{C}$ was carried out using an automated vertical Suga open tube furnace (Hokkaido, Japan). Each cycle consisted of one hour at testing temperature followed by a half hour at ambient temperature at which time 
the sample weighed. The samples were removed from furnace after five hundred cycles for microstructural characterization. Due to the number of samples that needed to be tested and the availability of the furnace, the samples analyzed at higher temperatures were tested in a different furnace. Cyclic oxidation at 1200 and $1300^{\circ} \mathrm{C}$ was manually carried out using a Thermo Scientific Lindberg Blue M 1500 (Asheville, North Carolina) horizontal open tube furnace. Each cycle consisted of two hours at the desired testing temperature followed by half an hour at ambient temperature at which time the mass measurements were recorded. The samples were removed from the furnace after one hundred hours at the testing temperature to characterize the scale microstructure.

After oxidation tests, each sample was gold sputtered and then copper plated. The copper coating helps to retain the oxide scale during the polishing process. After copper plating each sample was vertically mounted using epoxy resin. The samples were then cut so that the middle of the oxidized sample was visible at the surface. This surface was then polished on a polishing wheel down to a $0.3 \mu \mathrm{m}$ surface finish. The polished samples were then analyzed using a JEOL 5910Lv scanning electron microscope (SEM) using an accelerating voltage of 20 $\mathrm{kV}$.

\section{Results and Discussion}

Isothermal Oxidation at $1150^{\circ} \mathrm{C}$

Figures 1 and 2 show the oxide scales of the alloys after 100 hours of testing at $1150^{\circ} \mathrm{C}$. The copper plating and the sample surface are labeled in the figures with the oxide scale being the dark line between these two regions. All compositions are given in atomic percent with the hafnium amount being 0.05 at $\%$ unless otherwise noted. 

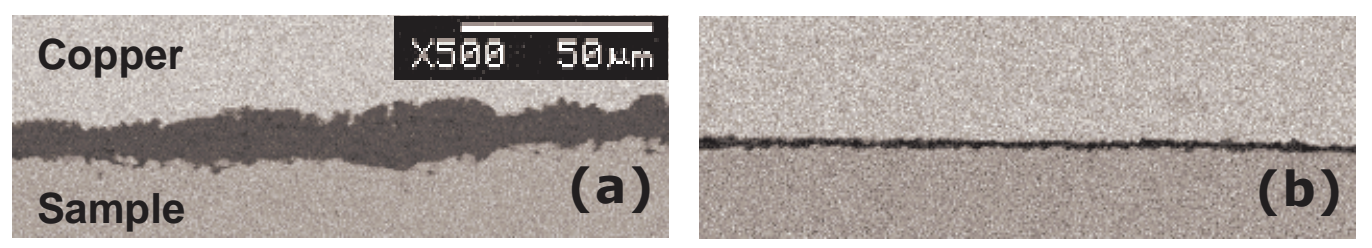

Figure 1: Microstructures of oxidized alloys after isothermal oxidation at $1150^{\circ} \mathrm{C}$ for 100 hours (a) $\beta-\mathrm{NiAl}$, (b) NiAl+Hf

PGM additions alone were found to be inadequate to sufficiently form a protective oxide scale at higher temperatures (Table 1), so hafnium was introduced into these alloy systems in the early stages of alloy development. The micrographs shown in Figure 1 indicate that the hafnium addition has a beneficial effect at $1150^{\circ} \mathrm{C}$. Compare $\beta-\mathrm{NiAl}$ (Figure 1a) to $\beta-\mathrm{NiAl}+\mathrm{Hf}$ (Figure 1b) and notice that without $\mathrm{Hf}$ addition the $\mathrm{NiAl}$ exhibits an adherent but non-uniform and relatively thick oxide scale which was measured to be about $15 \mu \mathrm{m}$ at the thickest point. The same alloy with hafnium addition exhibits a very thin, continuous and uniform oxide layer that was measured to be $2 \mu \mathrm{m}$ at the thickest point. The hafnium modified alloy appears to be more protective than the former because a thinner oxide scale contains less residual stress than a thick oxide scale $(10-13)$ and would retain the oxide scale more readily.

At $1150^{\circ} \mathrm{C}$, the PGM modification seems to have a negligible effect when compared to the hafnium effect (Figure 2). The sample shown in Figure 2a contains PGM with no hafnium and shows a scale that is more planar and slightly thinner than the NiAl shown in Figure 1a. All PGM+Hf alloys show similar scales that are continuous and have relatively uniform thicknesses of 1-2 $\mu \mathrm{m}$. At seemingly random intervals, the oxide scale protrudes into the sample and creates small pockets of thicker oxide. Yang referred to these pockets as "oxide pegs" and they are believed to anchor the oxide to the substrate creating a more 
adherent oxide scale (14). The white spots noticed at the bottom of these oxide pegs (Figure $2 \mathrm{a}$ and $2 \mathrm{~b}$ ) were found to be regions high in hafnium. It is plausible that the small additions of hafnium allow the formation of these pegs to anchor the oxide to the substrate alloy. These oxide scales are comparable to the oxide scale formed by $\mathrm{NiAl}+\mathrm{Hf}$ alloy shown in Figure $1 \mathrm{~b}$.
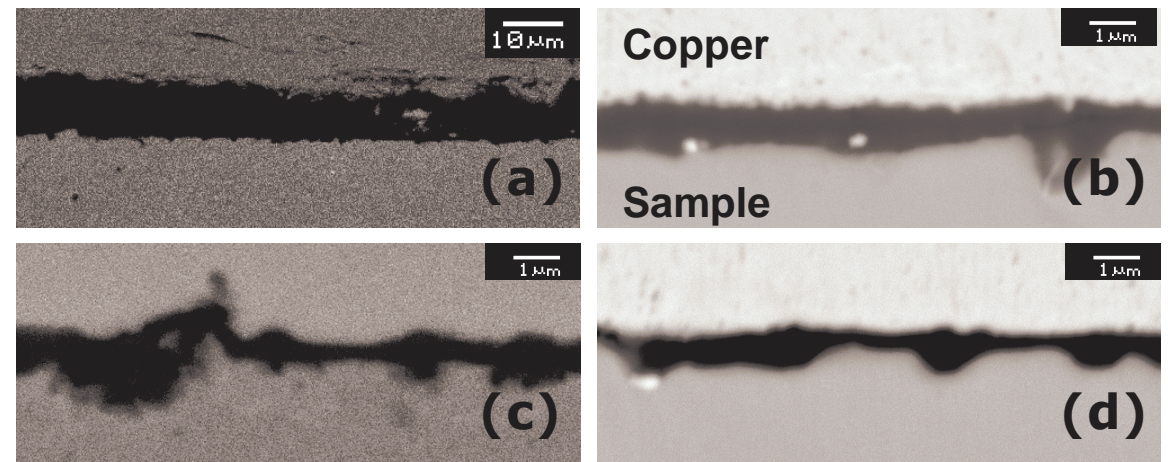

Figure 2: Microstructures of alloys after isothermal oxidation at $1150^{\circ} \mathrm{C}$ for 100 hours (a) Ni-50Al-9lr, (b) Ni-50Al-6Rh+Hf, (c) Ni-50Al-6lr+Hf, (d) Ni-50Al-6Pd+Hf

Figure 3 shows a graphical representation of the calculated parabolic rate constants. The rate constants provide a clear and concise way of representing and comparing the oxide scale growth rates $(15,16)$. Within the NiAl alloy systems, the dominating factor of $\mathrm{Al}_{2} \mathrm{O}_{3}$ scale growth is primarily oxygen diffusion through the scale to the alloy surface followed by the upward diffusion of aluminum to the oxide scale (17-20). A faster growing scale would increase in thickness rapidly until the residual stresses within the oxide layer could no longer be contained (10-13). At this point the oxide begins to form cracks to relieve the built up stresses and eventually breaks off from the metal surface.

These rate constants were calculated using data between 50 and 100 hours to ensure that the transient oxidation from $\theta-\mathrm{Al}_{2} \mathrm{O}_{3}$ to $\alpha-\mathrm{Al}_{2} \mathrm{O}_{3}$ had completed and was not contributing to irregular mass changes since $\theta-\mathrm{Al}_{2} \mathrm{O}_{3}$ grows at a different 
rate than $\alpha-\mathrm{Al}_{2} \mathrm{O}_{3}(5,6,21,22)$. All of the isothermal oxidation curves fit a parabola with $\mathrm{R}^{2} \geq 0.85$.

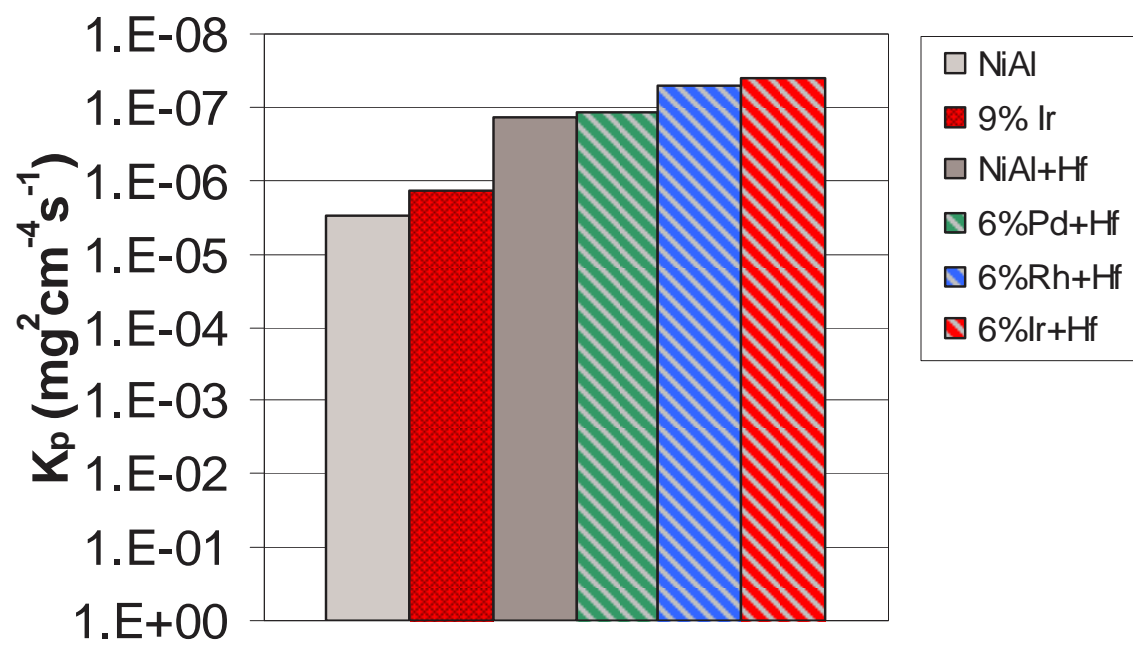

Figure 3: The parabolic rate constants of oxide growth during isothermal oxidation at $1150^{\circ} \mathrm{C}$ for 100 hours. Note the y scale is chosen such that the higher the bar, the lower the oxidation rate.

The baseline alloy $\beta$-NiAl shows the highest oxidation rate. $9 \%$ Ir substitution was used as a reference to show how PGM modification affects the oxide growth rate. The largest substitution of iridium was tested to show the highest effect. This alloy showed a slightly slower oxidation rate than the baseline $\beta$-NiAl. The hafnium modified $\mathrm{NiAl}$ alloy showed a significantly slower growing oxide than the baseline NiAl. It is understood from this data that of the two modifications, adding hafnium is more effective than substituting PGMs at forming a slower growing oxide. The alloys that produced the slowest growing oxides at $1150^{\circ} \mathrm{C}$ were the ones that contained both PGM and hafnium modifications. Combining the iridium with the hafnium modification in the same alloy produced the slowest growing oxide scale. 
Isothermal Oxidation at $1200^{\circ} \mathrm{C}$

Figure 4 shows the oxide scale morphology of the alloys after testing at $1200^{\circ} \mathrm{C}$ for 100 hours. Compared to Figures 1 and 2, these samples appear to have oxide scales that are non-uniform and thicker. At $1200^{\circ} \mathrm{C}$ the NiAl alloy produced an oxide scale that spalled off in one large piece during retrieval of the specimen from the test rig. This is evidenced in the micrograph of Figure $4 a$ by the missing oxide layer. The other PGM+Hf modified alloys are shown to have consistent oxidation resistance. The oxide scales at $1200^{\circ} \mathrm{C}$ a re about 5-6 $\mu \mathrm{m}$ as compared to $1-2 \mu \mathrm{m}$ at $1150^{\circ} \mathrm{C}$. Overall, the $\mathrm{PGM}+\mathrm{Hf}$ alloys are not sh owing signs of scale spallation.
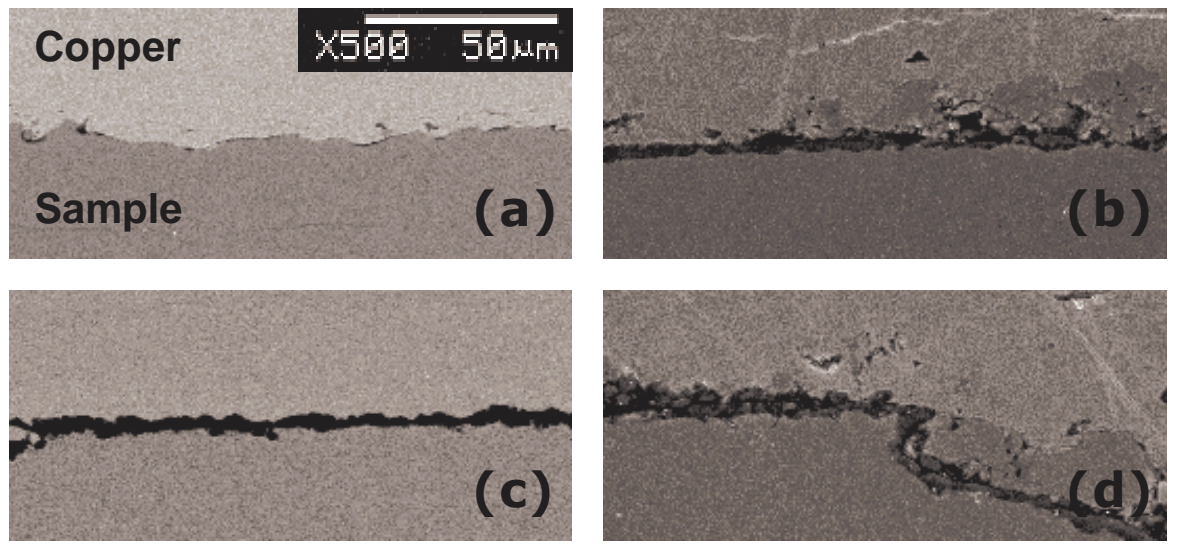

Figure 4: Microstructures of oxidized samples after isothermal oxidation at $1200{ }^{\circ} \mathrm{C}$ for 100 hours (a) $\beta-\mathrm{NiAl}$, (b) Ni-50Al-6Rh+Hf, (c) Ni-50Al-6lr $+\mathrm{Hf}$, (d) Ni$50 \mathrm{Al}-6 \mathrm{Pd}+\mathrm{Hf}$

Figure 5 shows a graphical representation of the measured parabolic rate constants of the alloys at $1200^{\circ} \mathrm{C}$. These rate cons tants were calculated using data between the testing hours of 50 and 100. All the isothermal oxidation curves at this temperature fit a parabola with $R^{2} \geq 0.93$ or higher. The graph is shown as a logarithmic scale starting at 1 and decreasing along the y-axis. Although the scale of the NiAl alloy spalled after the test (Figure 4a), no 
spallation was noticed during the test and the parabolic rate is assumed to be correct.

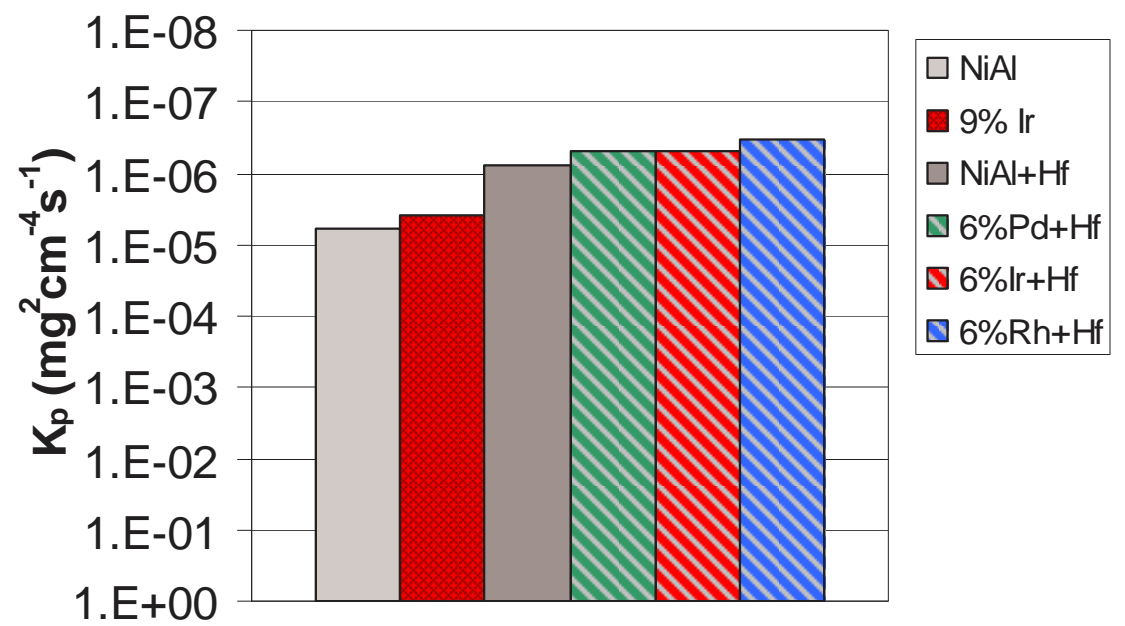

Figure 5: The parabolic rate constants of oxide growth after isothermal oxidation at $1200^{\circ} \mathrm{C}$ for 100 hours. Note the y scale is chosen such that the higher the bar, the lower the oxidation rate.

As demonstrated previously in Figure 3, the oxidation growth rates appear to be similar in trend for the $\mathrm{PGM}+\mathrm{Hf}$ modified alloys and the $\mathrm{NiAl}+\mathrm{Hf}$ alloy. Again the iridium does show a slight decrease in the oxide growth rate when compared to the baseline NiAl. The hafnium addition has a significant effect of slowing the growth rate. It should be noted that although they remain similar to each other, the oxidation rates did increase by an order of magnitude compared to the rate constants at $1150^{\circ} \mathrm{C}$ as expected.

\section{Isothermal Oxidation at $1300^{\circ} \mathrm{C}$}

Samples with varying levels of substitution for the $\mathrm{Ni}$ in $\beta$-NiAl base alloy were tested for oxidation resistance at $1300^{\circ} \mathrm{C}$. The the rmal shock at the end of the cycle could, in part, account for the spallation of the scale and therefore mass loss for some of the samples as shown in Table 1. 
Table 1: Specific mass change $\left(\mathrm{mg} / \mathrm{cm}^{2}\right)$ after isothermal oxidation at $1300^{\circ} \mathrm{C}$ for 24 hours

\begin{tabular}{|l|l|l|l|}
\hline Alloy & Ni-50Al-3X & Ni-50Al-6X & Ni-50Al-9X \\
\hline $\mathbf{X = P d}$ & -1.58 & -1.54 & -1.55 \\
\hline $\mathbf{X}=\mathbf{R h}$ & -1.73 & -1.08 & 1.42 \\
\hline $\mathbf{X}=\mathbf{I r}$ & -0.47 & 0.89 & 0.86 \\
\hline
\end{tabular}

For reference, the baseline $\beta$-NiAl had a mass change of $-1.75 \mathrm{mg} / \mathrm{cm}^{2}$

As seen in Table 1, the palladium substitutions have negligible effect on the oxidation resistance of NiAl. Rh and Ir substitutions help improve the oxidation resistance, with higher substitutions leading to better oxidation resistance.

Photographs of the specimens after the 24 hour oxidation test are displayed in Figure 6. It can be seen in these pictures that most of the oxide scale had fallen off of the surfaces of the $\beta-\mathrm{NiAl}$ and Pd substituted alloys (Figure $6 \mathrm{a}$ and $6 \mathrm{~b}$ ), leaving behind bulk alloy with small flecks of oxide scale. On the surface of the Ir and Rh containing samples (Figure $6 \mathrm{c}$ and $6 \mathrm{~d}$ ) no bare metal was visible. Each sample has a $10 \mathrm{~mm}$ diameter. 

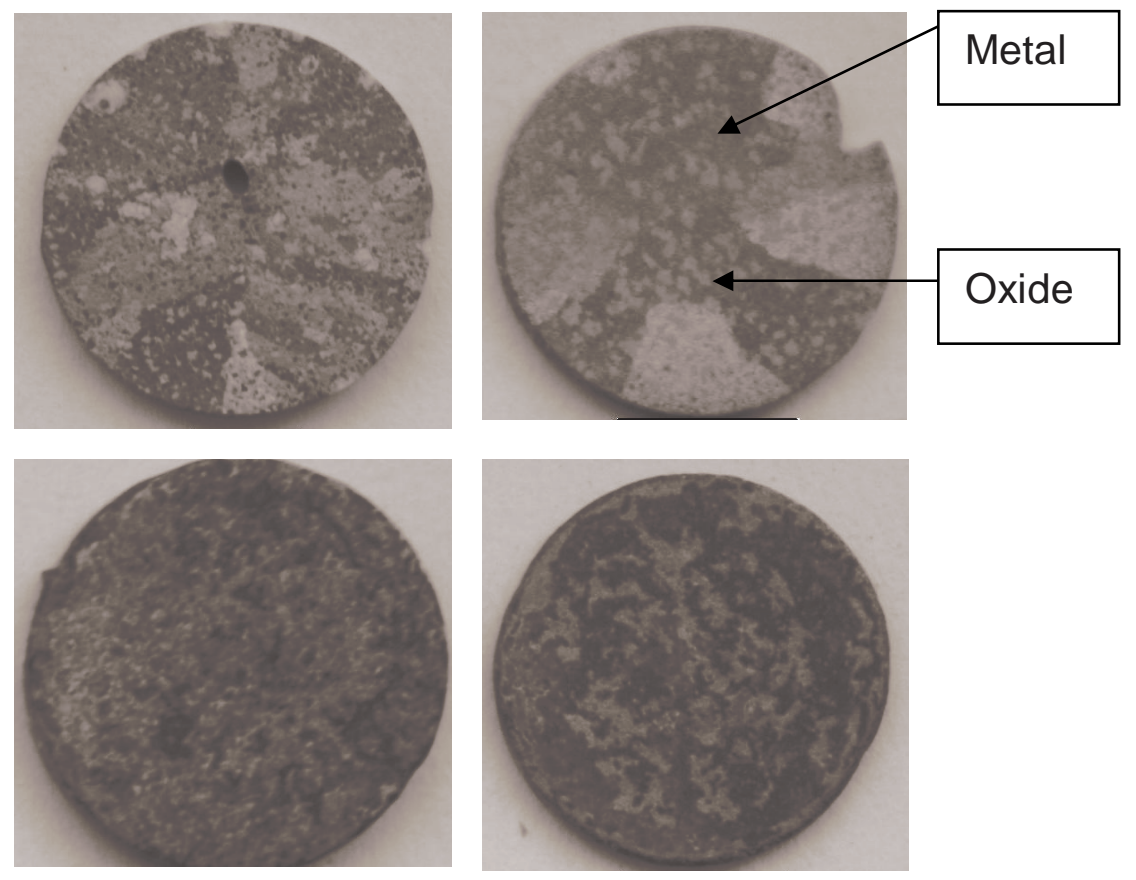

Figure 6: Photographs of the surface of the samples after isothermal oxidation at $1300^{\circ} \mathrm{C}$ for 24 hours. (a) Ni-50Al, (b) Ni-50Al-9Pd, (c) Ni-50Al-9lr, (d) Ni-50Al9Rh

Figure 7 shows the oxide morphology of the oxidized samples containing 6 at\% of each PGM after 24 hours of testing at $1300^{\circ} \mathrm{C}$. The dark band between the copper plating and the sample is the oxide scale. Two of the images (Figure 7a and $7 b$ ) do not show this oxide scale, presumably because the oxide had spalled off, leaving behind new sample surface without a protective oxide. 

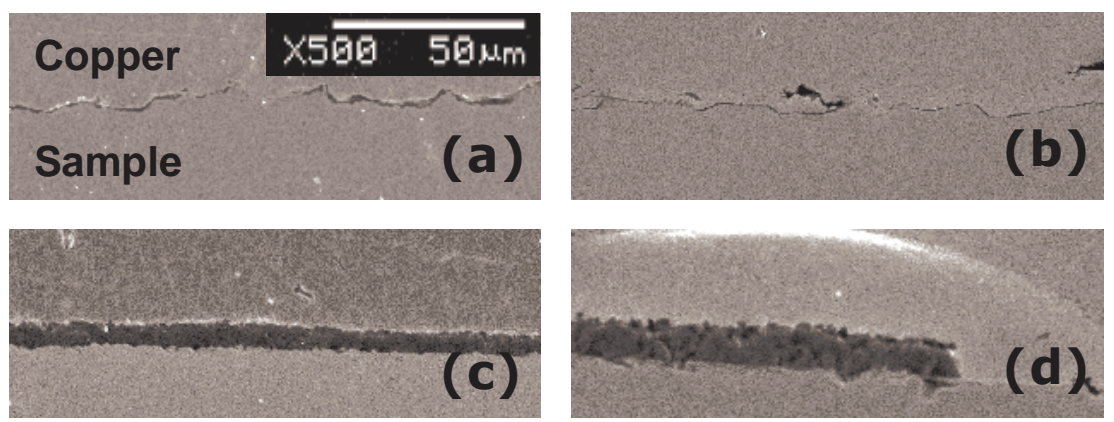

Figure 7: Microstructures of oxidized alloys after isothermal oxidation at $1300^{\circ} \mathrm{C}$ for 24 hours (a) $\beta-\mathrm{NiAl}$, (b) Ni-50Al-6Pd, (c) Ni-50Al-6lr, (d) Ni-50Al-6Rh

The oxidized microstructure of $\mathrm{NiAl}$ (Figure 7a) is almost identical to the oxidized microstructure of the Pd modified alloy (Figure 7b). As shown in the specific mass changes in Table 1, both of these alloys lost mass. These micrographs give evidence that the mass loss was due to the spallation of the oxide layer formed during oxidation testing. The oxide scale in the Rh modified alloy, while present, is not continuous (Figure $7 \mathrm{~d}$ ). The thickness of the remaining oxide was found to be about $10 \mu \mathrm{m}$. The Ir modified alloy shows a continuous oxide scale (Figure 7c), with a thickness of approximately $8 \mu \mathrm{m}$.

Small amounts of hafnium additions to similar alloys have produced a more adherent and protective oxide scale (23-27). Hence further tests were carried out by adding $\mathrm{Hf}$ in minor amounts to the Ni-50Al-6Rh alloy. Addition of as low as $0.05 \mathrm{at} \% \mathrm{Hf}$ resulted in a mass gain of $0.46 \mathrm{mg} / \mathrm{cm}^{2}$ while the same alloy without the $\mathrm{Hf}$ addition had a mass loss of $1.08 \mathrm{mg} / \mathrm{cm}^{2}$ (See Table 1). Higher $\mathrm{Hf}$ additions showed similar mass gains, i.e. $0.1,0.25,0.5 \mathrm{at} \% \mathrm{Hf}$ addition resulted in $0.47,0.48,0.54 \mathrm{mg} / \mathrm{cm}^{2}$ mass gain respectively.

Hafnium addition was shown to result in forming an adherent and continuous oxide scale as shown in Figure 8 compared to discontinuous scale observed the 
same alloy without $\mathrm{Hf}$ addition (see Figure 7d). Therefore, the $\mathrm{Hf}$ additions were limited to 0.05 at\% $\mathrm{Hf}$ for the alloys studied going forward.

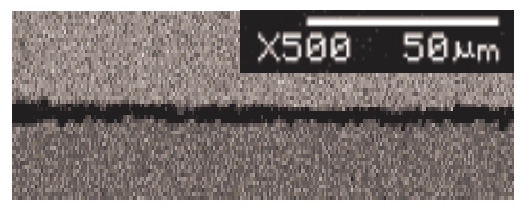

Figure 8: Microstructure of oxidized $\mathrm{Ni}-50 \mathrm{Al}-6 \mathrm{Rh}+0.05 \mathrm{Hf}$ alloy after isothermal oxidation at $1300{ }^{\circ} \mathrm{C}$ for 24 hours

\section{Cyclic Oxidation at $1150^{\circ} \mathrm{C}$}

Figure 9 shows the specific mass change as a function of oxidation cycles for 0 , 3, 6, 9 at\% PGM substitutions (Figure 9a, 9b, 9c respectively) as well as alloy with 9 at\% PGM and 0.05 at\% $\mathrm{Hf}$ (Figure 9d). Specific mass change for $\beta-\mathrm{NiAl}$ is also shown as a baseline for comparison. Mass loss on any sample with oxidation implies spallation of oxide scale. This continual oxide spallation process would eventually deteriorate the sample beyond use after many cycles. Spallation in these cyclic experiments is assumed to result from the stresses caused by the thermal expansion mismatch between the alloy and oxide scale (27-29). 

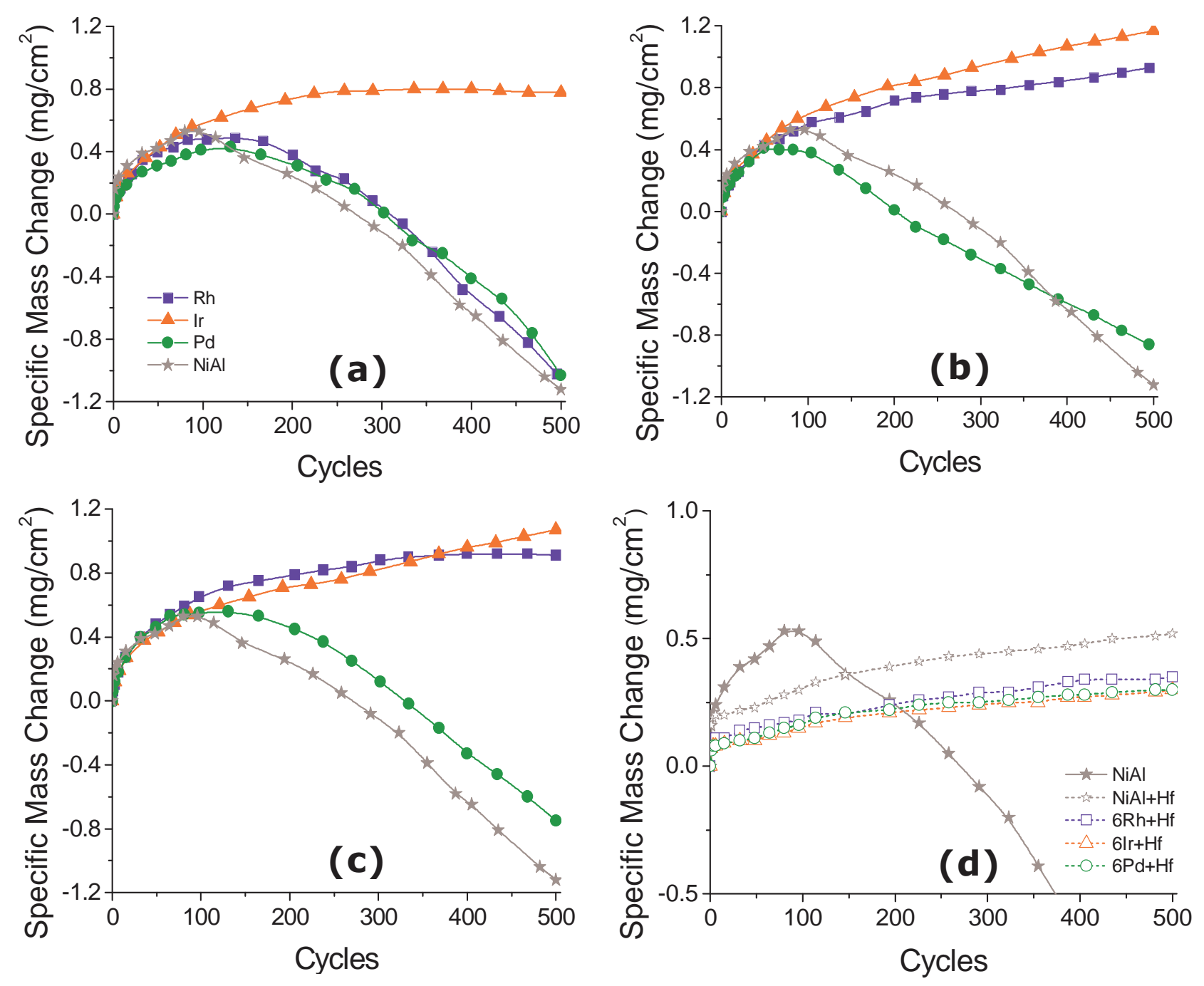

Figure 9: Mass change per surface area plots for alloys during cyclic oxidation at $1150{ }^{\circ} \mathrm{C}$ for 500 cycles (a) 3\% PGM, (b) 6\% PGM, (c) $9 \%$ PGM, (d) 6\% PGM+Hf

The graph in Figure 9a shows that with the exception of Ir, the PGM substitutions at $3 \%$ have no beneficial effect to the cyclic oxidation resistance. At $6 \%$ substitution (Figure $9 b$ ) the iridium containing alloy shows no oxidation spallation over the entire 500 cycle test at $1150^{\circ} \mathrm{C}$. The rhodium containing alloy also showed improved oxidation resistance, with possibly slight spallation as indicated by small scatter in mass change. The palladium modified alloy performs very 
similarly to the baseline NiAl alloy and shows mass loss after 100 cycles. Alloys containing $9 \%$ of the PGM (Figure 9c) show very similar results to that of the $6 \%$ modifications. Here the rhodium containing alloy again shows a slight decrease in mass change at 500 cycles. Finally, alloys containing 6\% PGM substitution along with $\mathrm{Hf}$ modifications (Figure 9d) appear to have the best cyclic oxidation resistance. The oxide grows very slowly as seen by the minimal mass gain over long periods of time and the oxide adheres well to the surface due to the oxide pegs seen before in Figure 2. Here the PGM+Hf alloys show very similar oxidation resistance. Some of these alloys can be compared to previous work done by Leyens et al. in which low substitution amounts of iridium outperformed low substitution amounts of palladium during cyclic oxidation testing at $1150^{\circ} \mathrm{C}$ (8). In this work, he also noticed that none of the precious metal modifications improved oxidation resistance as effectively as $\mathrm{Hf}$ doping.

Figure 10 shows the oxide scales of the cyclic tested samples at $1150^{\circ} \mathrm{C}$ for 500 cycles. Alloy compositions are designated on each micrograph. The black band represents the oxide scale with copper plating above. No hafnium is shown in these images as all hafnium containing alloys show a very continuous, thin (3$4 \mu \mathrm{m})$, and adherent oxide scale. 

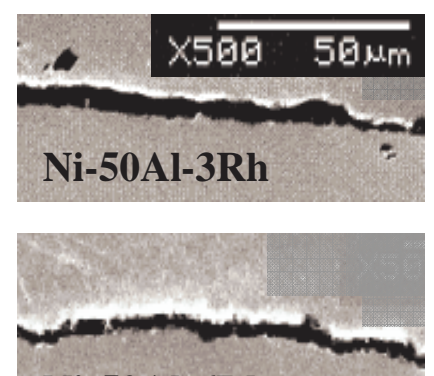

Ni-50Al-6Rh

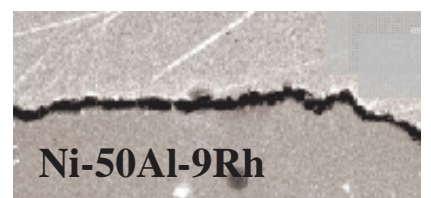

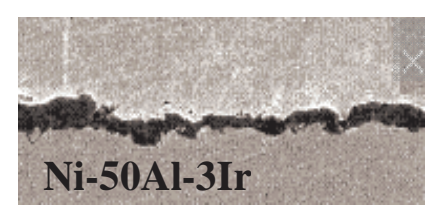

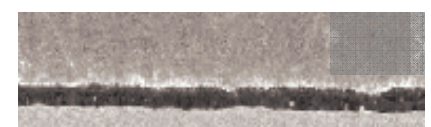

Ni-50Al-6Ir

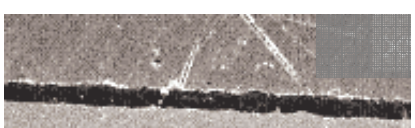

Ni-50Al-9Ir
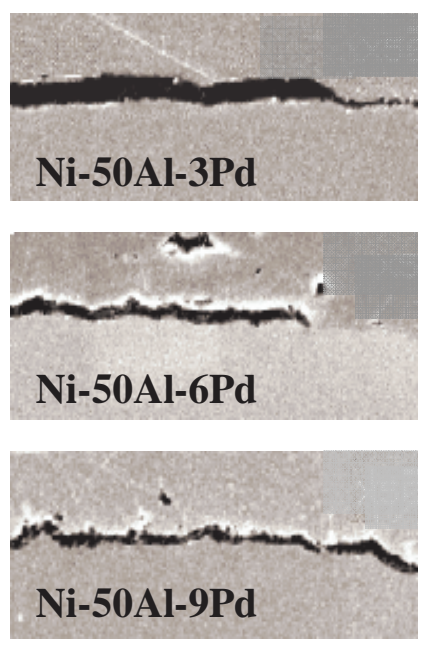

Figure 10: Microstructures of oxidized alloys after cyclic oxidation at $1150^{\circ} \mathrm{C}$ for 500 cycles. Samples are labeled within the figure with the copper plating being on top.

Comparison of the micrographs for several types of PGM substituted alloys at three substitution levels indicates that all 3\% PGM substituted alloys showed a non-uniform and undulating oxidation layer indicative of scale spallation. Of the 6\% PGM substituted alloys; iridium exhibited a uniform, continuous scale with a thickness of $8 \mu \mathrm{m}$. Increasing the PGM content from 6 to $9 \%$ has resulted in slight improvement in oxidation resistance. Among the three PGMs, palladium was the least effective showing mass loss and spallation at all substitution levels as indicated in Figure 9.

\section{Cyclic Oxidation at $1200^{\circ} \mathrm{C}$}

Figure 11 shows the specific mass change for alloys with 3, 6 and 9\% PGM (Figure $11 \mathrm{a}, \mathrm{b}$, and c respectively) along with 6\% PGM and $0.05 \% \mathrm{Hf}$ addition at $1200^{\circ}$. 

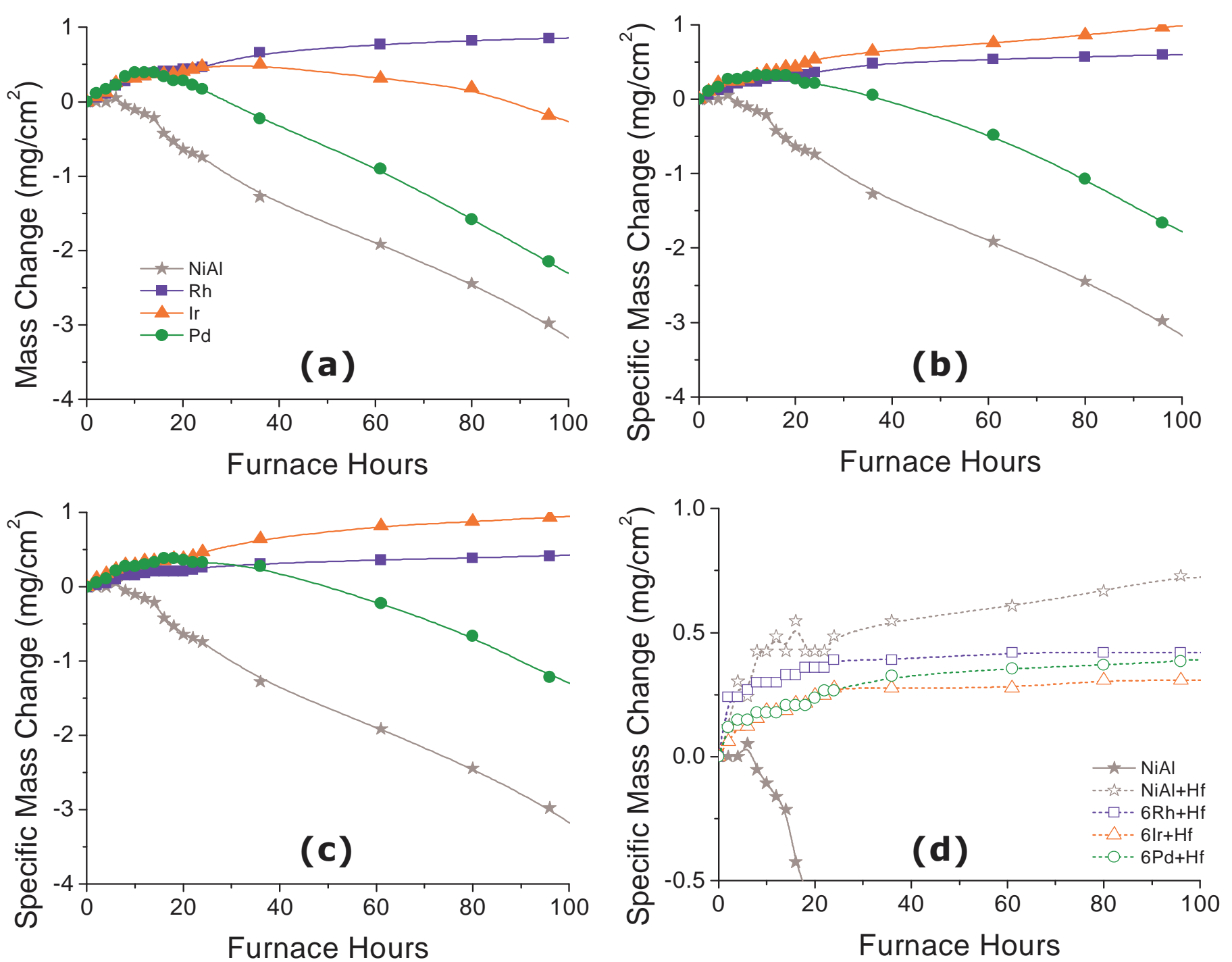

Figure 11: Mass change per surface area plots for alloys during cyclic oxidation at $1200^{\circ} \mathrm{C}$ for 100 hours (a) 3\% PGM, (b) 6\% PGM, (c) 9\% PGM, (d) 6\% $\mathrm{PGM}+\mathrm{Hf}$

The trends observed for specific mass change at $1200^{\circ} \mathrm{C}$ is similar to that at $1150^{\circ}$ C. The two PGMs that showed to produce a prot ective oxide scale at this temperature are iridium and rhodium containing alloys. Clearly, addition of 
hafnium prevents the spallation for all the samples including the benchmark $\beta$ NiAl (Figure 11d).

Figure 12 shows cross-sections of the oxidation scales after cyclic testing at $1200^{\circ}$ C. As demonstrated before in Figure 8 , the all oys that continue to form a protective oxide scale are the higher substitution amounts of both iridium and rhodium. Palladium formed an oxide scale that spalled off within all substitution amounts tested. The hafnium modified alloys all showed a thin, adherent, and continuous oxide scale.
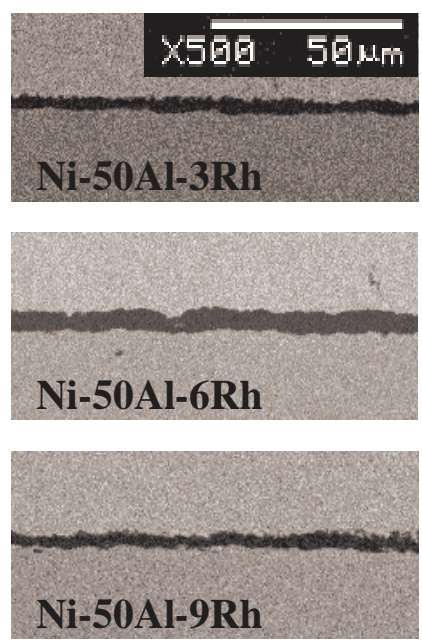
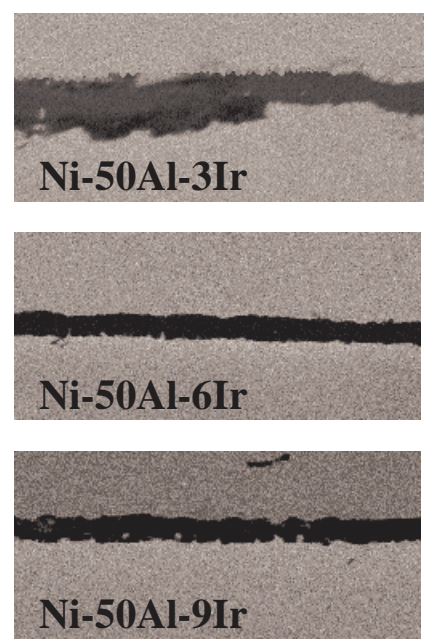
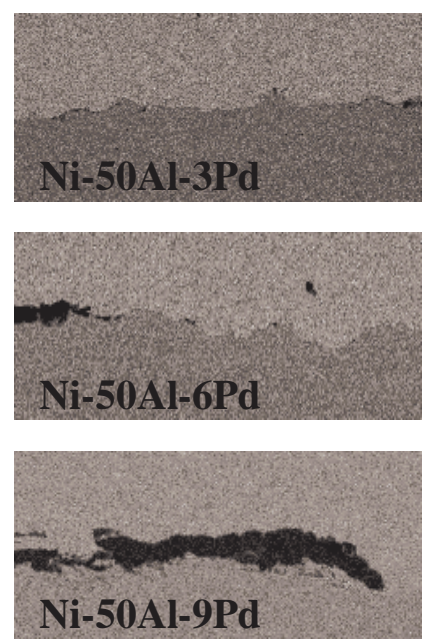

Figure 12: Microstructures after cyclic oxidation at $1200^{\circ} \mathrm{C}$ for 100 hours at testing temperature. Samples are labeled within the figure with the copper plating being on top.

The $3 \%$ iridium containing alloy (Figure 12) shows a thicker oxide scale than the $3 \%$ rhodium containing alloy yet the specific mass change plot shows the rhodium alloy to have gained more mass. This can be explained due to the missing oxide at other locations on the sample surface of the $3 \%$ Ir sample. The image displayed in Figure 12 is of a region that retained the oxide. The rhodium containing alloys in Figure 12 seem to show improved scale morphology when 
compared to those in Figure 10. This apparent discrepancy can be explained primarily due to the number of cycles to which the alloys were exposed. Previously the alloys were tested for 500 cycles at $1150^{\circ} \mathrm{C}$, whereas in this test the cycles were reduced to about 20 at $1200^{\circ} \mathrm{C}$. The change in temperature and number of cycles accounts for the more planar looking oxide on the $1200{ }^{\circ} \mathrm{C}$ rhodium containing alloys in Figure 12.

\section{Cyclic Oxidation at $1300^{\circ} \mathrm{C}$}

Figure 13 shows the specific mass change curves for varying amounts of PGM substituted alloys. Figure 13 shows results from the most aggressive test conducted on these alloys. All of the 3\% PGM alloys showed signs of spallation within the first few hours during this test. The 6\% PGM substituted alloys all showed the effects of scale spallation within the first ten hours. The 9\% PGM substituted alloys performed slightly better and did not show signs of spallation until after 20 hours. In the 6 and 9\% PGM alloys it is noticed that the iridium containing alloy is the last to spall off its oxide scale. Both the palladium containing alloy along with the baseline $\beta-\mathrm{NiAl}$ showed poor oxidation resistance compared to the Ir and Rh substituted alloys. Again it can be seen that the hafnium along with the PGM substitutions give rise to the best oxidation resistant alloys. Of the PGM+Hf modified alloys, the PGM that gives rise to the most desired oxidation resistance is iridium. 

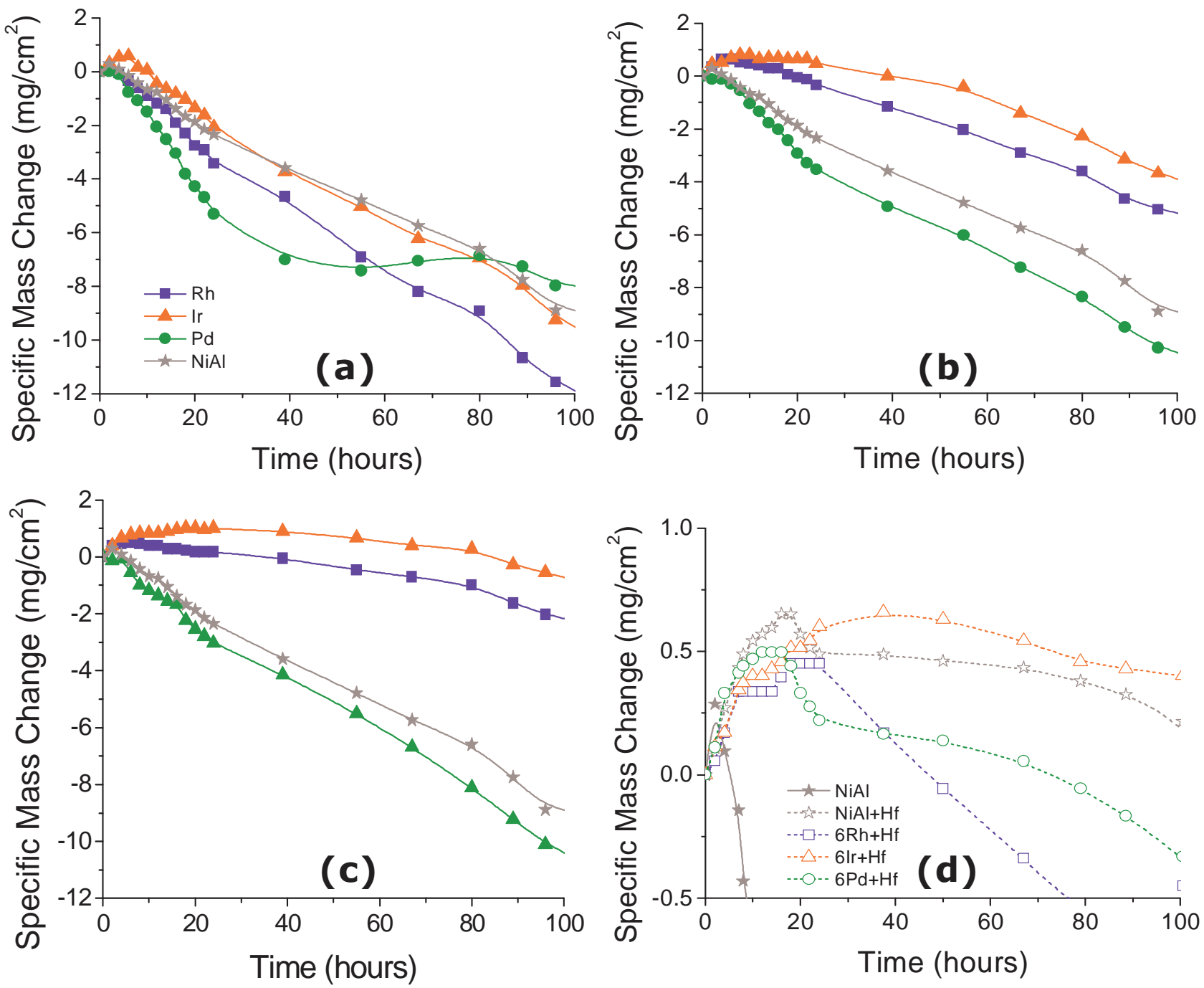

Figure 13: Mass change per surface area plots for alloys during cyclic oxidation at $1300{ }^{\circ} \mathrm{C}$ for 100 hours (a) $3 \%$ PGM, (b) 6\% PGM, (c) 9\% PGM, (d) 6\% $\mathrm{PGM}+\mathrm{Hf}$

Cyclic oxidation results show a continuing trend that both iridium and to a lesser degree rhodium substitution to $\beta$-NiAl have a beneficial effect on the oxidation resistance at high temperatures. Palladium additions continued to show little or no effect on oxidation when compared to the $\beta$-NiAl alloy. It is unknown at this time why palladium additions would have little effect on the scale adherence 
during cyclic oxidation while its neighbor on the periodic table, $\mathrm{Rh}$, would have a significant effect. Grain size effects on oxidation of similar alloys have been noted previously (14). Other changes such as the thermal expansion coefficient could be playing a role here as well.

\section{Conclusions}

Of the three types of PGM substitutions to $\beta-\mathrm{NiAl}$, iridium and rhodium showed significant improvement in oxidation resistance at all temperatures tested. Iridium slowed the growth of the oxide scale in the isothermal tests. This may also have contributed to the formation of a more adherent and protective oxide scale during the cyclic oxidation. The iridium substituted alloys were always the last of the PGMs tested to show signs of scale spallation. In general, the oxidation resistance increased as the amount of PGM increased.

It was shown that hafnium improves the oxidation resistance of both isothermal and cyclic oxidation environments in the temperature range tested. Analysis of the isothermal oxidation results gives evidence that hafnium addition as low as 0.05 at\% slows the oxidation rate giving rise to a thinner oxide scale. Analysis of the cyclic oxidation results gives evidence that hafnium additions forms an oxide that adheres better to the metal.

Combining the iridium substitutions along with the hafnium addition gives rise to an alloy with a slow growing, continuous, planar, and adherent oxide layer and hence superior oxidation resistance for both isothermal and cyclic environments.

\section{Acknowledgement}

This work was supported by the DOE-FE (AMR program) through Ames Laboratory contract no. DE-AC02-07CH11358 through lowa State University. 


\section{References}

1) M. Donachie, S. Donachie, Superalloys: A Technical Guide ( $2^{\text {nd }}$ Ed. $)$, pp. 8, 309-314, 2002

2) R. Reed, The Superalloys: Fundamentals and Applications, pp. 9-10, 2006

3) P.K. Ray, et al., Journal of Metals, Vol. 62, pp. 25-29, 2010

4) P.K. Ray, et al., Journal of Alloys and Compounds, Vol. 489, pp. 357-361.

5) J. Balmain, et al., Materials Science and Engineering, Vol. A224, pp. 87-100, 1997

6) Y. Cadoret, et al., Oxidation of Metals, Vol. 64, 2005

7) M.J. Li, et al., Surface and Coatings Technology, Vol. 167, pp. 106-111, 2003

8) C. Leyens, et al., Surface and Coatings Technology, Vol. 133-134, pp. 15-22, 2000

9) G. Fisher, et al., Surface and Coatings Technology, Vol. 113, pp. 259-267, 1999

10) W.J. Quadakkers, et al., Surface Coatings Technology, 1999

11) H.M. Tawancy, et al., Scripta Metallurgica et Materialia, Vol. 33, pp. 14311438, 1995

12) W.J. Brindley, R. Miller, Surface and Coatings Technology, Vol. 43, pp. 446457, 1990

13) E. Basuki, et al., Materials Science and Engineering, Vol. A224, pp. 27-32, 1997

14) S. Yang, et al., Intermetallics, Vol. 9, pp. 741-744, 2001

15) S. Mrowec, et al., Oxidation of Metals, Vol. 8, 1974

16) D. Monceau, B. Pieraggi, Oxidation of Metals, Vol. 50, pp. 477, 1998

17) B.A. Pint, et al., Solid State lonics, Vol. 78, pp. 99-107, 1995

18) B.A. Pint, et al., Oxidation of Metals, Vol. 39, pp. 167, 1993

19) J. Jedlinski, S. Mrowec, Materials Science Engineering, Vol. 87, pp. 281, 1987

20) F.H. Stott, Materials Science Forum, Vol. 251-254, pp. 19-32, 1997 
21) T.F. An, et al., Oxidation of Metals, Vol. 54, pp. 301-316, 2000

22) S. Xiaofeng, et al., International Journal of Materials and Product Technology,

23) B.A. Pint, Surface and Coatings Technology, Vol. 188-189, pp. 71-78, 2004

24) B.A. Pint, et al., Materials Science and Engineering, Vol. A245, pp. 201-211, 1998

25) B.A. Pint, Oxidation of Metals, Vol. 49, pp. 531-560, 1998

26) B.A. Pint, et al., Materials at High Temperature, Vol. 17, pp. 165-171, 2000

27) J.A. Haynes, et al., Materials at High Temperature, Vol. 21, pp. 87-94, 2004

28) Y.S. Touloukian, et al., Thermophysical Properties of Matter, Vol. 13, pp. 176, 1977

29) J.R. Nicholls, Materials at High Temperature, Vol. 14, pp. 289-306, 1997 


\title{
CHAPTER 4: \\ ROLE OF GRAIN SIZE ON THE OXIDATION RESISTANCE OF $\beta-\mathrm{NiAl}$
}

\author{
T. Brammer, M. Akinc and M.J. Kramer \\ Ames Laboratory and Department of Materials Science and Engineering \\ lowa State University, Ames, IA 50011
}

(To be submitted to Intermetallics)

\begin{abstract}
It has been shown in previous work that hafnium and certain platinum group metals (PGMs) have the ability to improve the oxidation resistance of NiAl alloys. This study focuses on the role that each of these modifications play in grain size of the alloys and how grain size can affect the oxidation performance of the alloys. It was seen that iridium and rhodium additions constrain the grain size during casting by forming PGM rich dendrites. The size of the dendrites then limits the average grain size of the alloy. During annealing at $1300{ }^{\circ} \mathrm{C}$, the dendrites diffuse during the first few hours and the grains start to grow at a similar rate compared to an unmodified NiAl alloy. It is therefore understood that PGMs play only a slight role in hindering grain growth. However, the grain growth of alloys containing 0.05 at\% hafnium is severely diminished. It is believed to be due to hafnium acting as pinning agents at the grain boundaries although this could not be verified due to the small quantity of $\mathrm{Hf}$.
\end{abstract}




\section{Introduction}

Nickel aluminide, $\beta-\mathrm{NiAl}$ is of great interest for high temperature applications due to its combination of low density $\left(5.86 \mathrm{~g} / \mathrm{cm}^{3}\right)$, high melting point $\left(1638^{\circ} \mathrm{C}\right)$, high modulus (240 GPa), high thermal conductivity $(76 \mathrm{~W} / \mathrm{mK})$, and in particular, its excellent oxidation resistance $(1,2,3)$. $\beta$-NiAl forms a protective $\mathrm{Al}_{2} \mathrm{O}_{3}$ scale upon exposure to oxidizing atmosphere at high temperature. However, the $\mathrm{Al}_{2} \mathrm{O}_{3}$ scale formed on cast $\beta$-NiAl alloy can suffer from thermal spallation due to poor adhesion between the scale and the substrate (4). Previous studies by Yang et al. concerning isothermal oxidation at $1000^{\circ} \mathrm{C}$ of ca st NiAl alloys and a sputtered $\mathrm{NiAl}$ coating showed that the sample with the smaller grain size restricted void formation at the scale/substrate interface which was more adherent $(5,6)$. The $\mathrm{NiAl}$ sample with the smaller grain size accelerated the phase transformation from metastable $\theta-\mathrm{Al}_{2} \mathrm{O}_{3}$ scale, which has a high growth rate, to the more stable $\alpha-\mathrm{Al}_{2} \mathrm{O}_{3}$. This accelerated phase transformation is believed to be due to large number of nucleation sites brought about by the large number of grain boundaries (7).

Previous work done on the oxidation resistance of NiAl alloys showed that some PGM substitutions along with minute additions of hafnium improved the oxidation resistance at high temperatures (8). These modifications were shown to decrease the growth rate of the oxide scale during isothermal oxidation testing at 1150 and $1200^{\circ} \mathrm{C}$. The modifications also formed an oxide layer that showed improved adhesion of the scale to the substrate in the temperature range tested up to $1300^{\circ} \mathrm{C}$. The oxides that formed were thinner, more planar, and more continuous along the alloy surface. It was desired to know how these modifications were able to improve the oxidation resistance. Grain size analysis of the alloys was completed to determine if differences in grain size could account for the improved oxidation resistance. 
In this article, we report the role that synthesis technique and chemical modification of $\beta-\mathrm{NiAl}$ (namely PGM substitutions and hafnium additions) play on the grain size of $\beta$-NiAl alloys. Furthermore, we studied the possible correlation between the grain size of the alloys and the oxidation resistance observed. It is primarily desired to understand if grain size plays a role in the oxidation resistance of these alloys. If it does, can the improvement in the oxidation resistance be accounted for solely due to this effect?

\section{Experimental Procedure}

\section{Materials}

In order to isolate the effect of chemical modification from the role of grain size, two samples having the same chemical composition but different grain sizes were prepared. For melt-spun samples with a fine grain size, a NiAl button was produced by arc-melting nickel and aluminum chunks in an argon atmosphere on a copper hearth. The alloy was placed into a graphite crucible which is transferred to a melt-spinner with a Pillar induction heating coil and the entire system was heated up to $1720^{\circ} \mathrm{C}$ in $\mathrm{He}$ atmosphere at $16 \mathrm{kPa}$. The molten $\mathrm{NiAl}$ was injected onto the edge of a chilled copper disk with a wheel speed of $20 \mathrm{~m} / \mathrm{s}$. The NiAl ribbon was then collected and annealed in an inert atmosphere at $1300{ }^{\circ} \mathrm{C}$ for 6 hours. Strips of the ribbon were then used for oxidation testing.

The cast alloys were produced from Al and Ni pieces cut from bulk metal sheets obtained from the Materials Preparation Center at Ames Laboratory, having a purity of $99.7 \%$ or more. Pure Ni and Al were arc-melted together in the desired ratio on a chilled copper hearth in an argon atmosphere using a non-consumable tungsten electrode to form $\beta$-NiAl alloy. The alloying additions were then melted along with the $\beta$-NiAl synthesized according to the aforementioned steps. The nominal compositions were prepared according to $\mathrm{Ni}_{50-x} \mathrm{Al}_{50} \mathrm{PGM}_{\mathrm{x}}(\mathrm{x}=0,3,6$, and 9 at\%) with the PGMs being either Ir, Rh, or Pd. The alloys containing hafnium 
were produced using pieces of $\mathrm{Hf}$ modified $\mathrm{Ni}$ sheet metal instead of pure $\mathrm{Ni}$. After initial arc-melting, the samples were turned over and re-melted a minimum of three times in an argon atmosphere to achieve better homogenization before drop-casting. After re-melting the samples were drop-cast into $10 \mathrm{~mm}$-diameter cylindrical rods. They were then annealed in an inert atmosphere at $1300{ }^{\circ} \mathrm{C}$ for varying time intervals ( $t=0,6,40,70$, and 106 hours).

\section{Characterization}

The cast and melt-spun alloys were annealed for 6 hours at $1300{ }^{\circ} \mathrm{C}$ before oxidation runs. Isothermal oxidation at 1150 and $1200^{\circ} \mathrm{C}$ was carried out using a high temperature oxidation testing rig fitted with a Mellen SC13R 1.25 inch vertical tube furnace (Concord, New Hampshire) and a Cahn 2000 recording electrobalance (Madison, Wisconsin) having an accuracy of $1 \mu \mathrm{g}$. The sample was suspended from the balance on a sapphire wire hook. Dry air was passed through the system at a rate of $60 \mathrm{~mL} / \mathrm{min}$. An lonmaster fan was used to remove the static electricity in the system to ensure a higher signal to noise ratio in the measurements. The furnace was turned on and set to the desired dwelling temperature using a heating rate of $15^{\circ} \mathrm{C} / \mathrm{min}$ and th en held at the temperature for 100 hours.

In this study an AmRay 1845FE scanning electron microscope (SEM) utilizing an EDAX-TSL Delphi 2.5 Geneses model EBSD-EDX was used for orientation imaging microscopy (OIM). Epoxy mounted samples were polished according to standard metallurgical methods followed by electro-polishing for 8 seconds in a solution of 1 part $70 \%$ nitric acid 2 parts methanol at room temperature at 30 volts to remove smearing effects of mechanical polishing on the sample surface, as well as etch the alloy to bring out the grain boundary relief. The specimen was then lightly polished with colloidal silica to remove any adherent reaction products. The specimens were analyzed at a $70 \cong$ from horizontal geometry. The 
resulting reflected Kikuchi patterns were analyzed using TSL version 5.02 software (TexSEM Laboratories, Inc. Draper, UT). A hexagonal pixel step pattern was used with step size small enough to assure at least 10 pixels per grain at a rate of 4 patterns per second. The resulting solutions and Hough filter solutions were recorded at each pixel for later evaluation. Average grain size was measured using the TSL software by estimating an ellipse to best fit each grain.

\section{Results and Discussion}

Before oxidation testing, the average grain size along with standard deviation was determined for both the NiAl alloys. The results are given below in Table 1 .

Table 1: Average grain size of $\mathrm{NiAl}$

\begin{tabular}{|l|c|c|}
\hline Synthesis & Grain Size $(\boldsymbol{\mu m})$ & St. Dev. \\
\hline Cast & 635 & 54 \\
\hline Melt-spun & 126 & 9 \\
\hline
\end{tabular}

Table 1 shows a significant difference in grain size of these samples having been annealed at $1300^{\circ} \mathrm{C}$ for 6 hours. To ensure that the melt-spun ribbons were single phase and did not form any undesired phases due to the rapid cooling, $x$ ray diffraction patterns were obtained for melt-spun and cast alloys after the 6 hours of annealing. XRD patterns are shown in Figure 1. The pattern from the melt-spun alloy was averaged between the free side and the wheel side of the ribbon. Both samples exhibit single phase $\beta$-NiAl with no unidentified peaks. 


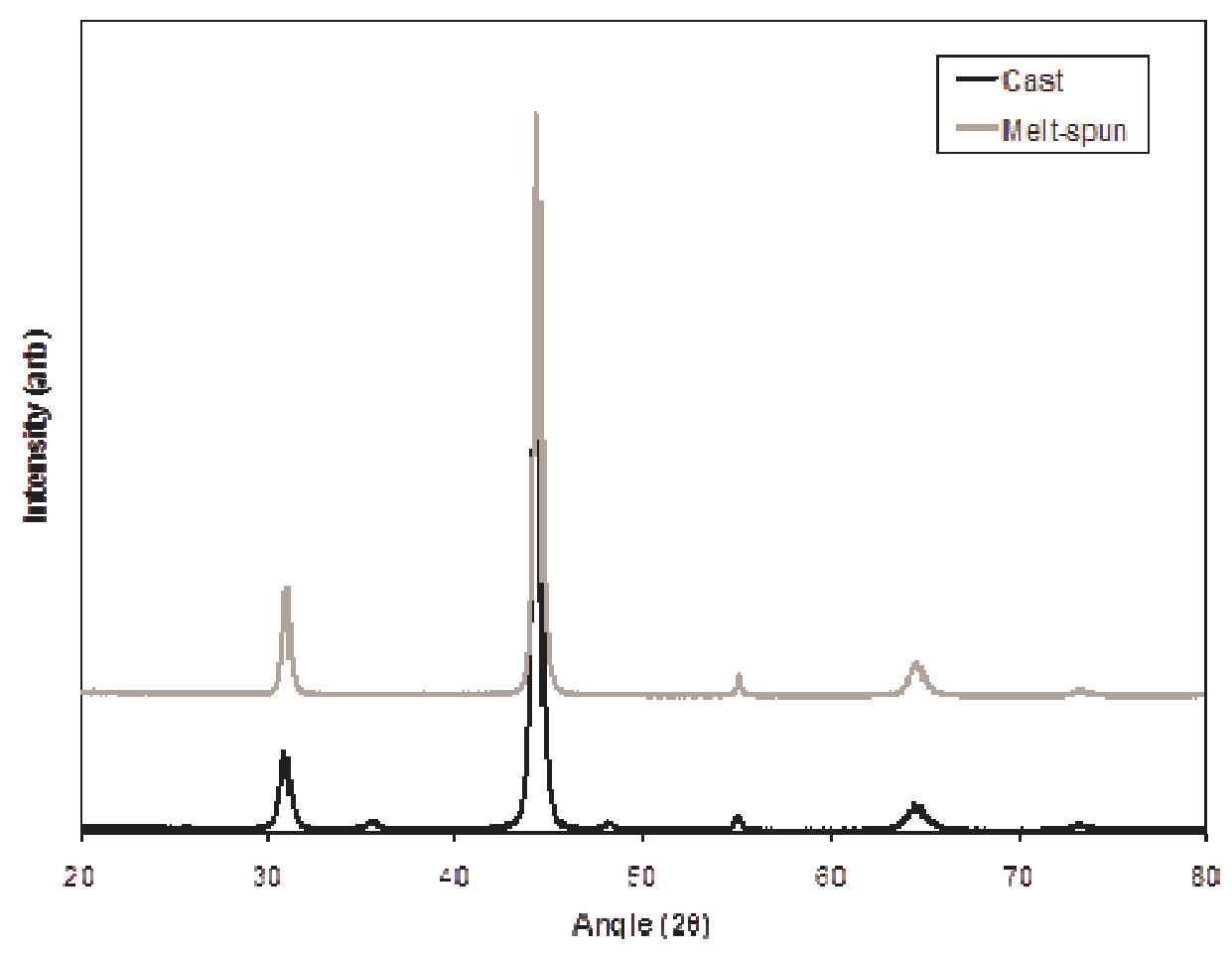

Figure 1: X-ray analysis of cast and melt-spun NiAl

Parabolic growth rate constants of cast and melt-spun $\mathrm{NiAl}$ at $1150^{\circ} \mathrm{C}$ and $1200^{\circ} \mathrm{C}$ are calculated and presented in Figure 2. The mass change data between 50 and 100 hours was used to ensure the transition from $\theta-\mathrm{Al}_{2} \mathrm{O}_{3}$ to $\alpha$ $\mathrm{Al}_{2} \mathrm{O}_{3}$ had completed and was not contributing to irregular mass changes since $\theta$ $\mathrm{Al}_{2} \mathrm{O}_{3}$ grows faster than $\alpha-\mathrm{Al}_{2} \mathrm{O}_{3}$ (9-12). All of the oxidation curves fit a parabola with a line fitting $\mathrm{R} 2$ value of 0.97 or better. The graphs are shown as a logarithmic scale starting at 1 and decreasing along the $y$-axis. Therefore, the taller bars in the chart have a slower growing oxide. It is noticed that the smaller grained specimen formed a slower growing oxide when compared to the larger grained specimen. 


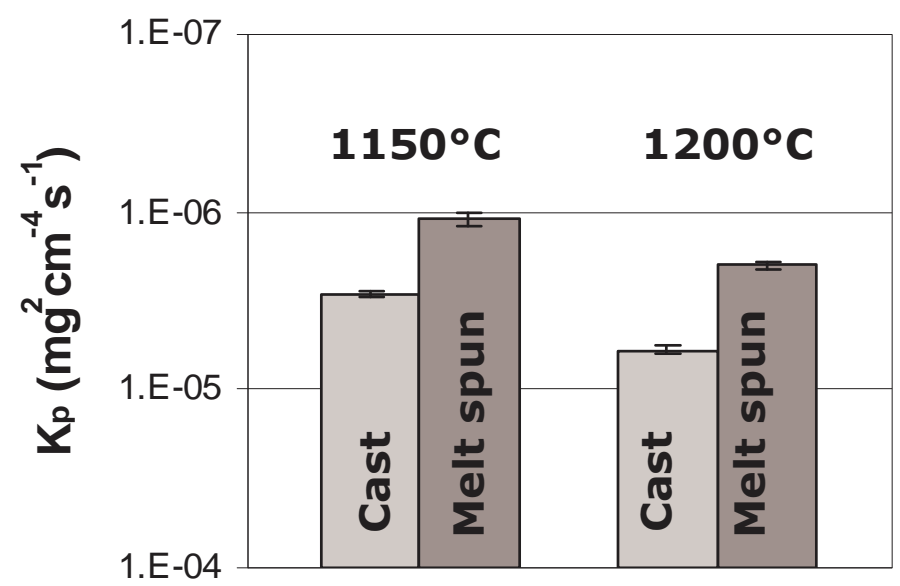

Figure 2: The calculated oxide growth rates between the hours of 50-100 for both cast and melt spun $\mathrm{NiAl}$ at $1150^{\circ} \mathrm{C}$ and $1200^{\circ} \mathrm{C}$

In Figure 2 the melt spun samples had a slower growing oxide scale than the cast samples. As expected based upon diffusion principles the same alloys subjected to the lower temperature showed a slower growing scale when compared to testing at the higher temperature. Therefore, the same alloy with no compositional change shows a consistent trend in oxide growth rate dependent upon the synthesis technique. Finer grain size has been shown to increase the aluminum diffusion to the oxide metal interface (13). This allows for fast shortcircuit diffusion of aluminum and creates an alumina scale that is compact and therefore reduces further growth rate of the oxide scale.

The mechanism by which the improvement in oxidation resistance brought about by iridium, rhodium, and hafnium addition is unclear (8). In order to assess the role of Pd, Ir, and Rh substitution, the grain size of the PGM substituted cast and annealed samples were analyzed by OIM employing TSL software. The average grain sizes are displayed in Figure 3a. Figure $3 b$ shows the role of $\mathrm{Ir}$ and $\mathrm{Rh}$ additions on the grain size the alloy on a finer scale. 
65
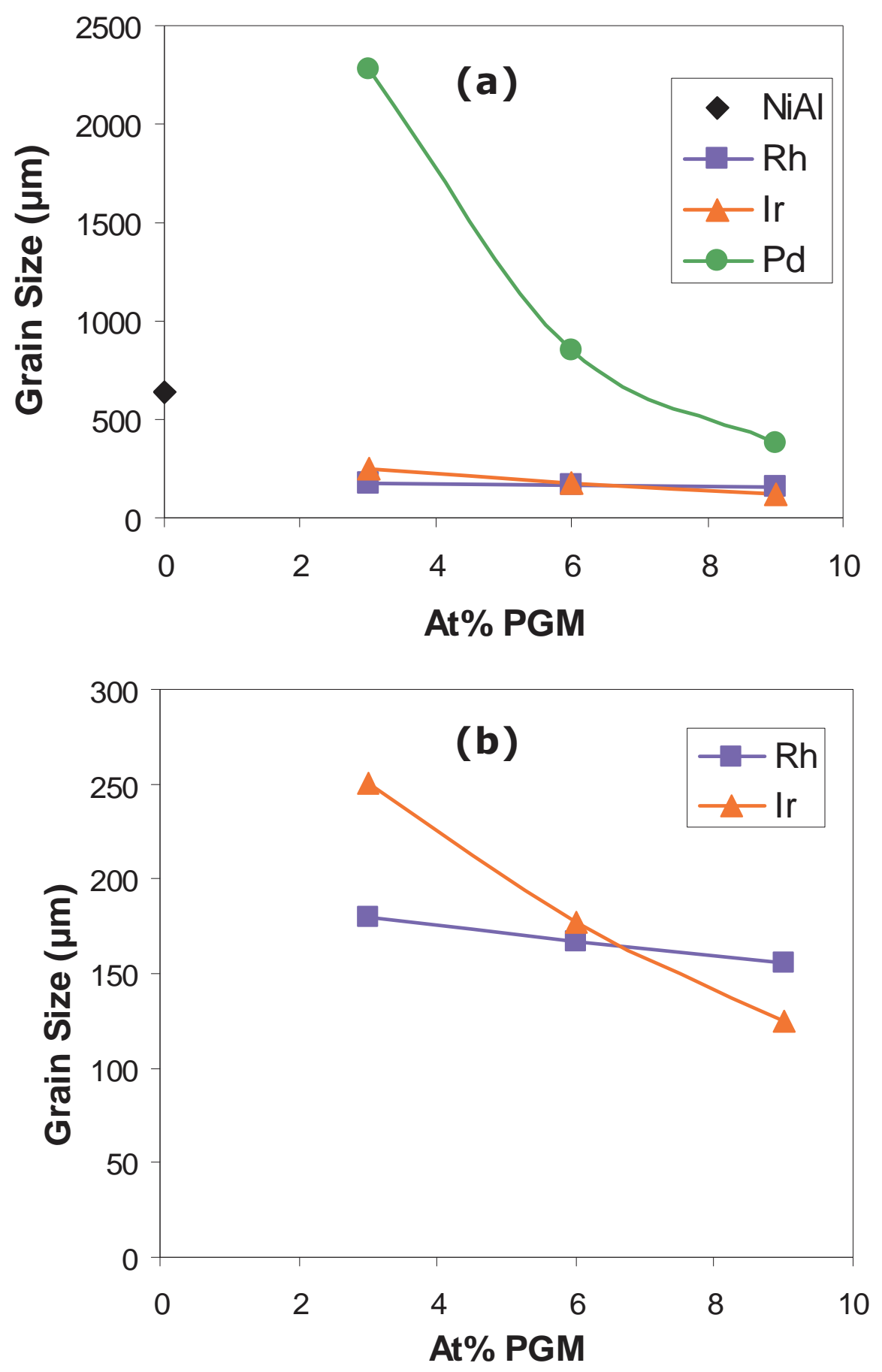

Figure 3: Average grain sizes for (a) NiAl and PGM modified alloys (b) Ir and Rh containing alloys 
In Figure $3 a$, it can be seen that compared to the baseline NiAl, the palladium addition increases the average grain size at $3 \%$ but the grain size decreases with more Pd addition. For Ir and Rh, substitution of these elements decreases the grain size. It seems $\mathrm{Rh}$ is more effective at lower concentrations than Ir but at the highest concentration of 9 at\% Ir is more effective than Rh (120 vs. $160 \mu \mathrm{m}$ ). Images obtained from $\mathrm{NiAl}$ and the 3\% PGM modified samples during OIM analysis are displayed in Figure 4.
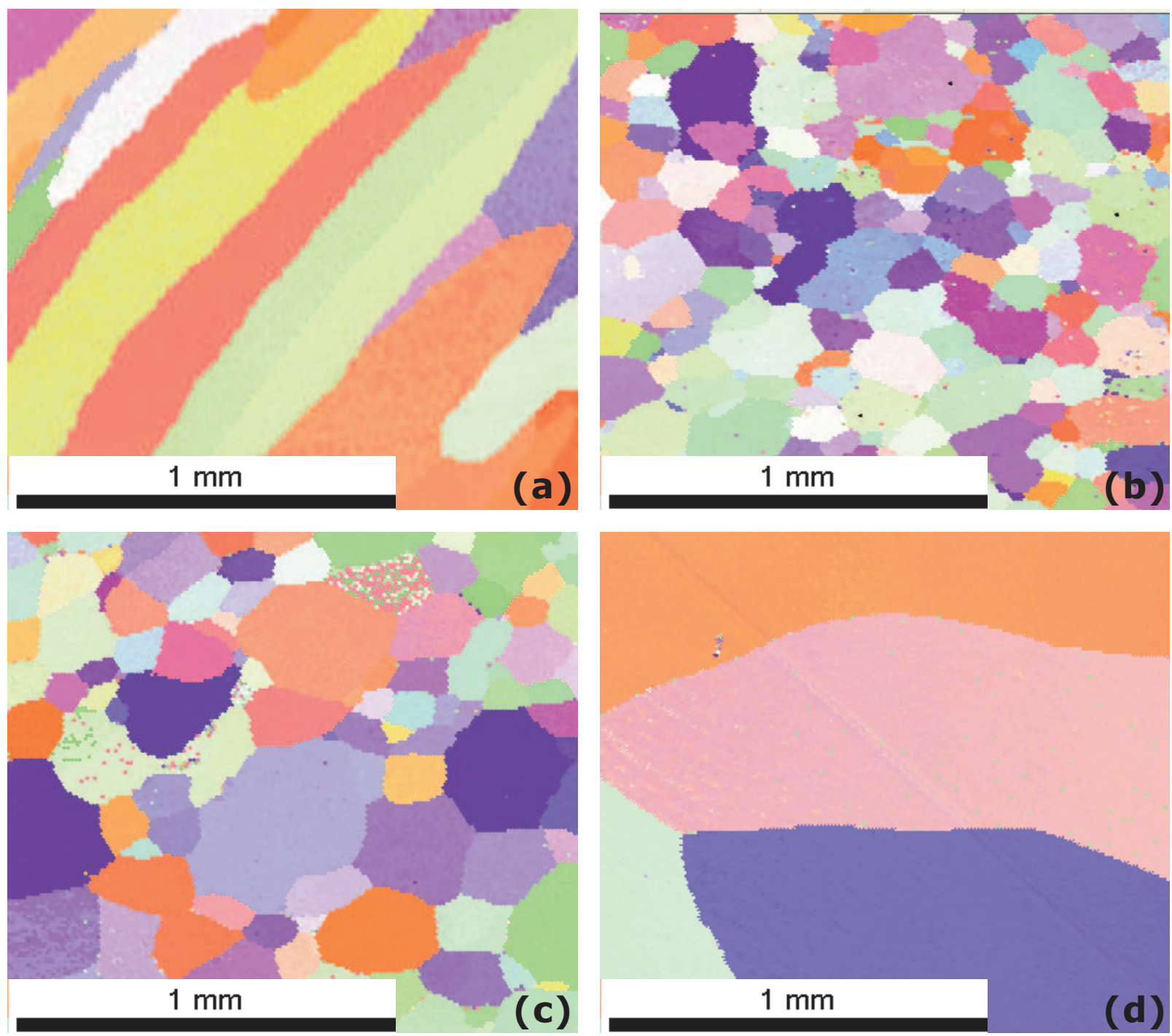
Figure 4: Images captured during OIM analysis of (a) NiAl, (b) Ni-50Al-3Rh, (c) Ni-50Al-3lr, (d) Ni-50AI-3Pd

Figure 4a shows anisotropic grains that are several $\mathrm{mm}$ long and approximately $0.2 \mathrm{~mm}$ wide that seem to radiate inward to the center of the casting which is towards the bottom left-hand corner of the image. Figure $4 \mathrm{~b}$ shows the cast $\mathrm{NiAl}$ alloy containing $3 \%$ rhodium. Compared to the baseline $\mathrm{NiAl}$, the grains are much smaller and isotropic in shape. Figure 4c shows the cast NiAl alloy containing $3 \%$ iridium. Here the grains are smaller than $\mathrm{NiAl}$ and as in $\mathrm{Rh}$ substitution, they are isotropic in shape. Figure $4 d$ shows the $3 \%$ palladium modified NiAl alloy in which the grains seem to radiate inward to the center of the casting which is in the bottom left-hand side of the image. The grains appear to be similar in length to the NiAl cast alloy, but instead of being anisotropic with high aspect ratio, these grains show lower aspect ratio with a large average grain size. All of the alloys show random grain orientation as indicated by the stark contrast differences between neighboring grains.

The columnar grains that are indicative of $\mathrm{NiAl}$ as well as the $\mathrm{Pd}$ substituted alloys are created due to the heat flow of the alloy and the hottest part of the system being the melt. Therefore the crystals grow inward from the interface of the mold with the crystals that are most favorably lined up with the direction heat flow growing faster. The equiaxed grains formed by the Ir and Rh substituted alloys are created by the heat flow of the system where the crystals are the hottest part. The crystals reject heat and solute during solidification. Therefore all the grains are equiaxed and they should be smaller due to the higher nucleation rate in an undercooled system. These two different types of heat flows cause the change between the grain structures seen in the different alloy systems. 


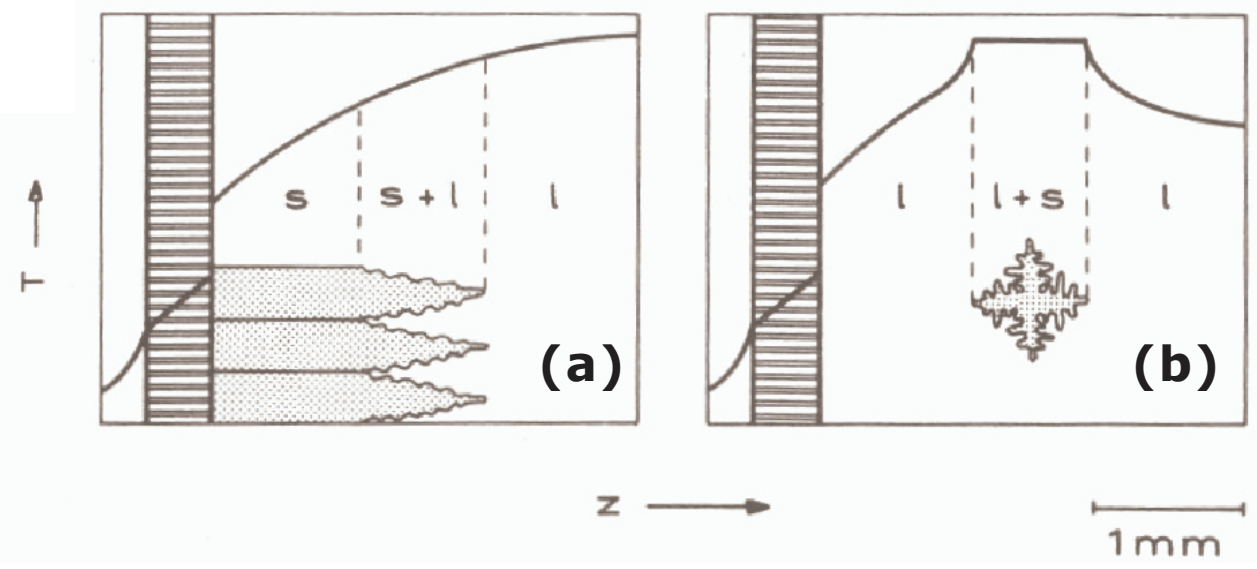

Figure 5: Solid/Liquid interface morphology and temperature distribution (14)

Confirmation of this mechanism that causes different grain sizes and shapes in the alloys upon casting was found during SEM analysis of the alloys. The SEM backscattered image of Ni-50Al-9lr is shown in Figure 6 after a colloidal silica etching. It is clear from this low magnification image that equiaxed dendrites are forming during the casting process and these dendrites limit the size of the grains. Discrete looking dendrites as shown in Figure 6a were only observed in the as-cast samples of iridium and rhodium containing alloys. No dendrites were observed in the palladium containing alloys which showed to have large grains. As it is shown in Figure 6b, all of the dendrites have diffused within six hours of annealing with only small residual chemical heterogeneity remaining as indicated by the slightly brighter and darker patches. Therefore the dendrites formed during casting were not thermodynamically stable and they diffused during annealing to reduce the chemical heterogeneity. 

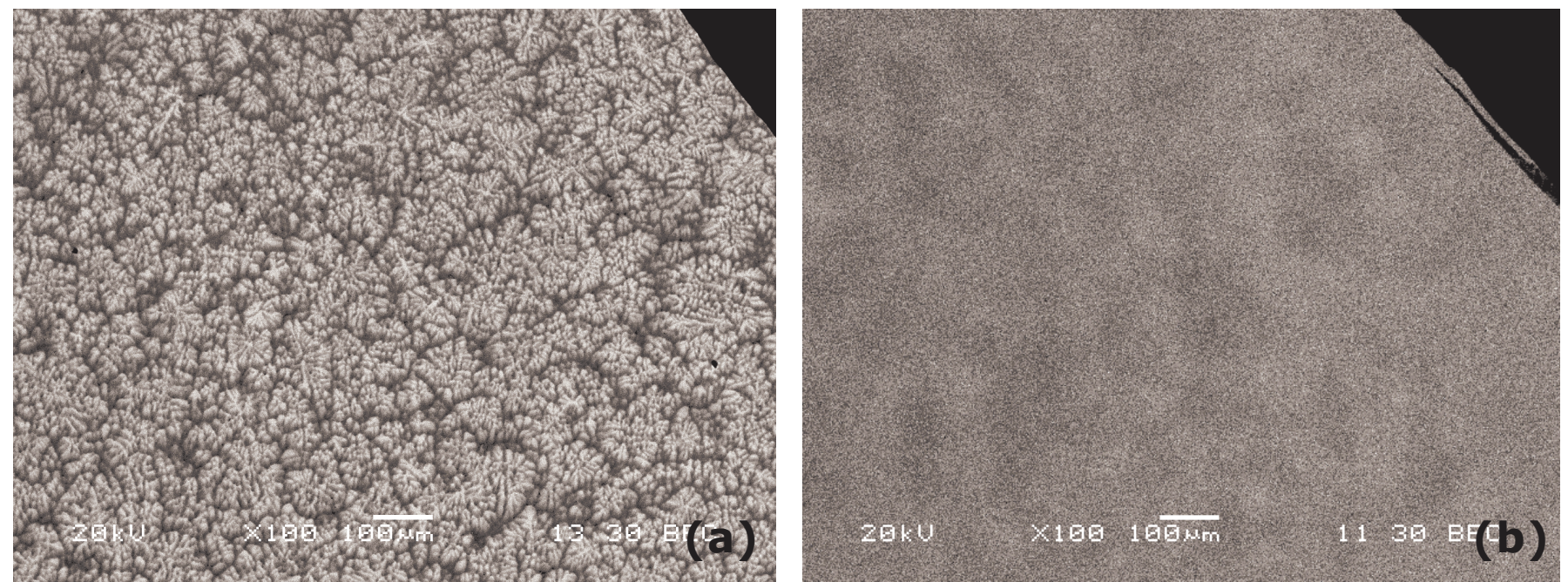

Figure 6: SEM backscattered images of (a) as-cast Ni-50Al-9lr, (b) Ni-50Al-9lr annealed for 6 hours at $1300^{\circ} \mathrm{C}$

The composition at the center of the dendrites was determined using EDS to contain approximately 20 at\% Ir. The surrounding darker regions were found to contain about 2 at\% Ir. Since dendrites were forming and the compositional heterogeneity was relatively large, $x$-ray analysis was carried out on this sample to ensure that it was single phase. The $x$-ray analysis results of as-cast and annealed 9 at\% Ir samples are shown in Figure 7. 


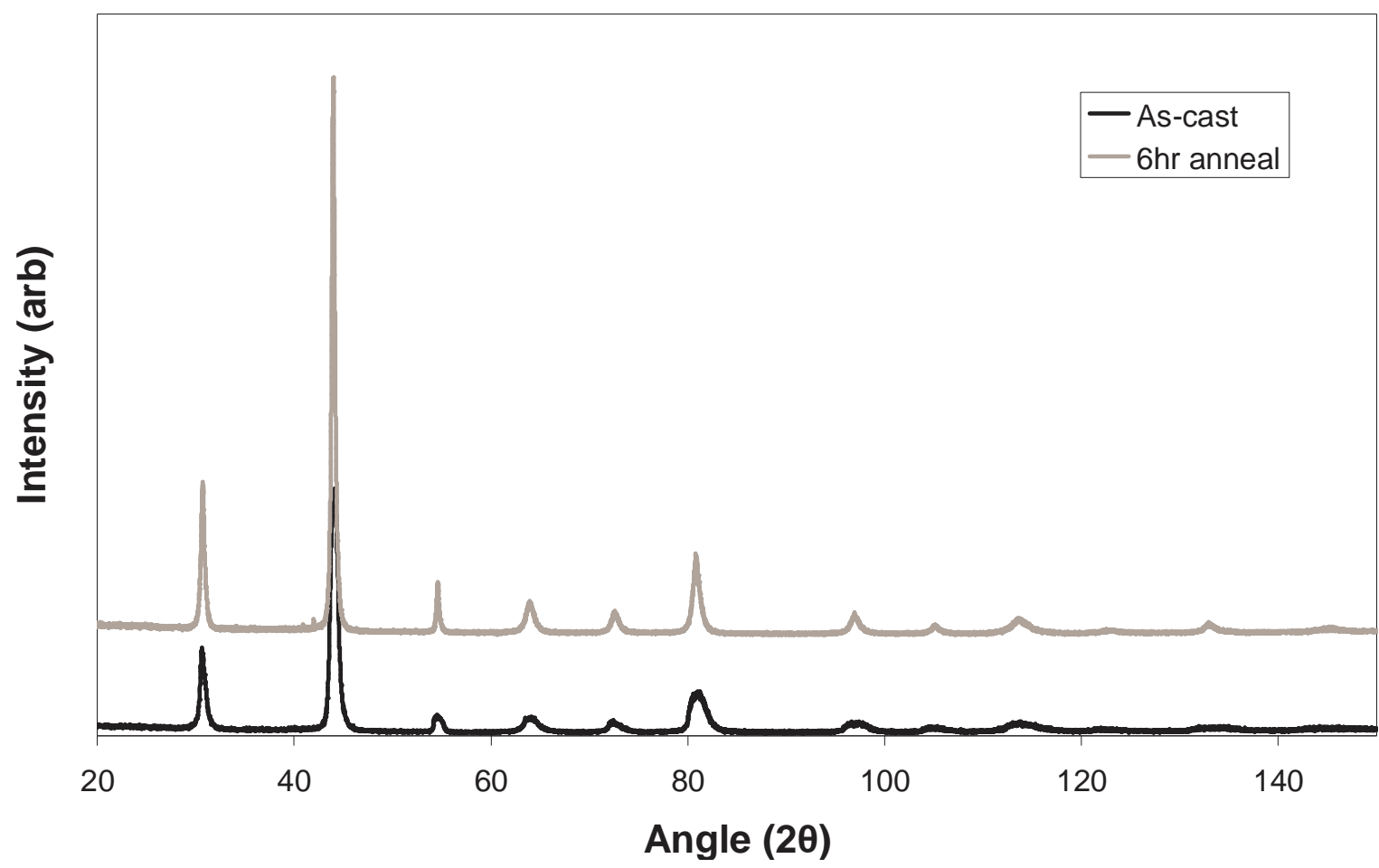

Figure 7: X-ray analysis of as-cast and annealed Ni-50Al-9lr

Both the as-cast and annealed samples appear to be single phase according to the x-ray data obtained. Therefore the dendrites shown in Figure $6 a$ and $6 b$, although they are rich in iridium, remain continuous in crystal structure throughout the sample.

The x-ray pattern for the as-cast sample appears to have broader peaks than the annealed sample. The increased iridium content in the dendritic regions would be expected to strain the lattice and cause the lattice parameter increase to account for the larger atom size. Iridium, which has an atomic radius of $180 \mathrm{pm}$, is substituted on a nickel site which has an atomic radius of $149 \mathrm{pm}$ (15). This increase in the atomic size would also increase the lattice parameters and would cause the Bragg diffraction angle to widen as seen in Figure 7. The measured lattice parameters for PGM substituted NiAl alloys are shown in Figure 8. The $\mathrm{x}$ ray data for each alloy was obtained and Rietveld refinement was used to 
determine the lattice parameter of each alloy. The measured lattice parameter increases with increasing PGM substitution. The two PGM substitutions that increase the lattice parameter the most are iridium and rhodium and they are also the two PGMs that cause the formation of the dendrites.

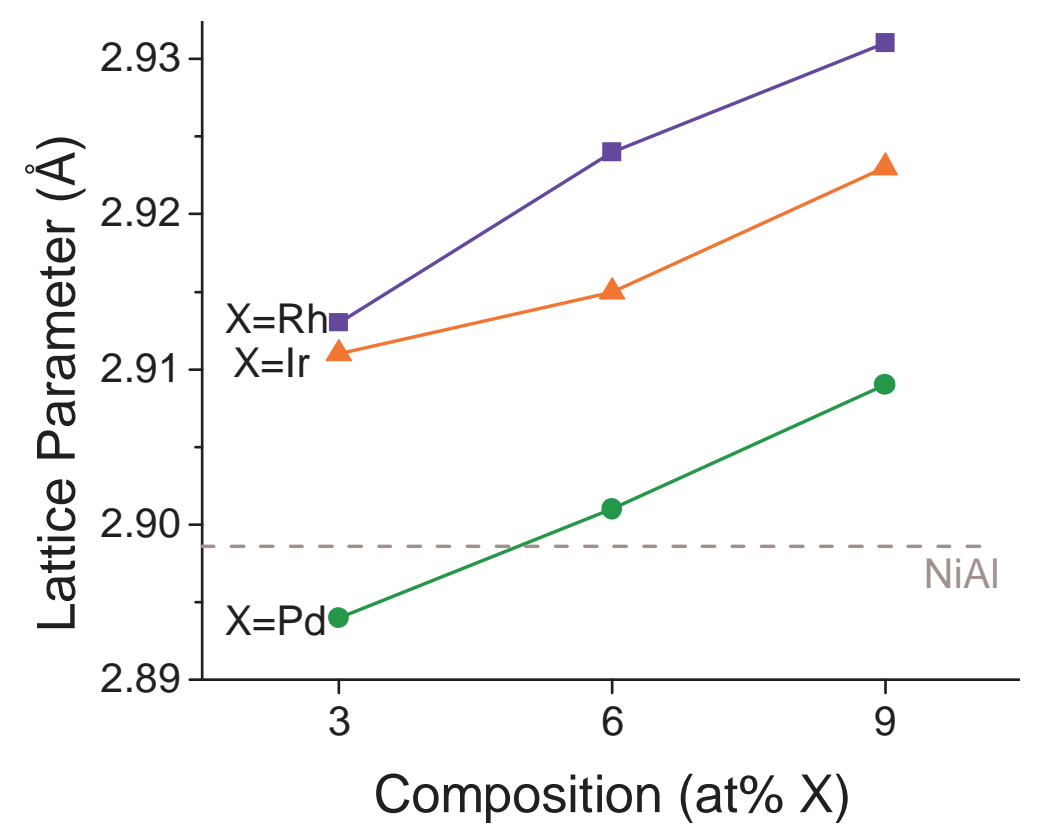

Figure 8: Measured lattice parameters for PGM substituted NiAl alloys

The possible solidification process causing the Ir rich dendrites to form is due to the increased melting temperature of Ir substituted NiAl. The first metal to solidify in the casting would be the metal containing the highest amount of Ir. The next enveloping layer to solidify would be slightly lower in Ir. This would continue to have layers of less and less Ir until the last molten metal solidified. This solidification process can be seen in Figure 9 and it explains how the dendrite lengths can limit the average grain size of the alloy. Both Ir and Rh substituted NiAl alloys show these dendrites. 


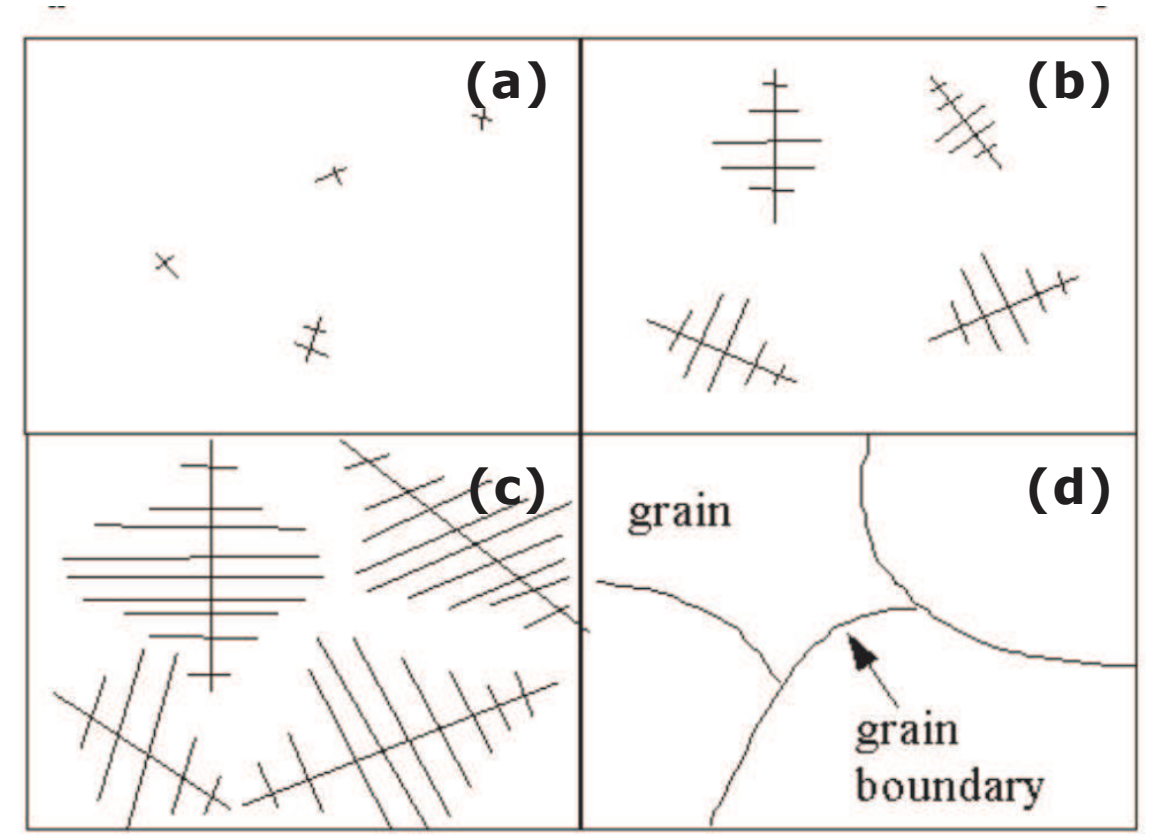

Figure 9: Schematic representation of dendrite formation during solidification (16) (a) nucleation of dendrites, (b) growth of dendrites, (c) complete solidification, (d) final grain size constrained by dendrites

The discrete and vivid looking PGM rich dendrites were not observed in any of the annealed samples. It is inferred that the dendrites diffuse during the 6 hours of annealing at $1300^{\circ} \mathrm{C}$ in order to equilibrate the composition and approach thermodynamic equilibrium as indicated in Figure $5 \mathrm{c}$ and $5 \mathrm{~d}$. Given that the dendrites diffuse during annealing and the dendrites limit the size of the grains during casting, annealing would possibly result in significant grain growth. Samples of as-cast and annealed NiAl, Ni-50Al-9lr, and Ni-50Al-9lr+Hf were analyzed using OIM to determine if the grains coarsened during annealing at $1300^{\circ} \mathrm{C}$. The average grain sizes of the alloys during the annealing test are displayed in Figure 10. 


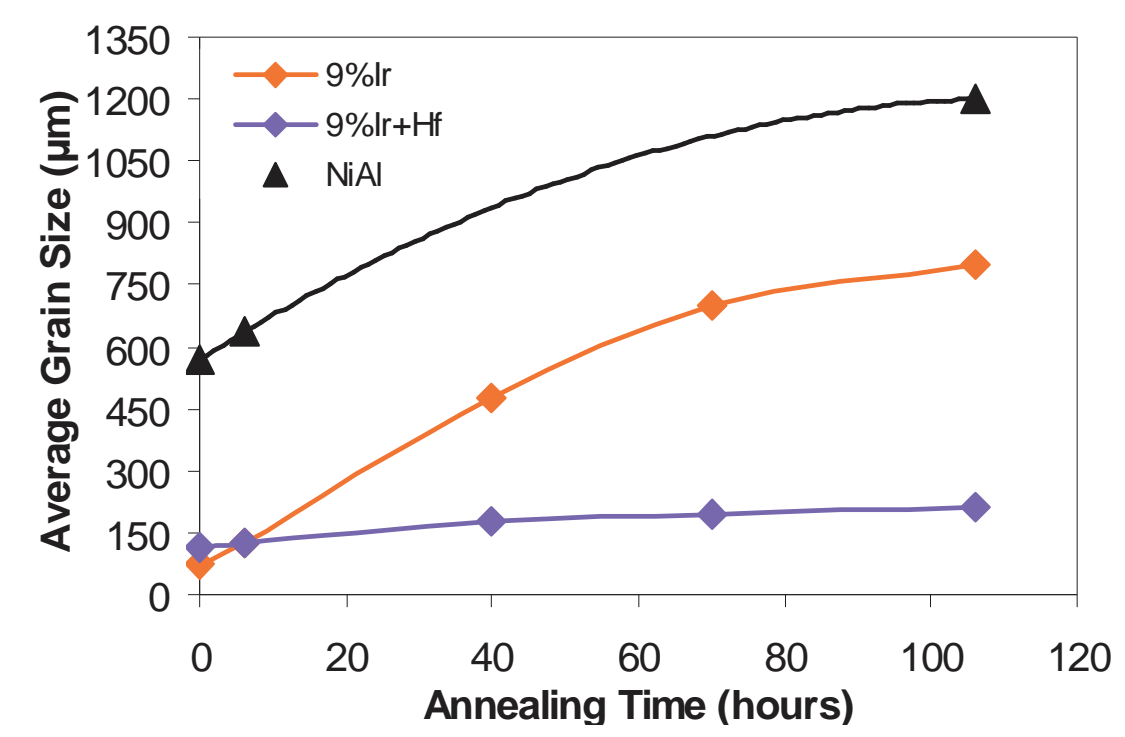

Figure 10: Grain growth of NiAl, Ni-50Al-9Ir and Ni-50Al-9lr+Hf during annealing at $1300^{\circ} \mathrm{C}$

It is clear in Figure 10 that the grains of the cast alloy NiAl as well as the alloy containing iridium grew readily at $1300^{\circ} \mathrm{C}$. Therefo re, although Ir substitution reduces the average grain size during casting it does little to stop the grain growth during annealing. Although coarse grains are desired for high temperature creep resistance (17), they were shown in Figure 2 to increase the oxide growth rate. The alloy containing hafnium on the other hand effectively hindered the grain growth at $1300^{\circ} \mathrm{C}$. Not even small amounts of dispersed alumina particles are able to stop grain growth in NiAl (18). It is believed that the hafnium is preferentially segregated to the grain boundaries where it can act as a Zener pinning agent $(19,20)$. Within the current scope of the study, presence of such a small quantity of $\mathrm{Hf}$ at the grain boundaries could not be ascertained.

OIM images of the grains for both of these alloys were captured after 6 and 106 hours of annealing. They are shown in Figure 11 to demonstrate the retarding effect of 0.05 at $\%$ hafnium on the grain growth. After 6 hours of annealing, both alloys have very similar grain sizes. After an additional 100 hours of annealing at 
$1300^{\circ} \mathrm{C}$, the average grain size area of the alloy wi thout $\mathrm{Hf}$ grew by 40 -fold while the alloy with $\mathrm{Hf}$ grew in average grain size area by only 3-fold.
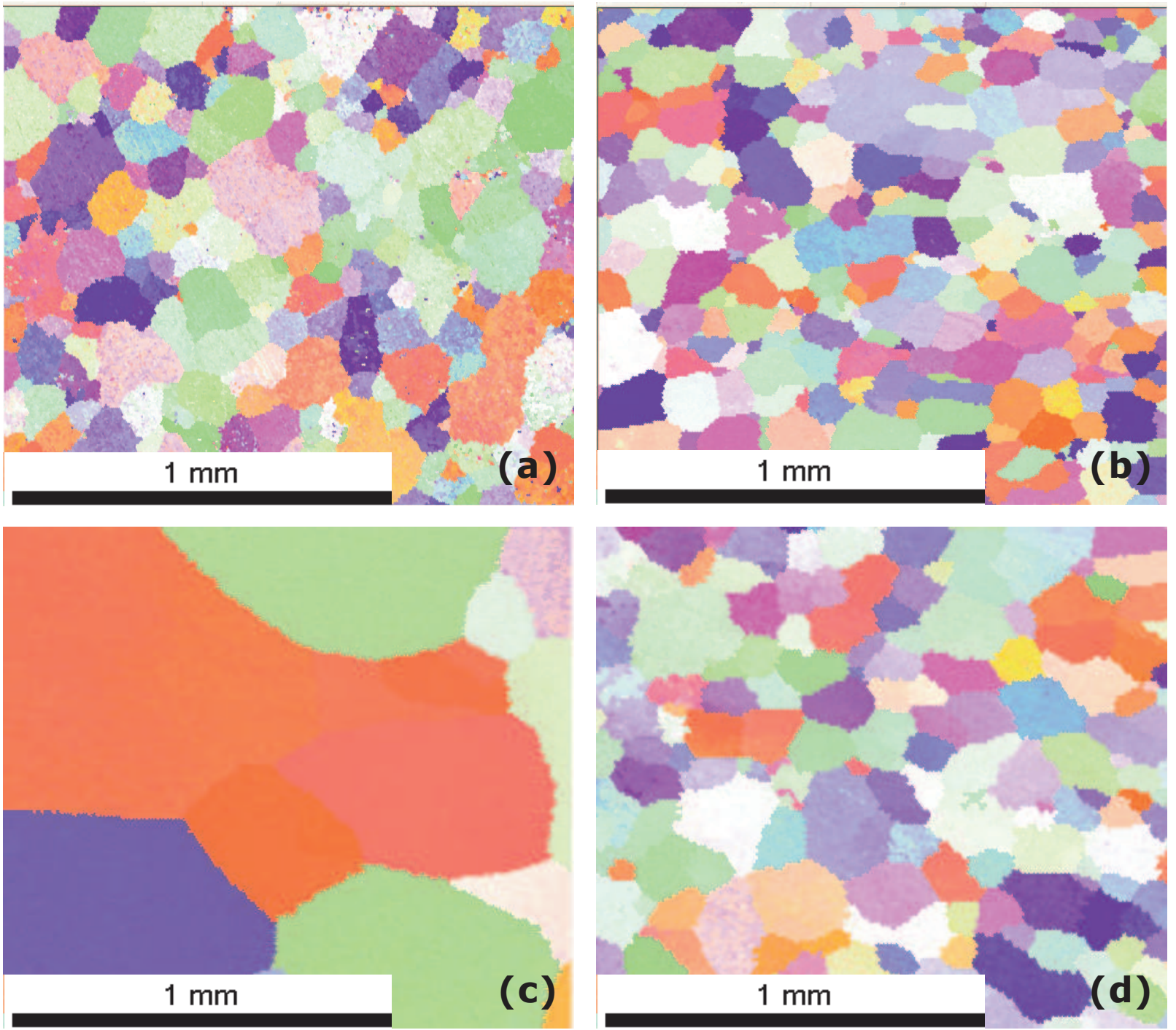

Figure 11: OIM images of the grains of (a) Ni-50AI-9Ir annealed for 6 hours, (b) $\mathrm{Ni}-50 \mathrm{Al}-9 \mathrm{Ir}+\mathrm{Hf}$ annealed for 6 hours, (c) Ni-50Al-9Ir annealed for 106 hours, (d) Ni-50Al-9Ir+Hf annealed for 106 hours 
Assuming the grain growth shown in Figures 10 and 11 are indicative of ideal grain growth, the data was used to calculate the temperature dependent grain growth constant which is given by:

$$
d^{2}-d_{o}^{2}=k t
$$

where $\mathrm{k}$ is the temperature dependent growth constant, $\mathrm{d}$ is the grain size at time $t$, and do is the initial grain size.

The grain growth constants for the three alloys shown in Figure 10 are shown below in Table 2.

Table 2: Temperature dependent grain growth constants

\begin{tabular}{|l|c|c|}
\hline Alloy & $\mathrm{k}\left(\mu \mathrm{m}^{2} / \mathrm{hr}\right)$ & $\mathrm{R}^{2}$ \\
\hline Ni-50Al & 10,528 & 0.999 \\
\hline Ni-50Al-9lr & 6,198 & 0.986 \\
\hline Ni-50Al-9Ir+Hf & 327 & 0.957 \\
\hline
\end{tabular}

\section{Conclusions}

Comparing the same composition of an as-cast and melt-spun sample, the meltspun sample had a much finer grain size and produced a more compact slower growing oxide scale which correlates well with Yang's work (6). It was shown in Figure 10 that the average grain size of an unmodified NiAl alloy increases drastically during annealing at $1300^{\circ} \mathrm{C}$.

Of the PGM modifications to NiAl, both the Ir and Rh additions constrained the grain size by forming PGM rich dendrites during the casting process. Both Ir and $\mathrm{Rh}$ have been noted to improve the oxidation resistance of NiAl by forming a slower growing and more adherent oxide scale (8). The PGM rich dendrites 
were still single phase with the rest of the alloy, but they did cause slight broadening of the peaks in the $\mathrm{x}$-ray diffraction plot. Pd modifications did not form dendrites and did not show any improvement in oxidation resistance when compared to $\mathrm{NiAl}$ (8). The PGM rich dendrites diffused after short annealing times at $1300^{\circ} \mathrm{C}$. As the dendrites diffused, the grains grew at a similar rate to the unmodified NiAl alloy indicating that they do little to slow grain boundary movement. It is unsure at this point whether Ir and Rh substitutions only improve the oxidation resistance due to the grain size role or if there are other effects that also play a factor in improved oxidation resistance.

Adding 0.05 at $\% \mathrm{Hf}$ to the alloys effectively hindered grain growth at $1300^{\circ} \mathrm{C}$. It is believed that $\mathrm{Hf}$ segregates to the grain boundaries and effectively pins the

grain boundaries so that grain coarsening is severely diminished. Hf has shown to improve the oxidation resistance of $\mathrm{NiAl}$ alloys by forming a slower growing and more adherent oxide scale (8).

\section{Acknowledgement}

This work was supported by the DOE-FE (AMR program) through Ames Laboratory contract no. DE-AC02-07CH11358 through lowa State University.

\section{References}

1) R.D. Noebe, R.R. Bowman, M.V. Nathal, Review of the physical and mechanical properties of the B2 compound NiAl, International Materials Review, Vol. 38, pp. 193-232, 1993

2) D.B. Miracle, R. Darolia, Intermetallic Compounds: Principles and Practice, Vol. 2, Chichester: John Wiley \& Sons, pp. 55-74, 1995

3) C.T. Liu, J.O. Stiegler, F.H. Froes, Metals handbook (10th Ed.), Vol. 2, ASMInternational, Metals Park, pp. 913-942, 1990 
4) J.L Smialek, Oxide morphology and spalling model for NiAl, Metallurgical Transactions A, Vol. 9, No. 3, pp. 309-320, 1978

5) S.L. Yang, F.H. Wang, Y. Niu, W.T. Wu: Isothermal oxidation of B-NiAl alloy and sputtered coating at $1000^{\circ} \mathrm{C}$ in air. Material Science Forum, Vol. 369-372, pp. 361-368, 2001

6) S.L. Yang, F.H. Wang, W.T. Wu, Effect of microcrystallization on the cyclic oxidation behavior of $\beta-\mathrm{NiAl}$ intermetallics at $1000^{\circ} \mathrm{C}$ in air, Intermetall ics, Vol. 9 , pp. 741-744, 2001

7) M.W. Brumm, H.J. Grabke, The oxidation behaviour of NiAl - Phase transformations in the alumina scale during oxidation of $\mathrm{NiAl}$ and $\mathrm{NiAl}-\mathrm{Cr}$ alloys, Corrosion Science, Vol. 33, No. 11, pp. 1667-1690, 1992

8) T. Brammer, M. Akinc, M.J. Kramer, Effect of platinum group metal substitutions and hafnium additions on the oxidation resistance of $\beta-\mathrm{NiAl}$, to be submitted to Intermetallics, 2011

9) J. Balmain, M.K. Loudjani, A.M. Huntz, Microstructural and diffusional aspects of the growth of alumina scales on $\beta$-NiAl, Materials Science and Engineering $A$, Vol. A224, pp. 87-100, 1997

10) Y. Cadoret, D. Monceau, M.P. Bacos, P. Josso, V. Maurice, P. Marcus, Effect of platinum on the growth rate of the oxide scale formed on cast nickel aluminide intermetallic alloys, Oxidation of Metals, Vol. 64, No. 3-4, 2005 11) T.F. An, H.R. Guan, X.F. Sun, Z.O. Hu, Effect of the $\theta-\alpha-\mathrm{Al}_{2} \mathrm{O}_{3}$ transformation in scales on the oxidation behavior of a nickel-base superalloy with an aluminide diffusion coating, Oxidation of Metals, Vol. 54, No. 3-4, pp. 301-316, 2000 12) M. Li, X.F. Sun, H.R. Guan, X. Jiang, Z.O. Hu, Oxidation behavior of Pdmodified aluminide coating at high temperature, Journal of Material Science and Technology, Vol. 19, No. 3, 2003

13) G.C. Rybicki, J.L. Smialek, Effect of the $\theta$ to $\alpha-\mathrm{Al}_{2} \mathrm{O}_{3}$ transformation on the oxidation behavior of B-NiAl+Zr, Oxidation of Metals, Vol. 31, pp. 275-304, 1989 
14) W. Kurz, D.J. Fisher, Fundamentals of Solidification, Trans Tech

Publications, USA, pp. 11, 1984

15) E. Clementi, D.L. Raimondi, W.P. Reinhardt, Journal of Chemical Physics, Vol. 47, pp. 1300, 1967

16) K.R. Trethewey and J. Chamberlain, Corrosion for Students of Science and Engineering (2nd Ed.), John Wiley Inc., New York, pp. 23-45, 1995

17) J.D. Whittenberger, R. Ray, S.C. Jha, Influence of grain size on the creep behavior or $\mathrm{HfC}$ - dispersed NiAl, Materials Science and Engineering, Vol. A151, pp. 137-146, 1992

18) M.M. Moshksar, H. Doty, R. Abbaschian, Grain growth in $\mathrm{NiAl}-\mathrm{Al}_{2} \mathrm{O}_{3}$ in situ composites, Intermetallics, Vol. 5, Issue 5, pp. 393-399, 1997

19) B.A. Pint, Experimental observations in support of the dynamic-segregation theory to explain the reactive-element effect, Oxidation of Metals, Vol. 45, pp. 137, 1996

20) M.A. Bestor, R.L. Martens, R.A. Holler, M.L. Weaver, Influences of annealing and hafnium concentration on the microstructures of sputter deposited $\beta$-NiAl coatings on superalloy substrates, Intermetallics, Vol. 18, pp. 2159-2168, 2010 


\title{
CHAPTER 5: \\ EFFECT OF PLATINUM GROUP METALS ON THE MELTING TEMPERATURE OF $\beta$-NiAI
}

\author{
T. Brammer, M. Akinc and M.J. Kramer \\ Ames Laboratory and Department of Materials Science and Engineering \\ lowa State University, Ames, IA-50011
}

(To be submitted to Intermetallics)

\begin{abstract}
The Rose-Ferrante relation was used to calculate the melting temperatures of platinum group metal (PGM) substituted $\beta-N i A l$. Experimental testing was completed of the same alloy systems and there is agreement between the calculated and experimental results. Iridium and rhodium substitutions increase the melting temperature of $\beta$-NiAl while palladium substitutions decrease overall the melting temperature. At $12 \%$ substitution amounts, iridium increases the melting temperature of $\mathrm{NiAl}$ by $150^{\circ} \mathrm{C}$, rhodium by $130^{\circ} \mathrm{C}$, and palladium decreases it by $50^{\circ} \mathrm{C}$. The melting temperature tren ds directly correlate to the oxidation resistance observed in previous studies $(1,2)$. This seems to indicate that the alloy with the lower homologous melting temperature performs better during high temperature oxidation testing.
\end{abstract}




\section{Introduction}

$\beta$-NiAl has been studied as a good candidate for implementation in high temperature environments (3). The alloy has good inherent oxidation resistance at high temperatures by forming a protective alumina scale (4). This scale shields the underlying metal from further oxidation. NiAl can also be used at high temperatures due to its high melting temperature of $1638^{\circ} \mathrm{C}$ (5). NiAl based alloys could be used at even higher temperatures if the alloy were modified to increase the melting temperature. The elemental modification to NiAl must create a solid solution with $\mathrm{NiAl}$ to increase the melting temperature while not adversely affecting the oxidation resistance.

It has been noticed in previous work that certain PGM substitutions to $\beta-\mathrm{NiAl}$ improve the oxidation resistance at high temperatures (1). It was desired to understand if the PGM substitutions had an effect on the melting temperature of the alloy and determine if the melting temperatures directly correlated to the oxidation resistance of the alloy. Given the same conditions, an alloy with a higher melting temperature would have a lower homologous melting temperature. Having a lower homologous melting temperature would ensure that the alloy would have reduced grain growth at the high temperatures, and grain size has been directly correlated to oxidation resistance (6).

\section{Experimental Procedure}

\section{Materials}

The alloys were produced from pieces cut from pure bulk metal sheets obtained from the Materials Preparation Center at Ames Laboratory, having a purity of $99.7 \%$ or more. Pure Ni and Al were first arc-melted together on a chilled copper hearth in an argon atmosphere using a non-consumable tungsten electrode. This initial melting ensured that $\beta$-NiAl would form. The alloying additions were then melted along with the $\beta-\mathrm{NiAl}$ synthesized according to the aforementioned 
steps. The nominal compositions were prepared according to $\mathrm{Ni}_{50-x} \mathrm{Al}_{50} \mathrm{PGM}_{\mathrm{x}}$ $(\mathrm{x}=0,3,6,9$, and $12 \mathrm{at} \%)$. After initial arc-melting, the samples were turned over and re-melted a minimum of three times in an argon atmosphere to achieve better homogenization before drop-casting. After re-melting the samples were drop-cast into $10 \mathrm{~mm}$ diameter cylinders. These cylindrical rods were then annealed in an inert atmosphere at $1300^{\circ} \mathrm{C}$ for 6 hours to achieve a better compositional homogeneity. A small sample size of about 0.2 grams was cut from the cylinder to be used for melting temperature studies.

\section{Testing}

Melting temperature testing was carried out using a Linseis L81/2400 high temperature combined differential thermal analysis (DTA) and thermogravimetric analysis (TGA) instrument (Princeton, NJ). Argon was allowed to flow through the system at a rate of $4 \mathrm{~L} / \mathrm{hr}$ to ensure no oxygen build up during testing. The sample was placed in a tungsten crucible with an alumina liner. The furnace uses a temperature ramping rate of $15^{\circ} \mathrm{C} /$ minute. The instrument uses C-type thermocouple wires and transmits the voltage difference between the sample and

an empty crucible to a program on the computer. The data is then read using a software program called STA Measurement. The melting temperature was calculated based upon the average of the onset of melting and crystallization.

\section{Results and Discussion}

The melting temperature of an alloy can be calculated with reasonable accuracy (14.5\%) using the Rose-Ferrante relation $(7,8)$. The Rose-Ferrante relation utilizes the universal binding energy theory to create a universal model for calculating melting temperatures. The model directly correlates the melting temperature of an alloy to the cohesive energy of the alloy. This relationship is shown in Equation 1. 


\section{$\underline{\text { Rose-Ferrante Relation for Pure Metal: }}$}

$$
T_{m}=0.03 E^{c} / k_{B}
$$

Where $T_{m}=$ melting temperature, $E^{c}=$ cohesive energy, $\mathrm{k}_{\mathrm{B}}=$ Boltzmann's constant

The prefactor 0.03 is used in the case of pure metals. For binary compounds where both metals have the same crystal structure, the prefactor changes to 0.0302. This small change can account for switching from a single metal system to a binary metal system. It is therefore assumed that it will not change much for ternary alloys with the same crystal structure either. Therefore it is assumed that the Rose-Ferrante relation is a decent model for estimating melting temperatures.

The calculated melting temperatures were based upon cohesive energy of the alloy as shown in Equation 1. The cohesive energy of an alloy is the energy required to break the atoms of the solid into isolated atomic species (9). The cohesive energy of the alloy can therefore be thought of as the total energy of the bonds within the alloy. The cohesive energy of the alloy is therefore related to the individual cohesive energies of the pure metals and the formation enthalpy of the alloy (10). This relationship is displayed in Equation 2.

\section{Cohesive Energy of Ternary Metal Alloy:}

$$
E^{c}=x_{1} E_{1}{ }^{c}+x_{2} E_{2}{ }^{c}+x_{3} E_{3}{ }^{c}-\Delta H_{f}
$$

where $E^{c}=$ cohesive energy of the alloy, $x_{1}=$ atomic fraction of metal 1 , $\mathrm{E}_{1}{ }^{\mathrm{c}}=$ cohesive energy of metal $1, \Delta \mathrm{H}_{\mathrm{f}}=$ formation enthalpy of alloy

The cohesive energies of the individual metals were found in C. Kittle's book (9) and they are reproduced in Table 1 for comparison. Since the PGMs are being 
substituted onto the nickel site, their cohesive energies would be replacing $\mathrm{Ni}$ in the amount of the desired substitution. If the PGM has a higher cohesive energy than nickel, the cohesive energy of the overall alloy would increase and therefore the calculated melting temperature would also increase. Iridium and rhodium have cohesive energies that are higher than nickel, while palladium has a lower cohesive energy.

Table 1: Cohesive Energies of Pure Metals

\begin{tabular}{|l|c|c|c|c|c|}
\hline Metal & Al & Ni & Rh & Ir & Pd \\
\hline Cohesive Energy (kJ/mol) & 327 & 428 & 554 & 670 & 376 \\
\hline
\end{tabular}

The other constituent needing to be accounted for before the melting temperature can be calculated is the formation enthalpy of the alloy. The formation enthalpies of PGM substituted NiAl alloys with nominal compositions of $\mathrm{Ni}_{50-\mathrm{x}} \mathrm{Al}_{50} \mathrm{PGM}_{\mathrm{x}}(\mathrm{x}=0,2,4,7$, and 11 at\%) were calculated using an extended Miedema model (10). The formation enthalpy of the alloys is shown in Figure 1. As it can be seen, all of the PGM substitutions create a NiAl alloy with a more negative formation enthalpy. The higher the amount of PGM substitution, the more negative the formation enthalpy of the alloy becomes. Since there is a negative sign in front of the formation enthalpy constituent in Equation 2, a more negative formation enthalpy value would denote an alloy with a higher melting temperature. Of the PGM substitutions, the one giving rise to the most negative formation enthalpy is rhodium followed by iridium and finally palladium. 


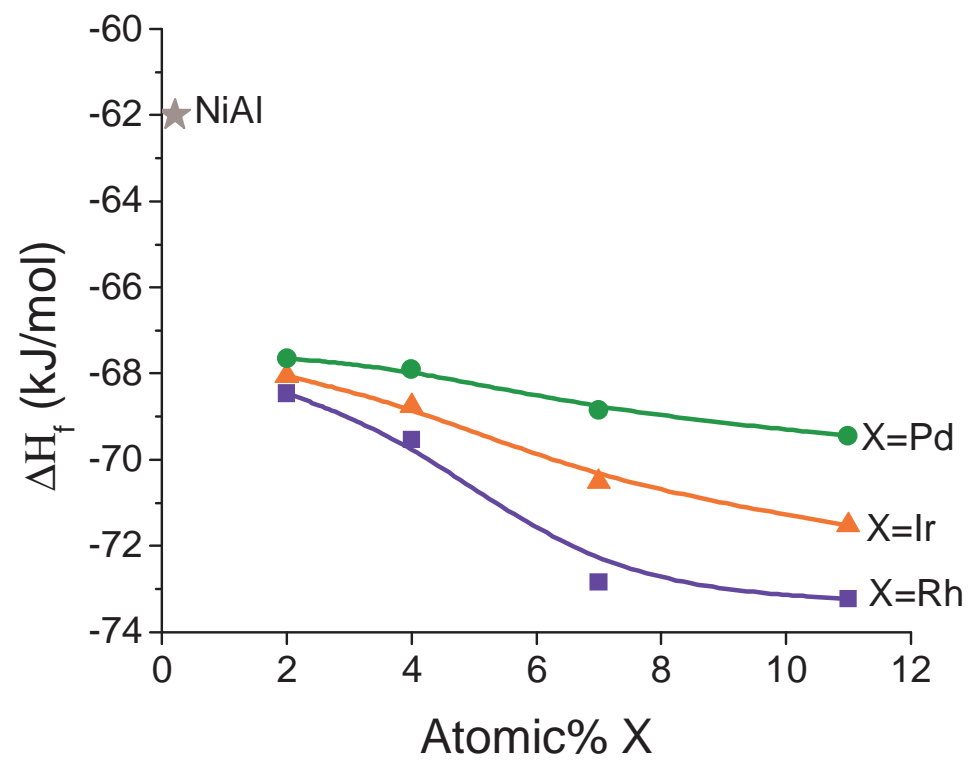

Figure 1: Calculated formation enthalpies for PGM substituted NiAl alloys

Now combining the data from the individual cohesive energies and the calculated formation enthalpies, the calculated melting temperature can be determined for each of the desired PGM substituted NiAl alloys. The results are displayed in Figure 2.

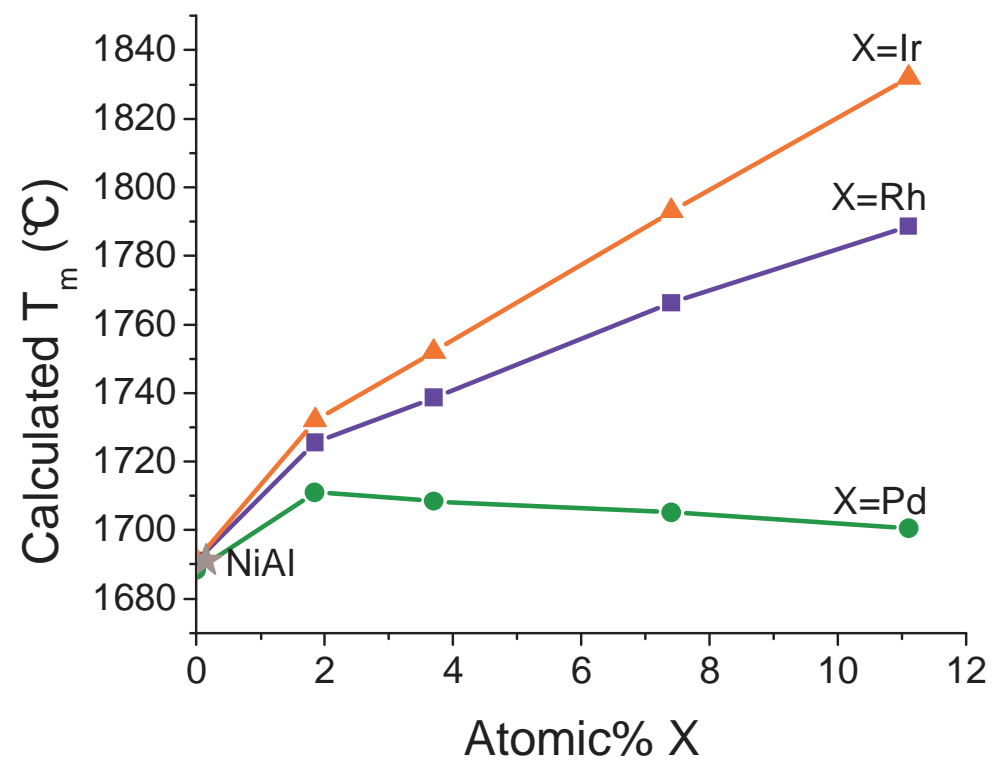

Figure 2: Calculated melting temperatures for PGM substituted NiAl alloys 
Figure 2 shows iridium to have the highest calculated melting temperature based upon the Rose-Ferrante relation. Iridium is the highest because it has a much higher cohesive energy than the nickel atoms it's substituting for. Also iridium substituted alloys were calculated to have formation enthalpies which are more negative than binary NiAl. Both of these constituents indicate that iridium substitutions will increase the melting temperature of NiAl. Rhodium likewise should produce an alloy with an increased melting temperature when compared to NiAl. Conversely, substituting palladium for nickel in NiAl is expected to decrease the overall melting temperature of the alloy. This reduction in melting temperature is primarily due to the lower cohesive energy of palladium when compared to the nickel it's substituted for.

The experimental melting temperatures of the alloys were determined using a high-temperature DTA. The resulting melting temperatures from each of the produced alloys are displayed in Figure 3. As it can be seen in the figure, the model used for calculations correctly predicted the general melting temperature trends when compared to the calculated melting temperatures in Figure 2. Substituting iridium creates the alloy with the highest melting temperature showing an increase from the baseline $\mathrm{NiAl}$ of $150^{\circ} \mathrm{C}$ at 12 at\% substitution. Substituting rhodium increases the melting temperature about $130^{\circ} \mathrm{C}$. Higher substitution amounts of iridium and rhodium continue to increase the melting temperature of the alloy. Palladium substitutions decrease the overall melting temperature of the NiAl alloy with higher substitution amounts continuing to decrease the melting temperature. At 12 at\% substitution, palladium decreased the melting temperature of $\mathrm{NiAl}$ by about $50^{\circ} \mathrm{C}$. 


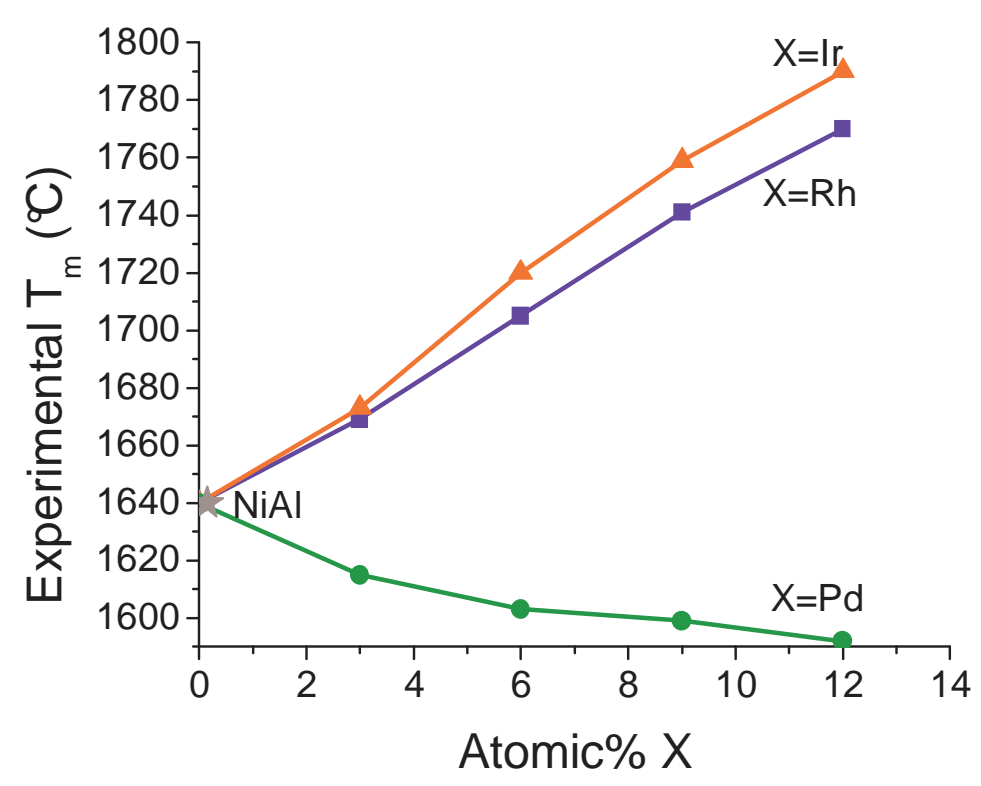

Figure 3: Experimental melting temperatures for PGM substituted NiAl alloys

One noticeable difference is that all of the experimental melting points seem to be about $50^{\circ} \mathrm{C}$ lower than the calculated melting tem peratures which are within the $14.5 \%$ stated accuracy of the Rose-Ferrante model. This discrepancy in the calculations could arise due to the fact that an extended Miedema model was used instead of the traditional binary Miedema model. As it was shown in Equation 1, the prefactor changes slightly when switching from pure metals to binary systems. The change in this prefactor from binary systems to ternary solutions has not been documented and could not properly be accounted for.

\section{Conclusions}

The calculations based on the Rose-Ferrante model produced relatively accurate melting temperatures that correlated closely to the measured melting temperatures. Substituting iridium and rhodium into the NiAl alloy increases the overall melting temperature of the alloy. The more substitution amount, the higher the melting point of the alloy. NiAl substituted with 12 at\% Ir showed a $T_{m}$ gain of $150^{\circ} \mathrm{C}$ and $12 \%$ Rh substitution showed a $T_{m}$ gain of $130^{\circ} \mathrm{C}$. Palladium 
substitutions decreased the overall melting temperature of the alloy by $50^{\circ} \mathrm{C}$ at 12 at\% substitution.

Substitutions that increase the overall melting temperature of the alloy also decrease the homologous melting temperature for that alloy. Decreasing the homologous melting temperature would lead to reduced grain growth at high temperatures, and grain growth has been shown to affect the oxidation resistance of these alloys (6).

\section{Acknowledgement}

This work was supported by the DOE-FE (AMR program) through Ames Laboratory contract no. DE-AC02-07CH11358 through lowa State University.

\section{References}

1) P.K. Ray, et al., Journal of Metals, Vol. 62, pp. 25-29, 2010

2) T. Brammer, et al., Oxidation Paper to be communicated to Corrosion Science Journal

3) D.B. Miracle, R. Darolia, Intermetallic Compounds, Vol. 3, pp. 55-74, 2000

4) H.J. Grabke, M. Schutze, Oxidation of Intermetallics, pp. 79-84, 1998

5) C.T. Liu, J.O. Stiegler, Science, Vol. 226, pp. 636-642, 1984

6) T. Brammer, et al., Grain Size Paper to be communicated to Intermetallics

7) P. Wu, et al., Journal of Physics and Chemistry of Solids, Vol. 64, pp. 201-212, 2003

8) J.H. Rose, et al., Physics Review Letter, Vol. 47, pp. 675, 1981

9) C. Kittel, Introduction to Solid State Physics (7 $7^{\text {th }}$ Ed.), pp. 55-57, 2001

10) P.K. Ray, et al., Journal of Alloys and Compounds, Vol. 489, pp. 357-361, 2010 


\section{CHAPTER 6: GENERAL CONCLUSIONS}

Alloys based on NiAl offer significant potential payoffs as structural materials in gas turbine applications due to a unique range of physical and mechanical properties. Alloying additions to $\mathrm{NiAl}$ could be used to further improve the pertinent properties that currently limit this system from replacing $\mathrm{Ni}$ based superalloys. Modifications to $\mathrm{NiAl}$ were explored to increase the phase stability and oxidation resistance which would allow these alloys to be used at even higher temperatures yielding greater efficiencies.

The extended Miedema model was an effective tool that screened all of the potential phase space for ternary substitutions to NiAl and found the few potential systems worth further investigation. After production of the alloys it was determined that $\mathrm{Ir}, \mathrm{Rh}$, and Pd were the top candidates for substitution on Ni site up to 12 at\%.

The melting temperature of $\mathrm{NiAl}$ could be increased as much as $150^{\circ} \mathrm{C}$ with 12 at\% Ir and $130^{\circ} \mathrm{C}$ with 12 at\% Rh substitution. Pall adium on the other hand decreased the melting temperature by $50^{\circ} \mathrm{C}$ at the 12 at\% substitution level.

The grain size was found to have a profound influence on the oxidation resistance. Both Ir and $\mathrm{Rh}$ substitutions resulted in finer grain sizes compared to Pd substitutions or base NiAl. The grain size increased drastically during high temperature annealing with the PGM substitutions hindering grain growth only slightly. However, the addition of 0.05 at\% $\mathrm{Hf}$ limited the grain growth dramatically during high temperature annealing.

$\mathrm{NiAl}$ inherently has respectable oxidation resistance up to $11000^{\circ}$. It was found through experimental testing that both $\mathrm{Ir}$ and $\mathrm{Rh}$ substitutions improve the 
oxidation resistance of NiAl at ultra-high temperatures with Ir performing the best. Both PGM substitutions decreased the growth rate as well as forming a more adherent oxide scale. Pd substitutions appeared to have a negligible effect to the oxidation resistance of $\mathrm{NiAl}$. Hafnium addition of 0.05 at\% was found to decrease the oxidation rate as well as increase the scale adherence. The combination of both Ir substitution (6-9 at\%) and Hf addition (0.05 at\%) produced the alloy with the best oxidation resistance.

Although improvements in phase stability and oxidation resistance have been made to the NiAl system, more development and testing are still needed. Two major issues yet to be resolved are the low fracture toughness at ambient temperatures and low creep resistance at elevated temperatures. Efforts are underway to improve both of these properties by adding a second phase refractory metal, namely molybdenum. 


\section{ACKNOWLEDGEMENTS}

This work was performed at Ames Laboratory, which is operated for the US Department of Energy (DOE) by lowa State University. This work was supported by the DOE-Fossil Energy (Advanced Materials Research Program) through Ames Laboratory contract no. DEAC02-07CH11358.

Special thanks to my parents, David and Sharla Brammer, and to my fiancée, Katie Brown, for their support and encouragement throughout my academic career.

I would also like to thank Drs. Mufit Akinc and Matthew Kramer, my co-major professors, for giving patient, insightful and thoughtful advice throughout my research experience. This work could not be completed without their instruction and criticisms. Their contribution to this work is greatly appreciated.

Thanks to my colleague Dr. Pratik Ray for useful discussions and advice throughout the work. His efforts are greatly appreciated.

Thanks to Fran Laabs for discussions on the OIM grain size analysis work.

Thanks to Mattew Besser for providing zirconia and alumina crucible liners.

Thanks to Arne Swanson for his work in drop-casting the alloys.

Thank to Dr. Zhihong Tang for help during the cyclic oxidation tests.

Thanks to my lab mate Kevin Severs for providing a healthy atmosphere in the labs as well as his criticism and discussions.

Thanks to other members of the ceramic processing research group for their discussion.

Finally thanks to my graduate committee, Dr. Mufit Akinc, Dr. Matthew Kramer, and Dr. Iver Anderson. 